\author{
UNIVERSIDADE DE SÃO PAULO \\ FACULDADE DE ODONTOLOGIA DE BAURU
}

ANA CAROLINA FRANCISCHONE

\begin{abstract}
AVALIAÇÃO DA QUALIDADE DE MARGEM DE PREPAROS CAVITÁRIOS REALIZADOS COM DIFERENTES TÉCNICAS E INSTRUMENTOS
\end{abstract}

BAURU

2009 



\section{AVALIAÇÃO DA QUALIDADE DE MARGEM DE PREPAROS CAVITÁRIOS REALIZADOS COM DIFERENTES TÉCNICAS E INSTRUMENTOS}

Tese apresentada à Faculdade de Odontologia de Bauru, Universidade de São Paulo, como parte dos requisitos para obtenção do título de Doutor em Odontologia.

Área de concentração: Dentística Orientador: Prof. Dr. José Mondelli

\section{BAURU}




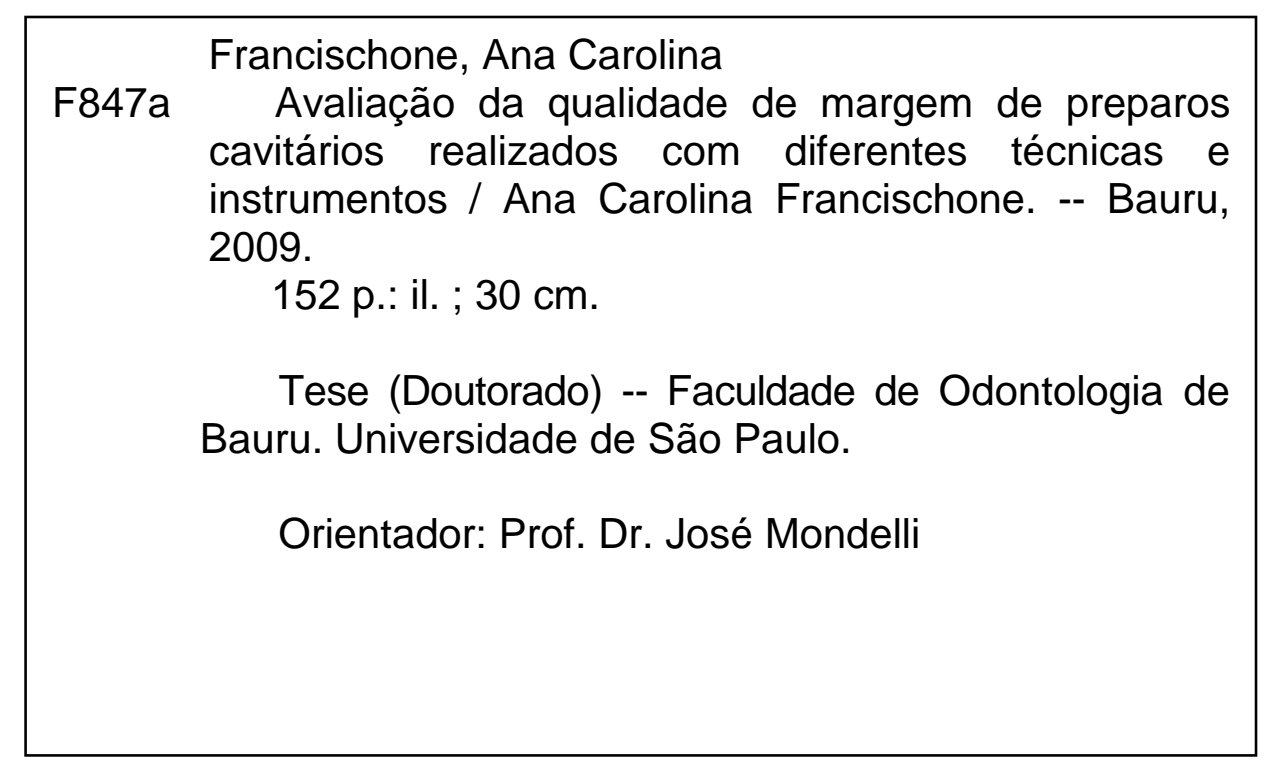

Autorizo, exclusivamente para fins acadêmicos e científicos, a reprodução total ou parcial desta tese, por processos fotocopiadores e outros meios eletrônicos.

Assinatura:

Data: 




\section{DADOS CuRRICULARES}

03 de dezembro de 1978

Bauru-SP

Filiação

$1997-2001$

$2002-2003$

$2003-2005$

$2005-2009$
Nascimento

Cidade

Carlos Eduardo Francischone

Ana Luiza B. Francischone

Curso de Graduação em Odontologia, na Universidade Sagrado Coração USC/Bauru

Curso de Especialização em Dentística, na Faculdade de Odontologia de Bauru, da Universidade de São Paulo

Curso de Pós-Graduação, em Dentística, em nível de Mestrado, na Faculdade de Odontologia de Bauru da Universidade de São Paulo

Curso de Pós-Graduação, em nível de Doutorado, área de Dentística na Faculdade de Odontologia de Bauru da Universidade de São Paulo 



\section{DEDICATÓRIA}





\section{QDedicatória}

Dedico aos meus pais Carlos Ceduardo e. Pha Cuiza, esse meu sonho realizado, porque sem o apoio, incentivo, compreensão e principalmente minha educação, não seria possível a realização dessa minha tese. Agradeço ainda por tudo que vocês sempre fizeram e fazem por mim, pelos exemplos sempre de honestidade, humildade e caráter que sempre nos deram.

Aos meus irmãos, Carlinhos e Fabricio, que estão sempre ao meu lado, em todos os momentos de minha vida, me apoiando e aconselhando. Muito obrigada por tudo e por sempre me proporcionarem momentos ótimos juntos.

Obrigada por fazerem parte, sempre presentes na minha vida!!!

Ao meu querido sobrinho Cucca, pela alegria imensa de ser tia. Realmente não tenho palauras para descrever a emoção do seu nascimento. Você é um presente de Deus para todos nós.!!! 

Ao Or. Mandelli, pelo exemplo de dedicação à nossa Odontologia. Por todo aprendizado que tive durante todos esses anos desde a minha especialização, mestrado e agora doutorado. Espero que durante toda a minha vida continue sempre nos incentivando a estudar, pesquisar, guiando-nos por um caminho seguro em busca de nossos sonhos. Para mim, é um orgulho sempre poder estar perto de você e aprender a cada dia uma nova forma de fazer e realizar a Odontologia. Obrigada por tudo!!!!! 

AGRADECIMENTOS 



\section{Agradecimentos}

Oos meus avós, Romildo (in memorian), Gidinha (in memorian),

Sebastião (in memorian) e. Miltes, que sempre me apoiaram, ensinaram e principalmente rezaram para que nossas vidas fossem repletas de alegrias e realizações.

M minha tia Seda e minha prima Letícia, por sempre estarem ao meu lado me apoiando e dividindo comigo alegrais e experiências. Obrigada por fazerem parte da minha vida, estando comigo em todos os momentos.

Ho meu vio Oaulo, via Tetma e Radrigo, pelo apoio sempre dado a qualquer hora e momento de minha vida.

M minha cunhada Priscilla, que entrou em nossas vidas e nos trouxe, hoje, o nosso maior presente e alegria, o Lucca, e que Deus ilumine essa nova família que acaba de se formar.

OA minha cunhada Denise, pelo carinho e atenção para comigo e toda nossa família.

Miminha amiga Marcela e famélia, pelos tantos anos de amizade sincera e fiel. Considero você minha irmã, amiga e companheira de todas as horas. Vocês sempre participam da minha vida intensamente.

To Renato e Oha Paula, pelos anos de convivência e pela sincera amizade. 

Sos meus amigos Adilson, Odirlei, Seonardo e Thiago pelo carinho, paciência e ensinamentos que me proporcionaram durante todos esses anos de convivência.

Atodos meus calegas de doutorado, por me proporcionarem momentos de amizade, companheirismo, apoio e incentivo durante todo o curso.

A minha amiga Beatriz, pelo carinho e amizade!!!

Ao professor Ceduarda Batista. Franco, pelos ensinamentos e por me guiar durante toda essa minha tese. Muito obrigada!!!

Aa Professor ORafael Mandelli, pelo carinho e por todas oportunidades dada a mim, durante esses anos em que estive no Departamente de Dentística da Faculdade de Odontologia de Bauru.

Atados os professores do Oepartamento de Oentística da Ofaculdade de Odontologia de Bauru, pelos ensinamentos transmitido a mim durante a especialização, mestrado e doutorado. Muito obrigada, pois sem esses ensinamentos com certeza, não seria possível realizar este trabalho.

Aa profeśsor Sérgio e Sinda, por terem também me ajudado neste trabalho. Muito obrigada!!

Aa professor Marea Yuingaro, pela paciência e dedicação para comigo, durante toda minha dissertação. Obrigada pela realização da MEV e também da estatística deste meu trabalho. Serei eternamente grata!!! 

Mtodos as funcionáxios do ODepartamento de Oentística que me apoiaram e sempre torceram por mim. Muito obrigada pelo carinho de vocês!!!

Sasfuncionáxios da Flínica Odontalógica Or. Francischone, pela dedicação com que vocês têm por nossa clínica e nossos pacientes. Com essa equipe, tudo ficaria mais difícil.

Alia Clo por corrigir este trabalho, com todo o carinho e dedicação que sempre demonstrou por mim e pela minha família. Muito obrigada por tudo!!!

Dos meus amigas Shiago e Emilene, pelo carinho, amizade e ensinamentos durante este ano. Muito obrigada!!

Mraculdade de Odontologia de Baum, por todo ensinamento durante todos esses anos.

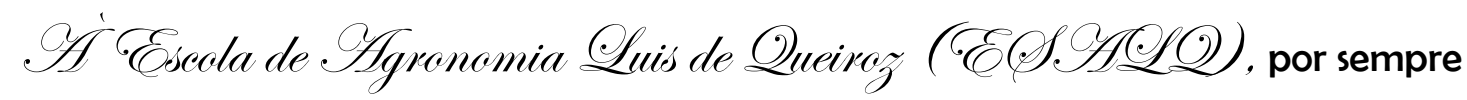
estarem incentivando a pesquisa e dividindo com os alunos conhecimentos e ensinamentos. Sem esse desprendimento não seria possível a realização deste trabalho.

Mtodos da academia. Fit Corpus, pelos anos de convivência, novas amizades que fiz e principalmente por me proporcionarem momentos de alegria e pura compreensão nos momentos de ansiedade e estresse!! 

EPÍGRAFE 

EPÍGRAFE

Eepigrafe

"Se chorei ou se sorri, o importante é que emoções eu vivi."

(Roberto Carlos)

ANA CAROLINA FRANCISCHONE 




\section{RESUMO}

Há mais de 50 anos, a Odontologia usa a mesma tecnologia para a preparação de cavidades, que é a alta velocidade com ponta diamantada e brocas carbides. Novos estudos e novas técnicas têm sido proporcionada para que haja uma opção a mais para esse procedimento no tratamento para os pacientes. Surgiram, então, novas tecnologias no mercado odontológico para eliminação mecânica da cárie e preparação de cavidades, como alta pressão de ar associado a jato de areia, aparelho de Laser, contra- ângulo multiplicador e ultrassom associado a pontas diamantadas. Mas por serem tecnologias novas, há ainda necessidade de pesquisas para a constatação de que realmente poderão vir a ser técnicas alternativas ou até substituir a tecnologia clássica que vem sendo utilizada com bons resultados. Assim, o propósito desta pesquisa foi avaliar, através de microscopia eletrônica de varredura (MEV), as margens cavitárias com e sem acabamento, realizadas com pontas diamantadas e CVDentus, associadas a diferentes tipos de dispositivos e mecanismo de ação. Os resultados encontrados mostraram não haver diferenças estatisticamente significantes $(p<0.05)$ entre as condições testadas, nas comparações individuais, com exceção dos grupos G4 x G7 (Alta velocidade+ Ponta Diamantada Preparo + Baixa Rotação + Ponta Diamantada para acabamento $x$ Ultrassom + CVDentus Preparo 50\% + Contra-ângulo). Concluiu-se que todas as formas de acabamento das margens cavitárias, testadas nesta pesquisa, são confiáveis e podem ser utilizadas. O uso do aparelho de ultrassom deve ser recomendado nas potências variando entre 50\% a 75\% para preparos cavitários.

Palavras-chave: Qualidade de margem. Preparo cavitário. Técnicas de instrumentação. 

ABSTRACT 



\section{ABSTRACT \\ Margin quality of cavity preparations with different techniques and instruments}

For more than 40 years, dentistry has used the same technology for cavity preparation, high-speed rotation systems with diamond burs. New studies and techniques have been performed to develop a new treatment option for patients. Thus, new technologies have been possible such as high pressure sandblasting systems, laser devices, multiplying low-speed rotation, and finally, the ultra-sound with diamond burs. However, whether these new technologies can be an alternative or substitute for old practices with standard results is not known. The aim of this study was to evaluate by SEM cavity preparation margins with and without finishing, made by diamond burs and the CVDentus system associated to different devices and action forms. The results showed no statistically significant differences $(p<.05)$ among the tested conditions on individual comparisons, except for GIV x GVII (highspeed rotation plus diamond bur + low-speed rotation plus diamond finishing bur $\mathrm{x}$ ultra-sound plus CVDentus 50\% power plus low-speed rotation). It was concluded that all finishing modes on margin cavities are reliable and can be used in clinical practice. The use of the ultra-sound device can be recommended within $50-75 \%$ power for cavity preparations.

Keywords: Margin quality. Cavity preparation. Instrumentation techniques. 




\section{LISTA DE ILUSTRAÇÕES}

\section{FIGURAS}

Figura 1 - Perfuração da fita isolante feita com perfurador de borracha para dique, a fim de padronizar o diâmetro das cavidades (A) e fixação da fita isolante sobre a face vestibular do dente $(B)$.

Figura 2 - Aparelho de ultrassom com ponta reta na qual é acoplada a ponta diamantada CVDentus angulada (A), utilizada para preparar cavidades(B) ....................................90

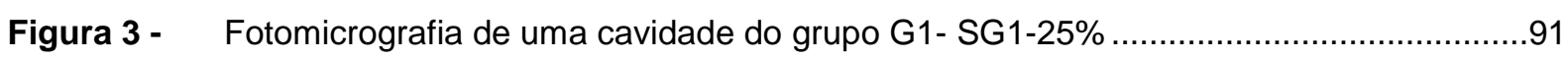

Figura 4 - Fotomicrografia de uma cavidade do grupo G1- SG2 - 50\% ...................................92

Figura 5 - Fotomicrografia de uma cavidade do grupo G1- SG3 - 75\% ......................................93

Figura 6 - Fotomicrografia de uma cavidade do grupo G1 - SG4 - 100\% .................................94

Figura 7 - Fotomicrografia de uma cavidade do grupo G2 - SG1 - 25\% ……..........................95

Figura 8 - Fotomicrografia de uma cavidade do grupo G2 - SG2 - 50\% ................................96

Figura 9 - Fotomicrografia de uma cavidade do grupo G2 - SG3 - 75\% ...................................97

Figura 10 - Fotomicrografia de uma cavidade do grupo G2 - SG4- 100\% ....................................98

Figura 11 - Fotomicrografia de uma cavidade do grupo G3 .....................................................99

Figura 12 - Fotomicrografia de uma cavidade do grupo G4 ......................................................100

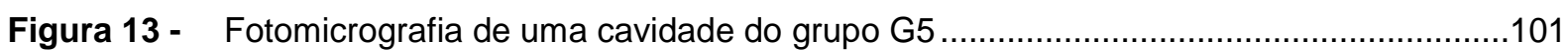

Figura 14 - Fotomicrografia de uma cavidade do grupo G6 ..................................................102

Figura 15 - Fotomicrografia de uma cavidade do grupo G7 ......................................................103

Figura 16 - (A) Amostras fixadas nos "stubs" já na máquina de metalização. (B) Amostras

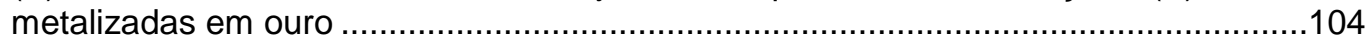

Figura 17 - Imagem da fotomicrografia mostrando o traçado realizado no programa Adobe Photoshop delimitando o perímetro total da cavidade .............................................105

Figura 18 - Imagem da fotomicrografia mostrando o traçado feito para análise do perímetro da margem cavitária ............................................................................................

Figura 19 - Imagem da fotomicrografia mostrando o contraste feito para a análise da área de

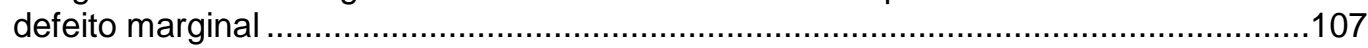

Figura 6.1 - Fotomicrografias mostrando as características dos defeitos na margem causados com o uso de alta velocidade e ponta diamantada (A). Em maior aumento (B), observa-se a boa regularidade da margem da cavidade. 125

Figura 6.2 - Fotomicrografias mostrando as características dos defeitos na margem causadas com o uso de ultrassom associado à ponta CVDentus (A). Em maior aumento (B), é evidente a presença de defeitos de esmalte, características do uso do ultrassom......125

\section{GRÁFICO}

Gráfico 5.1 - Médias e desvios-padrão da porcentagem de defeitos das condições experimentais estudadas 

LISTA DE TABELAS 



\section{LISTA DE TABELAS}

Tabela 5.1 - Coeficiente de Concordância de Kendall aplicado às Leituras dos perímetros das cavidades, obtidas pelos dois examinadores.

Tabela 5.2 - Coeficiente de Concordância de Kendall aplicado às medições dos defeitos das margens dos preparos cavitários.

Tabela 5.3 - Médias e desvios - padrão da porcentagem de defeitos das condições experimentais estudadas

Tabela 5.4 - Análise de variância - Um critério de classificação aplicada para a comparação entre

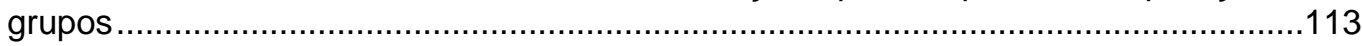

Tabela 5.5 - Teste de Tukey - Nível de significância =0,05, para comparações individuais 113 




\section{SUMÁRIO}

4 MATERIAL E MÉTODOS

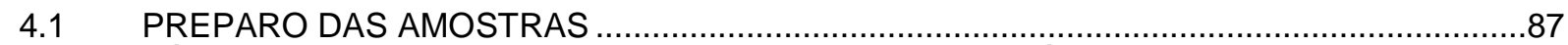

4.2 TÉCNICAS PARA CONFECÇÃO DOS PREPAROS CAVITÁRIOS …...................................89

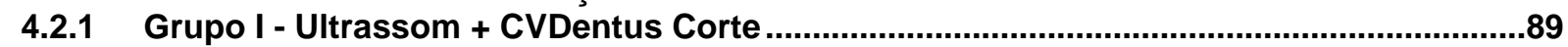

4.2.2 Grupo II- Ultrassom + CVDentus Corte + CVDentus Acabamento ....................................94

4.2.3 Grupo III - Alta velocidade+ Ponta Diamantada Convencional .........................................98

4.2.4 Grupo IV - Alta velocidade + Ponta Diamantada Convencional + Baixa Velocidade + Ponta Diamantada Acabamento

4.2.5 Grupo V - Velocidade Intermediária + Ponta Diamantada Convencional

4.2.6 Grupo VI - Baixa-velocidade + Ponta Diamantada Convencional ....................................101

4.2.7 Grupo VII - Ultrassom + CVDentus-Corte 50\% + Acabamento Ponta

4.3 PREPARO DAS AMOSTRAS PARA OBTER IMAGENS DOS PREPAROS CAVITÁRIOS POR MEIO DE MICROSCÓPIO ELETRÔNICO DE VARREDURA, PARA AVALIAÇÃO DA

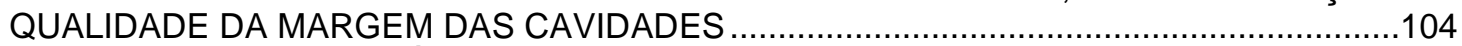

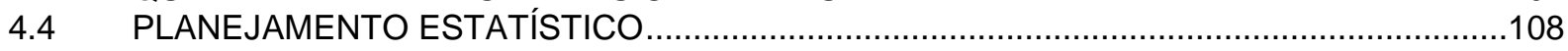

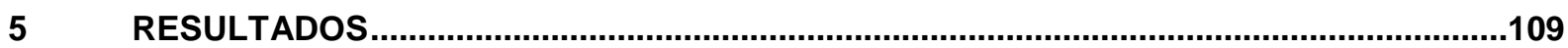

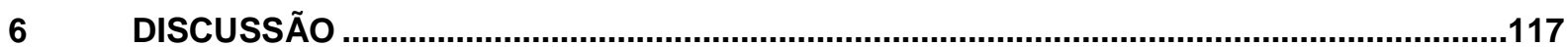

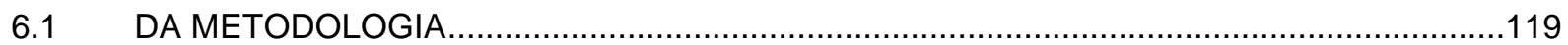

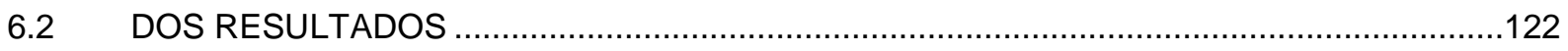

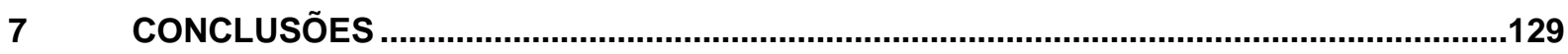

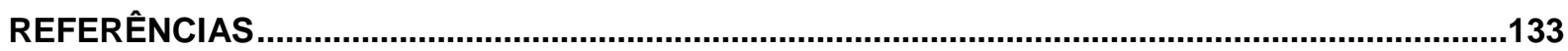

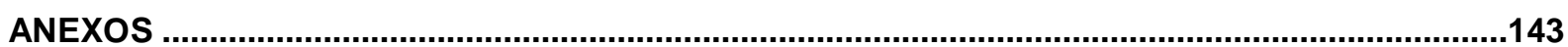






\section{INTRODUÇÃO}

Depois da Segunda Guerra Mundial, deu-se início a uma grande busca para o aumento da velocidade dos motores elétricos utilizados em odontologia ou sua substituiçãopor outro sistema de movimentação dos instrumentos rotatórios. Assim, em 1943, a velocidade era de 10.000 rpm; em 1950 passou para 25.000 rpm; em 1955 em 45.000 rpm, velocidades essas obtidas mediante a combinação de motores mais velozes juntamente com multiplicadores adaptados ao equipo e roldanas de diferentes diâmetros (as maiores no eixo dos motores elétricos e a menor acoplada na peça de mão) (PARULA, 1972). Dentro da evolução histórica, as turbinas de alta velocidade, que surgiram a partir de 1960, atingem atualmente velocidade acima de 300.000 RPM (MONDELLI, 2006). Apesar de ser uma tecnologia introduzida há aproximadamente meio século, as turbinas de alta velocidade permanecem, até os dias de hoje, como as mais utilizadas para preparação de cavidades na Odontologia.

O primeiro instrumento rotatório com grande eficiência a se fixar no mercado odontológico foram as pontas diamantadas, formada por uma haste de metal altamente resistente, tal como o aço inoxidável, onde pequenas lacunas ou depressões alojavam grânulos ou lascas de diamante. O método mais utilizado para unir as partículas de diamantes na haste metálica é o de codeposição eletrolítica do diamante natural ou sintético, ou de métodos alternativos como soldagem, aglomeração e adesivos (SIEGEL; VON FRAUNHOFER, 1998). Essa tecnologia, apesar de ser usada até os dias atuais, apresenta algumas limitações, devido à heterogeneidade no formato das granulações do diamante, à dificuldade de automação em sua fabricação e sua baixa durabilidade (BORGES et al., 1999).

Novas tecnologias foram desenvolvidas para serem utilizadas na preparação de cavidades, entre elas a implementação de instrumentos como alta pressão de ar associado a jatos de areia (sucessor do jato abrasivo de 1950), laser para tecidos duros e ultrassom associados às pontas diamantadas especiais. Para estas pontas, empregados com ultrassons sistema de aplicação e fixação dos grânulos de diamante é diferente dos demais. Uma das tecnologias para confecção dessas pontas diamantadas foi desenvolvida pelo Instituto Nacional de Pesquisas Espaciais 
(INPE), denominada CVD. Essa tecnologia foi usada inicialmente, na produção de equipamentos para engenharia de aeronaves e, posteriormente, para uso na Odontologia. Por ser nova na Odontologia, ainda carece de estudos científicos e clínicos para constatar sua eficiência ou não. O diamante obtido e a sua fixação nas pontas diamantadas CVDentus são diferentes das pontas diamantadas convencionais, pelo fato de ser um diamante obtido por deposição química a partir da fase de vapor (Chemical Vapor Deposition). É um processo complexo onde a formação do diamante ocorre diretamente sobre uma haste de molibdênio, utilizando gases como metano na presença de hidrogênio. Nesse processo, após algumas interações físico-químicas o diamante é formado como peça única sobre a haste metálica sem necessidade de métodos de aderência (MAY, 1995, VALERA, 1996, LIMA et al., 2006).

O diamante CVD é obtido na forma de pedra única, com superfície rugosa e bem ordenada,, apresentando algumas propriedades como maior durabilidade, redução de retenção de resíduos e biologicamente compatível, sendo favorável em aplicações odontológicas. É diferente da tecnologia usada para fabricação das pontas diamantadas convencionais, cujos grânulos de diamante são agregados em uma matriz metálica, o que se desgastam com o uso devido ao desprendimento dos grânulos de diamante (MAY, 1995, VALERA, 1996).

A associação da ponta de diamante CVDentus ao aparelho de ultrassom permite o aproveitamento dessas duas tecnologias bastante inovadoras, tornando possível a preparação de cavidades menos invasivos, devido à precisão de corte da ponta com a instrumentação ultrassônica. Além disso, as diferentes angulações das pontas diamantadas CVDentus permitem um aumento da visibilidade do campo operatório. (VALERA, 1996).

Dessa forma, a possível melhora na qualidade dos preparos cavitários poderá contribuir para o aumento da longevidade das restaurações. Há algum tempo existe a preocupação em relação ao acabamento das margens dos preparos cavitários, referente à presença de prismas de esmalte friáveis e irregulariedades que ocorrem durante a preparação, podendo causar infiltrações marginais, assim como pequenas fraturas, após restaurados. Com isso, neste trabalho alteraram-se as técnicas e instrumentos utilizados para preparos cavitários, a fim de se poder avaliar qual técnica daria melhor acabamento e, consequentemente, menores 
infiltrações futuras. Utilizaram-se diferentes potências vibratórias, através do aparelho de ultrassom, para observar se a sua maior intensidade poderia causar maior quantidade de lascas, podendo estas ser maiores ou menores.

Considerando a falta de estudos comparativos entre as tecnologias rotatória e ultrassônica, este trabalho teve como objetivo analisar, por meio de microscopia eletrônica de varredura (MEV), a qualidade das margens dos preparos cavitários realizados com diferentes tipos de pontas diamantadas, bem como a efetividade de diferentes formas de acabamento marginal das cavidades. 




\section{REVISÃO DE LITERATURA}

A importância do preparo cavitário é, sem dúvida, reconhecida e estudada profundamente sob vários aspectos na Odontologia Restauradora. Diversos fatores estão intimamente ligados a esse processo. Dentre eles, destacam-se a habilidade do profissional, os dispositivos e equipamentos empregados, as técnicas de preparos disponíveis, que podem contribuir para o bom ou mau comportamento clínico da restauração.

A seguir, apresenta-se uma revisão da literatura separada em tópicos de interesse os quais, em conjunto, constituem um amplo cenário envolvido com a avaliação da qualidade das margens de preparos cavitários realizados pelas pontas CVDentus, pontas diamantadas associados a aparelhos de ultrassom, alta velocidade e baixa velocidade.

\subsection{PREPARO CAVITÁRIO: DA PRÉ-HISTÓRIA À ODONTOLOGIA MODERNA}

A evidência pré-histórica de perfurar dentes humanos in vivo é referida na descrição de onze molares de nove adultos que tiveram suas coroas perfuradas, descobertos por Coppa et al. (2006) em um cemitério Neolítico no Paquistão, o qual data de 7.500-9.000 anos atrás. Essas evidências proveem um tipo de protoodontologia existente dentro de uma sociedade ainda em estágio precoce do conhecimento da agricultura. A descoberta foi feita no sítio arqueológico de Mehrgarh, em Baluchistan, situado ao longo da rota principal que conecta o Afeganistão para ao vale de Indus. Depois de ocupações intermitentes por caçadores-coletadores, a economia de subsistência de Mehrgarh passou para o cultivo de cevada e trigo, algodão e criação de gado, evidências de uma vida cultural crescentemente rica, com sofisticação tecnológica baseada em matérias-primas diversas. A escavação do cemitério neolítico, conhecido como MR3, rendeu a descoberta de mais que 300 sepulturas. 
Coppa et al. (2006) identificaram quatro mulheres, dois homens e três indivíduos que possuíam onze coroas permanentes perfuradas com algum tipo de ferramenta de perfuração que produzia cavidades cônicas, cilíndricas ou trapezoidais, possivelmente equivalente à ponta ativa de um instrumento. Os "preparos cavitários" eram evidentes em dentes da maxila e mandíbula (04 na maxila; 07 na mandíbula) e exclusivamente nos primeiros ou segundos molares permanentes. Com exceção de um preparo localizado na porção cervical distovestibular de um primeiro molar inferior, os demais preparos estavam localizados na face oclusal e abrangiam esmalte e dentina. Os preparos possuíam de 1.3-3.2 mm de diâmetro, com uma inclinação ligeiramente para o plano oclusal e profundidade entre 0.5 e $3.5 \mathrm{~mm}$. A microscopia eletrônica de varredura demonstrou que os soalhos cavitários eram concêntricos, confeccionados com um instrumento de perfuração. Pelo menos uma das cavidades apresentou indícios de que 0 procedimento não envolveu somente a remoção de estrutura do dente pelo instrumento, mas também houve ainda o auxílio de microferramentas utilizadas subsequentemente para esculpir a parede cavitária pelo operador ou pelo próprio paciente, como um acabamento do preparo. Em todos os casos foi confirmado, através de exames das superfícies das margens das cavidades, que os preparos foram executados em pessoas que ainda estavam vivas, e que continuaram com sua função mastigatória normalmente após as perfurações dentárias, a ponto de as margens cavitárias tornarem-se mais lisas.

Mais tarde, durante os períodos de 300 a.C. até 900 d.C, os Maias americanos também realizavam formas de preparos cavitários, algumas até preenchidas com incrustações de pedras preciosas. Pinturas realizadas durante aquele período indicam que os preparos cavitários da época eram confeccionados com instrumentos rotatórios arcaicos. Eram constituídos por pedras de quartzo montadas em uma haste, impulsionadas com o auxílio de um arco. (RING, 1985).

O aparecimento de tecnologia em instrumentos rotatórios e brocas já se misturam com a própria história da Odontologia moderna. Desde o século XIX, mais precisamente em 1858, Charles Merry desenvolveu um instrumento de baixa rotação que consistia em um cabo espiral que impulsionava uma broca. Já em 1871, a evolução desse aparelho, conduzida por James Beall Morrison, associou o seu mecanismo à ativação por pedal com uma série de roldanas. A S.S. White adotou 0 
conceito modificando-o, e já em 1872 produzia um modelo elétrico, inventado por George F. Green. O modelo associava uma peça de mão a um motor em sua porção posterior. O aparelho era extremamente pesado e de difícil manuseio. Foi nessa era de "invenções" na Odontologia que Greene Vardiman Black (1836-1915) exerceu importante papel, estabelecendo paradigmas até hoje vigentes. Ele estabeleceu princípios e preconizou métodos para a preparação de cavidades publicados em seu livro de Dentística Operatória (1908). Nele livro-texto, descreve toda a conformação das paredes e constituintes das cavidades além de recomendar o uso de instrumentos cortantes manuais após a preparação das cavidades com instrumentos rotatórios. Além disso, nesse livro foi mencionada pelo autor a importância do acabamento das margens que deve ser dado nos preparos cavitários. (RING, 1985).

Antes da década de 1890, foram usados discos e pedras de carboneto de sílica para cortar esmalte, pois as brocas de aço de carbono eram ineficientes. Em 1897, Willman e Schroeder, da Universidade de Berlim, Alemanha, manufaturaram a primeira "broca" de diamante (VINSKY, 1979, SIEGEL; VON FRAUNHOFER, 1998). Já em 1899, no catálogo de Claudius Ash and Sons Ltd., constava "brocas" de diamante para o acabamento e polimento das "margens de esmalte" e aconselhava o uso de refrigeração com água e aparelho de alta velocidade (SIEGEL; VON FRAUNHOFER, 1998). Em 1913, no catálogo da S.S. White Dental Manufactoring Co. Consta uma precursora da broca de diamante.

A "broca" diamantada moderna foi criada em 1932 por W.H. Drendel, um industrial alemão que desenvolveu um processo para unir grânulos de diamante à haste de aço inox (WALSH, 1953). Antes de 1939, as "brocas" de diamante eram mais utilizadas na Europa e foram sendo introduzidas nos Estados Unidos, chegando a uma maior utilização a partir da Segunda Guerra Mundial, devido à escassez de aço existente na época.

Segundo Mondelli (2006), o termo "ponta diamantada" deve ser utilizado para classificá-la como instrumento rotatório de desgaste enquanto o termo "broca" deve ser utilizado para classificá-la como instrumento rotatório de corte.

O método convencional de fabricação das pontas diamantadas consiste em agregar uma ou mais camadas de fragmentos ou grânulos de diamante a uma haste metálica, tanto para uso na peça de mão, contra-ângulo ou turbina de alta velocidade. A haste normalmente é fabricada com um metal de alta resistência como 
o aço inox ou outras ligas. A ponta ativa é usinada com uma forma específica (cilíndrica, cone invertido, chama, etc.) onde os fragmentos ou grânulos de diamante são fixados. Tais fragmentos de diamante são presos à haste metálica de vários modos. O método mais comum utilizado hoje é o de codeposição eletrolítica de partículas de diamante naturais ou sintéticas sobre a ponta ativa. Constitui-se num procedimento de codeposição que, mecanicamente, trava as partículas de diamante sobre a ponta ativa. (HARKNESS; DAVIES, 1983).

\subsection{A UTILIZAÇÃO DAS TURBINAS DE ALTA VELOCIDADE}

Para Gegauff et al. (1998), realizar testes seguros de turbinas de alta velocidade significava um problema por causa dos muitos parâmetros significantes que deveriam ser identificados e quantificados. Portanto os autores se propuseram a medir e a comparar a degradação da turbina de alta velocidade de ar comprimido durante um teste simulado de desgaste com ponta diamantada. $O$ teste consistiu em 90 passagens por um substrato de vidro com 10 pontas diamantadas. O teste foi feito com um dispositivo computadorizado conectado, que controlou a força de contato da ponta diamantada e o substrato. O desempenho foi baseado no tempo exigido para cortar um trajeto padrão do substrato. Múltiplas análises de regressão mostraram diferenças significantes entre amostras do mesmo tipo e entre turbinas de diferentes tipos; quatro turbinas testadas exibiram melhor desempenho durante 0 teste simulado.

Christensen (1999) ressaltou que as turbinas de alta velocidade, introduzidas na Odontologia em meados do século XX, foram recebidas com grande entusiasmo. O conceito de corte da estrutura dentária em alta velocidade contribuiu para a corrente era de Odontologia quase indolor. As turbinas de alta velocidade foram, sem dúvida, uma conquistqa fantástica para a profissão. Porém, atualmente (mais de 50 anos depois de sua introdução), existem grupos de profissionais que não podem discutir o assunto de turbinas de alta velocidade sem acrescentar histórias reveladoras sobre as suas deficiências. O autor ainda cita que alguns profissionais, hoje em dia, estão frustrados com a geração atual desse tipo de instrumento 
odontológico, e que ainda é necessário melhorias urgentemente. Sendo assim o autor conclui que as turbinas de alta velocidade são, talvez, o mais importante equipamento em um consultório odontológico, com mais de 50 anos de grande serviço prestado para os pacientes e profissionais.

Dyson e Darvell (1999) realizaram um estudo com o intuito de verificar a velocidade, torque e desempenho das turbinas de alta velocidade. Para tanto, os autores avaliaram a pressão, a temperatura, a taxa de fluxo de gás e a taxa de rotação de 14 instrumentos de turbina de rolamento de esferas. As relações funcionais entre as propriedades dos gases, suprimento de pressão, taxa de fluxo e tipo de turbina foram identificadas como fatores determinantes para a velocidade corrente livre em equações que descrevem estes aspectos de comportamento. Os autores concluíram que cada turbina de alta velocidade odontológica possui velocidade corrente livre, que pode ser explicada de acordo com as propriedades dos gases e pressão, medida com um coeficiente de desempenho específico.

Parece não haver nenhuma diretriz clara que oriente o profissional durante a escolha de uma turbina de alta velocidade, visto a grande variedade disponível no mercado, dificultando o processo de seleção. Esta normalmente se baseia mais no preço, tato, peso, tamanho, ao invés de se fundamentar em critérios claramente definidos, que possam predizer a eficiência do aparelho. Siegel e Von Fraunhofer, (2000), conduziram uma pesquisa com alunos de Odontologia e observaram que os mesmos reconhecem a importância do resfriamento com água.

Siegel e Von Fraunhofer (2000) demonstraram que com o uso da refrigeração com água da turbina de alta velocidade aumenta a proteção térmica da polpa além de ainda melhorar as taxas cortantes desses instrumentos. Na realidade, abaixo de uma mesma carga aplicada e velocidade de rotação da ponta, observouse notadamente, taxas de corte diferentes quando o número e posicionamento de pontos de spray variaram.

Christensen (2002) destacou as vantagens e desvantagens das turbinas de alta velocidade a ar. Segundo o autor, as vantagens são as seguintes: remoção da estrutura dentária de forma rápida; quando usada corretamente, causam mínimo trauma para a estrutura dentária; possuem baixo torque, reduzindo o perigo quando acidentalmente as brocas tocam o tecido mole ou outros objetos; são moderadamente resistentes aos danos causados pelas técnicas de esterilização 
usuais e são relativamente fáceis de se reparar. As desvantagens destacadas são: esse tipo de instrumento possui concentricidade pobre, após um período relativamente curto de uso; possuem um nível de ruído alto; precisam de reparos com periodicidade freqüente; a iluminação, existente em algumas marcas, se estraga após somente algumas esterilizações; o rolamento endurece após um período moderado de uso; seu torque se degenera após um período relativamente curto de uso e são relativamente caros.

Siegel e Von Fraunhofer (2002) estudaram a diferença entre cortes executados em blocos de prova cerâmicos com turbinas de alta velocidade com um, três e quatro pontos de refrigeração operando em torque e rotação máximos com um fluxo de água de 25 mililitros por minuto. Os autores realizaram cortes de $6 \mathrm{~mm}$ de profundidade e $13 \mathrm{~mm}$ extensão nos blocos de prova, usando seis pontas diamantadas de média granulação para cada turbina testada. Cada ponta diamantada cortou um total de $78 \mathrm{~mm}$. Os autores determinaram a taxa de corte como tempo necessário para seccionar o bloco e analisaram estatisticamente a discrepância dos dados. Foram observadas taxas de corte que variaram de acordo com o tipo e o número de pontos de spray onde a turbina de apenas um ponto apresentou taxas de corte significativamente menores. Os autores concluíram que os dados indicaram que o número de pontos de spray afeta a interface cortante da ponta diamantada.

Dessa forma, pode-se observar que existe grande variedade de tipos e desempenho das turbinas de alta velocidade e que isto poderá refletir na qualidade dos preparos cavitários, em especial, de suas margens. 


\subsection{O ULTRASSOM NA ODONTOLOGIA}

Catuna (1953) descreveu pela primeira vez o uso do ultrassom na Odontologia para preparar cavidades. O equipamento era um aparelho de ultrassom magnetoestrictivo, que transformava impulsos elétricos de alta frequência em vibrações mecânicas. Essa frequência oscilava de 16.000 a 29.000 ciclos por segundo $(\mathrm{kHz})$, em um componente cônico de 50,8mm fixo no transdutor, onde era possível acoplar instrumentos intercambiáveis funcionando como instrumento abrasivo.

Roche (1954) apresentou outro equipamento que consistia de um ultrassom magnetoestrictivo, que produzia na ponta ativa movimentos oscilatórios verticais que variavam de 16000 a 24000 ciclos por segundo, com amplitude de $0.33 \mathrm{~mm}$. Para o preparo cavitário, com esse equipamento, era necessária uma leve pressão e a associação da ponta ativa a um abrasivo (carborundum, rubi, óxido de alumínio ou pó de diamante) misturado a água ou óleo.

Postle (1958) descreveu a técnica de instrumentação ultrassônica para a realização de preparos de cavidade com aparelho Cavitron, que consistia de duas etapas, o pressionamento e a planificação. O pressionamento tratava-se da remoção de esmalte e dentina com a ponta abrasiva acoplada ao ultrassom. A planificação consistia em estender as paredes pré-estabelecidas até os limites desejados. $O$ autor ressaltava também a importância de saber manusear o equipamento com pressão suficiente para guiar a ponta, possibilitando uma boa eficiência de corte, uma lisura no cavo superficial do preparo cavitário, uma redução na sensibilidade dolorosa, no tempo de trabalho, no ruído e na geração de calor.

O impacto abrasivo sônico envolve o movimento vibratório de uma ferramenta para dirigir fragmentos de diamante abrasivo contra um determinado material duro, perfurando-o. Assim, cavidades poderiam ser produzidas em corpos metálicos, ou muito duros e friáveis como superfícies dentárias, cerâmicas, etc. $O$ uso do impacto abrasivo sônico vinha se desenvolvendo desde o início da década de 60 através de esforços para aplicar essa tecnologia em brocas de uso odontológico. Segundo Salmon (1962), a maior controvérsia existente na época seria o possível dano pulpar com o uso da referida técnica. 
Balamuth (1963) discutiu as várias aplicações de uso do primeiro ultrassom (Cavitron) desenvolvido para a prática odontológica, o qual incluía o desgaste, a curetagem, a remoção de amálgama, a instrumentação endodôntica, remoção de cálculo e cirurgia gengival. Segundo o autor, a instrumentação ultrassônica associada ao pó de óxido de alumínio usado como agente abrasivo podia realizar preparos cavitários com pouco aquecimento, pela eliminação da fricção inerente ao processo rotatório. Outra observação pertinente foi a de que a vibração ultrassônica reduz drasticamente o tempo de contato da ponta com o dente, minimizando a dor e o desconforto e aumentando a aceitação do paciente.

\subsection{DAS GEMAS DE DIAMANTE À TÉCNICA DE CVD}

Provavelmente, mais que qualquer outra gema, os diamantes caracterizamse como a pedra mais predominante dentro da história e herança cultural da raça humana. Os diamantes foram valorizados por sua escassez durante séculos, e ainda permanecem um símbolo de riqueza e prestígio nos dias de hoje. A palavra diamante vem do grego adamas, que significa indestrutível. Há mais de 4000 anos, já havia relatos de extração de diamantes na Índia, mas a era do diamante moderno só começou em 1866, quando foram descobertos depósitos de diamantes enormes em Kimberley, África do Sul. A riqueza gerada pela sua exploração ajudou a manter o império britânico, e mudou os destinos de muitos países africanos. À parte de sua atração como gemas, os diamantes possuem uma gama notável de propriedades físicas. Dentre elas, o diamante é o material mais duro conhecido, tem a condutividade térmica mais alta à temperatura ambiente, é transparente em cima de uma gama de comprimento de onda muito larga, é o menos compressível dos materiais e é inerte à maioria dos reagentes químicos (MAY, 2000).

A constituição do diamante é conhecida há 200 anos (TENNANT, 1797), e muitas tentativas foram feitas com o intuito de sintetizá-lo artificialmente para o uso como um material a partir de outro composto de carbono, como é o carvão ou grafite. Essas tentativas mostraram-se ser extremamente difíceis, principalmente porque na temperatura e pressão ambiente, o grafite é 0 alótropo 
termodinamicamente estável do carbono. Embora o padrão de transformação do diamante e do grafite só diferirem em $2.9 \mathrm{~kJ} \mathrm{~mol}^{-1}$ (BUNDY, 1980), existem barreiras de ativação muito grandes que separam as duas fases, prevenindo a interconversão, dentre elas a temperatura e pressão ambiente. Ironicamente, essa barreira de energia grande que faz o diamante tão raro, também é responsável por sua existência, pois uma vez formado, não se pode converter espontaneamente para a fase de grafite mais estável. Assim, diz-se que o diamante é metaestável, quer dizer, cineticamente estável, mas não estável termodinamicamente.

Para superar esses problemas, os investigadores perceberam que, para formar diamantes, são necessárias condições em que ele esteja na fase mais estável. O conhecimento das condições sob as quais um diamante natural é formado no subsolo sugere que o diamante poderia ser formado aquecendo o carbono sob pressão extrema. Este processo forma a base de alta temperatura em alta pressão denominada (high pressure high temperature HPHT). A técnica de geração de diamante por esse método foi comercializada inicialmente pela General Electric (FIELD, 1992) e foi utilizada para produzir o "diamante industrial" durante várias décadas. Nesse processo, o grafite é comprimido em uma prensa hidráulica em dez mil atmosferas, aquecido acima de $2000 \mathrm{~K}$ (1786.85으 $\mathrm{C}$ ) na presença de um catalisador metálico ideal, permanecendo assim até que o diamante se cristalize. Os cristais de diamante produzidos por esse método são usados para uma gama extensa industrial que emprega a dureza e as propriedades de resistência do diamante para o corte e usinagem de componentes mecânicos. Porém, a desvantagem do método HPHT é que este produz diamantes na forma de cristais únicos, que variam em tamanho de nanômetros até milímetros, e isso limita a gama de aplicações para as quais pode ser usado.

A tentativa de reproduzir o método natural para gerar diamantes (como no método HPHT), poderia ser alcançada se pudessem ser somados átomos de carbono um a um, formando uma matriz, de tal modo que os átomos de carbono formassem uma rede tetra-hédrica. Se isso pudesse ser realizado na fase de gás, que necessita de uma pressão muito mais baixa que na técnica HPHT, haveria uma vantagem óbvia em termos de equipamento e custos de energia. Essas idéias conduziram às experiências de Eversole e Kenmore (1958) e Deryagin e Fedoseev (1970) os quais, utilizando a decomposição térmica de gases contendo carbono sob 
pressão reduzida, conseguiram gerar cristais de diamante na superfície de um diamante natural aquecido a $900^{\circ}$ C. Por outro lado, a taxa de crescimento nessas experiências iniciais era baixa, pois grafite foi codepositado com o diamante, que indicava uma mistura impura de fases.

A inovação durou até que Angus, Will e Stanko (1968) descobriram que a presença de hidrogênio atômico durante o processo de deposição conduziria a uma reação química de redução do grafite, e não do diamante (POFERL; GARDNER; ANGUS, 1973). Um trabalho subsequente mostrou que em tal deposição por vapor químico (CVD) poderiam ser usadas técnicas para cultivar diamantes em substratos não diamantados (DERYAGIN et al., 1976, SPITSYN; BOUILOV; DERYAGIN, 1981). Em 1982, investigadores japoneses do Instituto Nacional para Pesquisa em Materiais Inorgânicos (NIRIM) sintetizaram estes resultados, após construir um "reator de filamento quente", cultivando filmes de diamante de boa qualidade em substratos não diamantados a taxas significantes (MATSUMOTO et al., 1982a, b). No ano seguinte o mesmo grupo informou outro método para alcançar o crescimento de diamantes, usando um reator de plasma de microonda (KAMO et al., 1983, SAITO; MATSUDA; NOGITA, 1986). Essas descobertas estimularam o interesse mundial em diamantes CVD, tanto na área de pesquisa quanto na indústria, o que continua até hoje.

Assim, entende-se como deposição por vapor químico (chemical vapor deposition), mais conhecido pela sigla CVD, uma reação química na fase de gás que acontece sobre uma superfície sólida, a qual causa a deposição de uma substância, no caso o diamante. Todas as técnicas de produção de filmes de diamante pelo método CVD requerem meios de ativar, na fase de gás, moléculas precursoras de carbono. Isso geralmente envolve uma corrente térmica (por exemplo, um filamento quente) ou ativação por plasma (corrente direta, radiofrequência ou microondas), ou uso de uma chama de combustão (oxiacetileno ou tochas de plasma). Cada método difere em detalhes, e todos eles compartilham características em comum. Por exemplo, para produzir diamante (em vez de produzir outra forma menos definida de carbono), normalmente requer-se que o substrato seja mantido a uma temperatura por volta de 1.000-1.400 K (726,85-1.126,85 C), e que o gás do precursor seja diluído em um excesso de hidrogênio (MAY, 1995). 


\subsection{A AÇÃO DOS INSTRUMENTOS NO PREPARO E ACABAMENTO CAVITÁRIO}

Street (1953) avaliou a qualidade das paredes cavitárias de dentes extraídos em microscopia óptica. A utilização de discos de papel resultou no melhor acabamento. $O$ autor preconizou que as paredes de esmalte deveriam estar devidamente secas. Foram utilizadas pontas diamantadas cilíndricas lisas e pedras de carborundum, sendo constatada a formação de sulcos rasos. Contudo foram proeminentes os sulcos encontrados nas superfícies tratadas com discos de carbonundum e de diamante. $O$ autor observou a presença de irregularidades de várias profundidades na superfície dentária quando o cinzel de Wedelstaedt e o cinzel biangulado foram utilizados, não confirmando a hipótese de que estes instrumentos manuais proporcionavam paredes cavitárias de esmalte lisas. A refrigeração com jatos de ar/água demonstrou também melhora na qualidade de acabamento. Não houve diferença significante entre as velocidades testadas do instrumento rotatório $(300,600,1.500$ e 3.400 rpm).

Hartley et al. (1957) relataram a vantagem na utilização de pontas diamantadas pela sua eficiência no desgaste de esmalte, apesar do conhecimento de que as partículas de diamante aderidas à haste seriam perdidas conforme o uso. Foi avaliada a perda de diamante das pontas utilizadas em diferentes velocidades (3000, 5000. 10000 e 15000 rpm) após desgastarem o vidro (0.64 centímetros de espessura). Concluiu-se que quanto maior a velocidade, maior o desgaste da ponta diamantada, e que na região periférica ocorria uma maior perda de diamantes que na região central da ponta ativa.

Lammie (1957) utilizou o perfilômetro para mensurar a rugosidade superficial de dentes humanos após o desgaste com vários tipos de instrumentos rotatórios. Dentre eles foram utilizados instrumentos diamantados e carborundum, abrasivos e cortantes rotatórios. O grupo de dentes desgastado com pontas diamantadas proporcionou ranhuras mais profundas. O grupo de dentes que recebeu desgaste com as brocas de aço mostrou a necessidade da utilização de duas ou mais brocas novas para cada desgaste. Já o grupo de dentes desgastados com discos de carborundum apresentou as superfícies mais lisas devido ao pequeno tamanho das partículas de carborundum do disco. Segundo o pesquisador, as características das 
ranhuras vão depender do tipo de instrumento utilizado (diamantado, carborundum, aço ou carbide), granulometria e sentido de corte/abrasão.

Menegale, Swartz e Phillips (1960) avaliaram a adaptação dos materiais restauradores às paredes cavitárias, com e sem acabamento, através da penetração de Cálcio. Foi observada a ocorrência de infiltração marginal nas cavidades que receberam acabamento embora proporcionassem melhor adaptação dos materiais plásticos. A justificativa encontrada pelos autores, para a menor infiltração dos preparos sem acabamento, foi que as irregularidades da superfície dentária melhoram a retenção dos materiais restauradores.

Scott e O'Neil Jr. (1961), em um estudo de microscopia, revolucionaram a análise da "“smear layer"' utilizando o microscópio eletrônico de transmissão para descrever, em detalhes, a morfologia da superfície cortada do dente. Foram observadas anomalias criadas pela ação dos instrumentais e relataram-se também grandes diferenças na textura provocada pelos instrumentos, com difração eletrônica em réplicas da estrutura prismática do esmalte. Os autores demonstraram que a dentina cortada estava sempre irregular e com os túbulos dentinários obstruídos.

Schuchard e Watkins (1967) compararam a efetividade do corte de brocas carbide e pontas diamantadas em alta velocidade (200.000 - 250.000 rpm) com pressão de $170 \mathrm{~g}$. As brocas lisas produziram melhores cortes e lisura superficial que as brocas picotadas, enquanto as pontas diamantadas ocasionaram maior irregularidade nas paredes cavitárias. Notou-se, ainda, que o movimento excêntrico do instrumento rotatório na alta velocidade pode tornar as paredes dos preparos mais iregulares.

Allan (1968) reportou maiores quantidades de irregularidades nos preparos cavitários realizados em alta velocidade $(250.000 \mathrm{rpm})$ que em baixa rotação (2.500 rpm). O autor justificou esse resultado pelo movimento excêntrico do instrumento rotatório, em alta velocidade, bem como o torque irregular das lâminas da broca na parede cavitária. Os instrumentos rotatórios, utilizados em baixa rotação, com alto torque e em sentido horário, tenderam a proporcionar o aspecto arredondado na parede de entrada. O cinzel proporcionou o melhor resultado quando utilizado na planificação das paredes, por sua capacidade de eliminar os prismas de esmalte sem suporte. 
Boyde e Knight (1969) introduziram a microscopia eletrônica de varredura para a avaliação de preparos cavitários. Os autores realizaram cavidades in vivo, em dentes restaurados e extraídos, para a observação através da MEV. Observou-se que as pontas diamantadas utilizadas em alta velocidade produziam sulcos profundos com mais de $20 \mu \mathrm{m}$, devido ao tamanho das partículas de diamante. Similar resultado foi obtido quando as cavidades foram confeccionadas com pontas diamantadas e o acabamento realizado com cinzéis. Os sulcos encontravam-se menos profundos, demonstrando que o acabamento cavitário seria interessante principalmente na confecção dos ângulos cavo-superficiais dos preparos. Os melhores resultados foram obtidos com broca carbide, que apresentaram irregularidades inferiores a $0.5 \mu \mathrm{m}$. Notaram-se, ainda, imperfeições nas arestas das lâminas das brocas de aço, que poderiam provocar fraturas com dimensões superiores a $4 \mu \mathrm{m}$.

Eick et al. (1970) avaliaram o uso do MEV como instrumento para estudar as diferenças em dentes humanos na topografia superficial desgastada, identificar quimicamente a “"smear layer"” produzida e estabelecer o padrão de desgaste, utilizando pontas diamantadas e instrumento cortante rotatório em alta velocidade, (200.000 rpm) com e sem irrigação. As superfícies desgastadas com pontas diamantadas se apresentaram mais rugosas que as desgastadas com brocas de aço.

Tronstad e Leidal (1974) avaliaram, através da MEV, as paredes do preparo cavitário da caixa proximal, a fim de comparar diferentes técnicas de acabamento. Foram utilizados pré-molares hígidos, cavidades de classe II foram preparadas com brocas carbide, em turbina de alta velocidade, com refrigeração ar/água. Para o acabamento utilizaram-se machado para esmalte, recortador de margem gengival, além de pontas para acabamento em velocidade convencional (6.000 rpm) com jato de ar/água, com sentido de corte de saída para todas as paredes cavitárias. A avaliação qualitativa dos ângulos cavo-superficiais obedeceu ao sistema IMC (Índice de Margem Cavitária). Baseado nesse sistema, as médias finais de acabamento de paredes proximais foram instrumentos manuais (IMC-2); brocas de aço com rotação anti-horária (IMC-1); discos de papel abrasivos (IMC-0). As médias dos escores para as paredes gengivais foram: recortador de margem gengival (IMC-0); brocas de aço (IMC-3), pontas diamantadas (IMC-3). Os melhores resultados para o acabamento 
das caixas proximais foram o disco de papel abrasivo para paredes laterais e recortador de margem gengival para a parede gengival. Segundo os autores, esse procedimento possuía uma série de limitações, pois só poderia ser utilizado onde o acesso permitisse. Nas caixas proximais conservativas, o instrumento manual poderia ser aplicado, evitando o movimento de ação de clivagem, dando preferência ao movimento de raspagem, respeitando o modo de ação do recortador de margem gengival.

Lester (1978) investigou as irregularidades na superfície cavitária causadas por instrumentos convencionais para acabamento através da MEV. O autor encontrou melhores resultados utilizando brocas carbide em forma de pera em alta velocidade. O recortador de margem gengival mostrou-se apropriado para o acabamento das paredes gengivais e proximais de classe II, com movimentos de raspagem perpendiculares às paredes cavitárias.

Gilboe et al. (1980) estudaram a produção e análise em MEV da “"'smear layer"' realizada em molares humanos (in vitro), variando a ponta de desgaste (diamantada ou cortante de aço) em alta velocidade (200.000 rpm), atuando sob refrigeração ou não (spray ar/água ). Nas fotomicrografias, os grupos que sofreram desgaste com pontas diamantadas evidenciaram a presença de estrias e "“smear layer'”' que, aparentemente, apresenta-se pouco aderente à dentina, sendo parcialmente removida pelas brocas de aço associado ao "spray" de ar/água, possibilitando a visualização da luz de alguns túbulos dentinários. Os dentes desgastados sem irrigação demonstraram que a superfície dentinária foi totalmente coberta por "“smear layer"” homogênea, obstruindo os túbulos dentinários. O estudo concluiu que a superfície desgastada é recoberta por ““'smear layer”"'.

Westland (1980) estudou a eficiência de vários tipos de brocas dentárias. A eficiência de processo foi avaliada durante o desgaste de dentes humanos e "plugs" de amálgama, com pontas diamantadas e brocas de carboneto de tungstênio em diferentes velocidades e diâmetros de broca, não encontrando diferenças significantes entre as mesmas. Somente a eficiência do processo cortante foi avaliado, desconsiderando vários outros aspectos essenciais no processo de desgaste, como a qualidade da superfície remanescente após o desgaste e a geração de vibrações durante o desgaste. 
Boyer e Svare (1981) relataram que a permeabilidade dentinária dependia do método de corte ao qual a dentina era submetida. A proposta desse trabalho visou à determinação da permeabilidade dentinária em relação aos diferentes métodos de desgaste, comparando os efeitos gerados pelo disco diamantado, brocas de aço e pontas diamantadas e, após o acabamento, com brocas de aço modificadas ou pontas cegas. Concluiu-se que em todas as metodologias de desgaste empregadas a permeabilidade dentinária foi reduzida, apresentando os túbulos dentinários obstruídos pelo "smear plug" e não apresentando diferenças entre os grupos estudados.

Em relação à energia gerada na interface dentina/broca, Gwinnett (1984) afirma que tal energia é desenvolvida durante o desgaste, promovendo o aquecimento dentário, deformação plástica e deformação elástica, podendo formar uma “"smear layer'”' contaminada. Demonstrou também as diferenças morfológicas causadas pelos diferentes instrumentos abrasivos e de corte dentário testados, utilizados ar seco ou sob refrigeração e a ocorrência de “"smear layer"”' com áreas de pouca aderência. Segundo o autor, as partículas de "“smear layer"' mudam de acordo com as condições operatórias, pressão empregada, instrumento utilizado e calor gerado, sendo que a refrigeração contribui para a diminuição em sua deposição.

Lussi, Hugo e Hotz (1992), avaliaram in vivo a qualidade do ângulo cavosuperficial proximal em função de diferentes técnicas de acabamento proximal. Foram confeccionados preparos cavitários classe II para amálgama, confeccionados por 4 operadores. Para a avaliação das paredes cavitárias V e L utilizaram a MEV observando réplicas de resina epóxica de preparos cavitários. A avaliação da qualidade dos ângulos foi determinada qualitativamente através de escores. $O$ sistema para acabamento com granulometria de $25 \mu \mathrm{m}$, modificado pela redução de tamanho e alta flexibilidade, mostrou-se estatisticamente superior ao recortador de margem gengival em todas as paredes, sem ganho no tempo operatório.

$\mathrm{Xu}$ et al. (1997) investigaram os danos causados no esmalte pela ponta diamantada durante os preparos cavitários. Foram avaliados o mecanismo dos preparos cavitários e extensão dos danos superficial e ao redor produzidos durante a confecção do mesmo com pontas diamantadas, além dos tamanhos das partículas das pontas diamantadas, prismas de orientação e, por fim, a quantidade de esmalte 
removido durante o preparo. Os resultados mostraram que há maior presença de trincas nos preparos feitos com pontas diamantadas de média granulação, extendendo-se ao limite dos prismas de esmalte. Realizou-se acabamento com ponta diamantada de fina granulação e essas fissuras foram removidas do esmalte.

Com o objetivo de avaliar qualitativamente o acabamento dos ângulos cavosuperficiais proximais em esmalte vestibular, lingual e gengival, em preparos classe II, tipo caixa, mésio-oclusal e disto-oclusal, Coutinho (1995) utilizou a MEV e o programa AUTOCAD 12 para a análise quantitativa de 30 pré-molares humanos. A avaliação visou o tipo de instrumento rotatório (corte e desgaste), manuais como recortador de margem gengival e machado para esmalte, além da influência do sentido de corte de entrada e saída do instrumento rotatório junto ao ângulo cavosuperficial proximal. Os resultados demonstraram que não houve diferenças estatisticamente significantes em relação às irregularidades causadas pelas brocas. Nos ângulos cavo-superficiais proximais, o melhor acabamento foi obtido com instrumentos manuais após a instrumentação inicial com broca carbide lisa ou ponta diamantada de granulometria regular. Finalmente foi constatado, ainda, que a qualidade de corte ou desgaste foi superior no sentido de entrada dos instrumentos rotatórios, quando em comparação ao sentido de saída dos mesmos, com diferenças estatisticamente significantes.

Bianchi et al. (1999) avaliaram oito diferentes tipos de diamantes abrasivos utilizados na fabricação de pontas diamantadas, a fim de se realizar uma pesquisa sobre a possibilidade de fabricação e utilização de pontas descartáveis. Nos ensaios, o vidro foi desgastado enquanto a força tangencial de corte era monitorada em tempo real via computador. O melhor tipo de diamante, dentre os pesquisados, foi aquele que pôde remover mais material até que uma determinada força de corte máxima fosse alcançada. Os aspectos econômicos e de saúde também foram considerados. Dessa forma, o melhor tipo de diamante foi aquele que apresentou ao mesmo tempo, as melhores condições de remoção de material e o menor preço, permitindo a fabricação de pontas diamantadas descartáveis.

O objetivo do experimento de Watson et al. (2000) foi comparar a dinâmica de corte de peças de mão de alto torque e alta velocidade (velocidade crescente), com de baixo torque e alta velocidade (turbina-ar), além de avaliar o efeito do torque e do tipo de broca na produção de trincas no esmalte. Também foram registradas 
mudanças de temperatura nos dentes durante o preparo cavitário com peças de mão de alto torque e baixo com pontas de diamante e broca carbide. A metodologia empregada registrou as interações entre as brocas e o esmalte através de tomadas de vídeo utilizando um microscópio confocal. A geração de calor foi medida com sensores térmicos colocados nas câmaras pulpares dos espécimes preparados com pontas diamantadas e brocas carbide, de acordo com a variação do torque da peça de mão, em preparos oclusais e cervicais. Os resultados demonstraram desempenhos semelhantes com cargas de torque leves. Porém diferenças marcantes foram encontradas quando aumentaram as forças aplicadas, geralmente as peças de mão com um aumento em taxa cortante. A turbina de ar não pôde conter a manutenção de cargas pesadas, tendendo a parar. Nenhuma diferença foi observada entre as diferentes peças de mão e brocas no que diz respeito a trincas de esmalte sub-superficiais. Semelhantemente, nenhuma diferença foi registrada na elevação de temperatura durante o preparo cavitário.

Pilcher, Tietge e Draughn (2000) compararam as taxas volumétricas cortantes de 6 brocas cilíndricas diamantadas utilizadas somente uma vez, e 2 pontas cilíndricas diamantadas de uso múltiplo. O grau de uso entre brocas também foi comparado através da MEV. Foram avaliadas cinco brocas de cada tipo, usandose turbina de alta velocidade. A taxa volumétrica média cortante do substrato cerâmico foi calculada para cada broca em relação aos milímetros cúbicos preparados por segundo. A topografia de uma broca de cada grupo foi avaliada em MEV após o segundo corte, e novamente depois do corte 20. Os autores observaram que, no corte 2 , as taxas cortantes más variaram de 3.3 a $5.3 \mathrm{~mm} 3 / \mathrm{s}$. As taxas cortantes médias para todos os tipos de brocas diminuíram $20 \%$ aproximadamente até o corte 20. A análise em MEV demonstrou ainda que todas as brocas exibiram desgaste das partículas de diamante, como também perda de partículas . Concluiu-se que cinco de seis brocas utilizadas uma única vez obtiveram taxas volumétricas médias cortantes semelhantes àquelas utilizadas 2 ou 20 vezes. Houve redução gradual da taxa cortante durante os 20 cortes para todos os tipos de brocas, como resultado do seu uso.

Com o intuito de avaliar diferentes métodos de acabamento e polimento do esmalte, Giampaolo et al. (2003) avaliaram esses métodos em dentes com cavidades MOD preparadas com ponta diamantada e alta velocidade. Os materiais 
de acabamento utilizados foram divididos em grupos, utilizando-se as pontas diamantadas para preaparos e acabamentos carbides, escovas Robson, taça de borracha, pontas diamantadas de fina granulação, pontas para acabamento de silicone em diferentes granulações, pastas para acabamentos e feltro. Os autores chegaram à conclusão de que foi encontrada maior rugosidade no esmalte nos preparos com ponta diamantada em alta velocidade sem acabamento, e houve uma queda nos valores de superfície rugosa no grupo que teve preparo feito com ponta diamantada em baixa velocidade, e que todos os métodos de polimento diminuíram significantemente a rugosidade da superfície do esmalte.

Com o objetivo de avaliar a microinfiltração marginal em cavidades restritas ao esmalte de dentes bovinos preparados com as pontas CVDentus e diamantadas convencionais, Diniz et al. (2005) realizaram preparos cavitários medindo $1 \mathrm{~mm}$ de profundidade em dois grupos de 15 dentes cada, utilizando ponta diamantada convencional associada à turbina de alta velocidade e ponta CVDentus associada ao ultrassom. As cavidades foram restauradas com selante para fóssulas e fissuras Fluroshield (Dentsply) de acordo com as instruções do fabricante. Após serem isolados com Araldite e esmalte cosmético, os dentes foram submetidos à termociclagem em água a $5^{\circ} \mathrm{C} \pm 2^{\circ} \mathrm{C}$ e $5^{5} \mathrm{C} \pm 2^{\circ} \mathrm{C}$, total izando 500 ciclos. Em seguida, foram corados com fucsina básica a $0,5 \%$, seccionados e lixados até ficarem com aproximadamente $0,25 \mathrm{~mm}$ de espessura, montados em lâminas e identificados. A análise da microinfiltração foi realizada em microscópio óptico ligado a uma câmara digital e conectado a um computador, o que permitiu a análise quantitativa da microinfiltração em milímetros por meio de uma imagem digitalizada e um software AxioVision. Os dados obtidos foram submetidos à análise estatística através do teste de Mann-Whitney. Foi observada acentuada microinfiltração marginal em ambos os grupos sem diferença estatística entre eles $(p>0,05)$.

Com o objetivo de avaliar, por meio de MEV, o padrão de condicionamento da dentina após a aplicação do primer autocondicionante de um sistema adesivo autocondicionante (Clearfill Liner Bond 2) e do ácido fosfórico a 37\%, variando-se o instrumento para preparo, Martins, Faria e Matson (2006) realizaram 30 preparos cavitários em 5 molares humanos recém extraídos, sendo 2 preparos com ponta diamantada, 2 preparos com brocas carbide em baixa rotação e 2 preparos com ponta de diamante acionada por ultrassom (para cada dente). Cada dente recebeu 
um tipo de tratamento: sem condicionamento, condicionamento com ácido fosfórico a $37 \%$ por 15 s ou aplicação do primer autocondicionante. Os espécimes foram analisados em MEV, onde foram feitas imagens com aumentos de 200, 2000 e 5000 vezes. Resultados: os casos preparados com a ponta CVDentus mostraram uma “"smear layer"”' com aspecto de flocos, além da presença de túbulos dentinários expostos. Nos preparos com ponta diamantadas convencionais e broca carbide, a “"'smear layer'”' apresentou-se mais compacta, com presença de resíduos na dentina intertubular. Baseados nos resultados observados, os autores concluíram que com a utilização das pontas CVDentus mais a aplicação de um primer autocondicionante obtém-se uma “'smear layer"' menos aderida, com um padrão de condicionamento diferente da dentina dos preparos convencionais.

Mandarino et al. (2006) compararam a infiltração marginal em preparos cavitários confeccionados com pontas CVDentus em aparelho de ultrassom ou com ponta diamantada em turbina de alta velocidade. Foram realizados preparos classe $V$ nas faces vestibular e lingual de molares humanos. Os dentes foram restaurados com resina composta e posteriormente polidos com discos sof-lex. Após termociclagem, os dentes foram impermeabilizados com esmalte cosmético com margem livre de $1 \mathrm{~mm}$ ao redor da restauração. O corante utilizado foi a Rodamina $B$ $(0,2 \%)$ por um período de $8 \mathrm{~h}$. Após seccionados, os dentes foram avaliados através da microscopia óptica. Avaliaram-se imagens das secções através de um software (Axon Vision). Os resultados demonstraram que, independente do instrumento, a margem cervical apresentou maior infiltração que a oclusal; menor infiltração na região oclusal ocorreu nos preparos realizados com pontas CVDentus.

Em 2006, Lima et al. realizaram um estudo para determinar a habilidade de corte das pontas de diamante obtidas pelo processo de deposição química a vapor (CVD) associadas ao aparelho de ultrassom no preparo cavitário minimamente invasivo. As cavidades foram padronizadas e preparadas nas faces mesial e distal de 40 terceiros molares, utilizando-se pontas de diamante CVD cilíndrica e esférica. A habilidade de corte foi comparada quanto ao tipo de substrato (esmalte e dentina) e quanto à direção do movimento realizado com a ponta. O trabalho evidenciou que a direção de movimento da ponta não influenciou o tamanho das cavidades, sendo os cortes produzidos pelas pontas de diamante CVD mais precisos e conservadores. 
Existem poucos trabalhos clínicos relacionados ao uso das pontas CVD disponíveis na literatura. Carvalho et al. (2007) relataram dois casos utilizando pontas CVD em aparelho de ultrassom. O estudo demonstrou um preparo interproximal de incisivo central superior, e outro caso exemplificando um preparo classe I em molar inferior, ambos restaurados com resina composta. Baseados nestes dois casos, os autores afirmam que as pontas de diamante CVD promovem um preparo ultraconservador com resultados clínicos satisfatórios.

Bernardes et al. (2007) avaliaram o tempo, a ocorrência de fratura, e a qualidade do preparo de cavitário apical com três pontas de diamante ultrassônicas diferentes: Satelec, Trinity, e CVD, através da análise em microscopia eletrônica de varredura. Foram utilizados pré-molares humanos unirradiculados, submetidos à apicetomia e preparados com pontas ultrassônicas. A presença de fraturas foi avaliada e a qualidade do preparo foi avaliada através da MEV por dois examinadores. O grupo preparado com as pontas CVD exibiu o tempo de preparo mais curto e não apresentou fraturas. Não havia nenhuma diferença estatística significante na qualidade do preparo entre as três pontas. As três marcas de pontas ultrassônicas produziram perfurações adequadas sem alterar a morfologia do forame apical.

Não existe, ainda unanimidade sobre a eficiência das pontas CVD. Cardoso et al. (2007), além de avaliarem a influência de técnicas alternativas para o preparo cavitário na efetividade de união de diferentes adesivos para dentina, e também verificaram as características morfológicas da dentina preparadas com essas técnicas. Os autores utilizaram o adesivo etch\&rinse (OptiBond FL, Kerr) e três sistemas de autocondicionante (Adper Prompt L-Pop, 3M ESPE; Clearfil S3 Bond, Kuraray; Clearfil S3 Bond, Kuraray) aplicados sobre a dentina preparada com ponta convencional em turbina de alta velocidade, com ponta CVD também em turbina de alta velocidade, com ponta CVD em ultrassom e com laser Er,Cr:YSGG. A força de união micro-elástica ( $\mu$ TBS- micro tensile bond streght) foi determinada após o armazenamento em água durante $24 \mathrm{~h}$ a $37^{\circ} \mathrm{C}$, e a avaliação morfológica foi executada por meio de microscopia eletrônica de varredura com canhão de emissão de campo (Feg-MEV). Os autores reportaram que a Feg-MEV revelou características morfológicas diferentes na dentina após o uso de ambas as técnicas convencionais e alternativas para o preparo cavitário, mais especificamente relativas à densidade 
de "smear layer" e aspereza da superfície. O corte das pontas CVD ultrassônicas e a dentina irradiada com laser resultaram em menores forças de união microelásticas que as observadas nos cortes realizados com brocas convencionais, independente do adesivo empregado. Os autores concluíram com o achado que as técnicas com pontas CVD de alta velocidade, pontas ultrassônicas CVD e a irradiação com laser, utilizadas no preparo cavitário, podem afetar a efetividade de união dos adesivos na dentina, independente de sua acidez ou forma de aplicação.

Predebon, Flório e Basting (2006) enviaram um questionário, via e-mail para mil e sessenta cirurgiões-dentistas para avaliar o uso de CVDentus em preparos cavitários com ultrassom. Os autores, chegaram à conclusão de que muitos dentistas conhecem as pontas CVDentus e as utilizam com maior frequência em cavidades conservadoras, e as consideraram com corte eficiente e notaram que, na maioria dos procedimentos, não há necessidade do uso de anestesias quando as mesmas são empregadas.

Shimidlin et al. (2007) realizaram um estudo laboratorial para avaliar a influência do bisel nas margens cavitárias e os efeitos na adaptação marginal após a aplicação do ultrassom durante o processo inicial de presa da resina fotopolimerizável. Foram confeccionados 80 preparos classe II tipo caixa em 40 molares humanos, utilizando quatro instrumentos diamantados diferentes: A -uma ponta ultrassônica diamantada em forma de U (PCS, SEM, Nyon Switzerland) sem biselamento para servir como controle; B- uma ponta diamantada de chanfro (Bevelshape, Intensiv, Viganelo, Germany); C- uma ponta coberta seletivamente com uma concavidade marginal integrada (SonicSys, KaVo, Biberach, Germany); Dum protótipo de uma ponta (Superprep, KaVo). O tempo adicional despendido com o preparo do bisel também foi medido. As cavidades foram preenchidas com resina composta em três incrementos. O Ultrassom foi aplicado em uma cavidade por dente, antes e durante a fotopolimerização (10 segundos). Os espécimes foram colocados em termociclagem e em um dispositivo de mastigação controlado por computador. A qualidade marginal foi avaliada através da MEV e os resultados foram comparados estatisticamente. O tempo adicional necessário para o acabamento foi $B>D>C(p<0.05)$. Em todos os grupos, a carga termomecânica resultou em uma diminuição na qualidade marginal. O biselamento resultou em valores mais altos de margens "contínuas" comparadas com os controles sem bisel. 
O protótipo mostrou uma qualidade marginal melhor às paredes axiais quando 0 ultrassom era utilizado. $\mathrm{O}$ bisel parece essencial para a adaptação marginal, porém há a demanda de maior tempo despendido no preparo. O uso de vibrações ultrassônicas pode melhorar a qualidade marginal das restaurações sem bisel.

Vieira et al. (2007), em pesquisa realizada com o objetivo de comparar preparos cavitários feitos com alta velocidade e ultrassom, em relação ao tempo de cada instrumento, assim como, a microinfiltração depois de feitas as restaurações. Foram usados dentes bovinos e cavidades foram feitas na face vestibular de cada dente em formato cilíndrico. No primeiro grupo empregado com alta velocidade com ponta diamantada; no segundo grupo, ultrassom acoplado com pontas CVD. O tempo de preparo de cada cavidade foi mensurado com o auxílio de um cronômetro. Feitas as cavidades, os dentes foram tratados com adesivo e restaurados com resina composta, seguidos de acabamento e polimento; os mesmo foram imersos em solução de nitrato de prata a $50 \%$. Os resultados mostraram que menor tempo de preparo cavitário foi apresentado pelo grupo da alta velocidade acoplado com ponta diamantada e neste não houve nenhuma microinfiltração marginal. Já no grupo do ultrassom com pontas CVDentus, $46 \%$ das amostras não mostrou microinfiltração. A conclusão a que os autores chegaram foi a de que a alta velocidade obteve melhor desempenho em relação ao ultrassom em ambas as situações.

\subsection{AS BROCAS CVD}

O surgimento da tecnologia CVDentus com cobertura de diamante está intimamente relacionada à produção de pontas odontológicas. Inclusive a manufatura dessas pontas foi um dos tópicos iniciais de apresentação dessa tecnologia. Trava-Airoldi, Corat e Moro (1995), um pesquisador brasileiro do INPE (Instituto Nacional de Pesquisas Espaciais), apresentou seu método de formação de filmes de diamante com CVDentus utilizando filamento quente, exemplificando a técnica na manufatura de pontas CVDentus e destacou a competitividade desse tipo de ponta em relação aos modelos convencionais. Em outro trabalho semelhante, o 
mesmo tema é apresentado e discutido, demonstrando a potencialidade do produto comercialmente (TRAVA-AIROLDI; CORAT; MORO, 1996).

Borges et al. (1999) consideraram o problema das pontas diamantadas convencionais quanto às suas limitações como a heterogeneidade de formas de grãos, a dificuldade de automatização durante a fabricação, a diminuição da efetividade do corte devido à esterilização contínua e vida curta. Outro problema relatado em relação às pontas diamantadas convencionais foi a liberação potencial de íons de níquel $\left(\mathrm{Ni}^{+2}\right)$ nos fluidos corpóreos. Com o objetivo de contribuir para a solução desses problemas, os autores investigaram o uso de pontas CVDentus comparando-as com pontas diamantadas convencionais. Testes de corte foram avaliados através da MEV e análise com sonda de elétrons (EMA) para localizar resíduos metálicos na superfície da ponta ou do substrato. A análise com a sonda EMA demonstrou que os metais $\mathrm{Ni}, \mathrm{Cr}$, $\mathrm{Si}$, e $\mathrm{Fe}$ estavam presentes na matriz metálica das pontas diamantadas convencionais e poderiam cobrir a superfície do substrato durante o corte. A análise em MEV demonstrou perda significante de partículas de diamante durante a ação das pontas convencionais. Por outro lado, a perda de partículas foi discreta ou ausente no grupo que utilizou as pontas CVDentus. Os autores concluíram que as pontas CVDentus não só se mostraram mais eficientes em sua habilidade de ação e longevidade, mas também excluíam o risco de contaminação de metais.

Sein et al. (2003) focalizaram a investigação na deposição de filme de diamante policristalino sobre pontas odontológicas com desenho tridimencional complexo ou cilíndrico, empregando um único passo, a deposição de diamante por vapor químico (CVD). Para a deposição de diamante utilizou o filamento quente na ativação de moléculas precursoras de carbono. Os autores apresentaram uma modificação na técnica de colocação do filamento sobre a superfície que vai receber o filme de diamente, com a intenção de simplificar e diminuir o custo do processo. Além disso, os problemas associados à adesão de filmes de diamante em substratos de WC-Co (Carboneto de Tugstênio-Cobalto) são associados à presença de Co, como causador de uma adesão pobre. A quantia de Co metálico na superfície pode ser reduzida usando-se um pré-tratamento em dois passos: um que emprega cauterização com agente de Murakami, seguido por um tratamento ácido. Foram examinados os filmes de diamante em relação à sua taxa de deposição, morfologia, 
adesão e eficiência cortante. Observou-se que as pontas CVDentus duraram 3 vezes mais do que as pontas convencionais.

Gozeloto et al. (2003) demonstraram a aplicação da tecnologia CVD na confecção de pontas especiais para aplicação não odontológica. Segundo os autores, a tecnologia de crescimento de filmes de diamante CVD tem sido usada para a fabricação de ferramentas de corte especiais, aplicadas para usinagem de materiais difíceis como o vidro de boro-silicato. A ponta anelar de diamante CVD é um exemplo desse tipo de ferramenta. Ela é composta por um anel de molibdênio recoberto com diamante CVD, crescido através da técnica assistida por filamento quente. Experimentos mostraram que as pontas anelares de diamante CVD possuem melhores resultados técnicos de operação, quando comparadas com as pontas anelares comerciais, fabricadas com o diamante HPHT, como menor ruído operacional e perfurações obtidas sem defeitos em suas bordas.

A granulação das pontas CVD foi avaliada no trabalho de Gäbler et al. (2003). Diferentes pontas de diamante CVD foram fabricadas com diâmetros de ponta variando de 0.06 a $2.0 \mathrm{~mm}$. Um reator de filamento quente CVD foi utilizado em combinação com um sistema de sustentação do substrato, com uma capacidade de até 240 pontas. Os autores destacam que o tamanho do grão é a propriedade mais importante nas ferramentas abrasivas. Deve ser ajustado então cuidadosamente no processo de deposição. A influência básica na geometria da ferramenta e nos parâmetros de cobertura no tamanho dos cristais é apresentada. Para um tempo de deposição para 90h, os autores obtiveram cristais de até $50 \mu \mathrm{m}$. Os autores destacam que, em escala industrial, o tempo de deposição não seria um problema, já que são utilizados reatores maiores com capacidade para um número considerável de instrumentos.

Ainda sobre os métodos de fabricação de pontas CVD, Gorokhovsky (2005) apresentou a tecnologia do arco em cascata de plasma-assistido CVD (CACVD), baseada na aplicação de um reator inovador que utiliza as propriedades de uma coluna de arco linear de plasma. A peculiaridade da tecnologia é que a deposição de diamante é realizada na mesma gama de pressão, de 0.1 Torr até a pressão atmosférica. O reator de CACVD supera as desvantagens de Tocha de Arco de reatores convencionais CVD, criando uma coluna de plasma concentrada homogênea em uma câmara de reação cilíndrica ou retangular com um comprimento 
de $1 \mathrm{~m}$ ou mais. No reator CACVD, um arco de plasma é sustentado através de campos magnéticos, criando um ambiente de plasma uniforme. No trabalho, a técnica foi usada para depositar diamante policristalino em camadas sob substratos tridimencionais como brocas odontológicas. O autor destaca ainda que o controle preciso da temperatura do substrato em processos de alta temperatura da técnica CVD são críticos para depositar camadas de diamante policristalino.

Trava-Airoldi, Corat e Moro (2006) apresentaram um estudo relativo à deposição de diamante através do processo CVD em formas diferentes de substratos metálicos, destacando a boa aderência do diamante, em pontas ultrassônicas odontológicas. Os autores destacaram a capacidade de ação de desgaste e menor ruído, resultando em menor produção de dor. A cobertura de diamante utilizou a técnica de Filamento Quente, com alta taxa de deposição, usando hidrogênio convencional e misturas de gás metano. Hastes metálicas usinadas na forma de pontas ultrassônicas odontológicas, com uma superfície prépreparada, foram cobertas com filme de diamante CVD espesso. As pontas CVD foram testadas em relação ao tempo de vida e precisão de corte, demonstrando desempenho muito bom. Segundo os autores, as pontas CVD ultrassônicas mostraram-se 30 vezes mais duráveis que as pontas diamantadas convencionais.

Lima et al. (2006) realizaram um estudo com o objetivo de determinar a habilidade de corte das pontas de diamante obtidas pelo processo de deposição química a vapor (CVD) associadas ao aparelho de ultrassom no preparo cavitário minimamente invasivo. Uma cavidade padronizada foi preparada nas faces mesial e distal de 40 terceiros molares, utilizando-se pontas de diamante CVD cilíndrica e esférica. A habilidade de corte foi comparada quanto ao tipo de substrato (esmalte e dentina) e quanto à direção do movimento realizado com a ponta. As características morfológicas, a largura e profundidade das cavidades foram analisadas e medidas em microscopia eletrônica de varredura. A análise estatística pelo teste de KruskalWallis $(p<0,05)$ revelou que a largura e profundidade das cavidades foram significativamente maiores em dentina. Cavidades mais largas foram obtidas quando se utilizou a ponta de diamante CVD cilíndrica, e mais profundas quando a ponta esférica foi empregada. A direção do movimento da ponta não influenciou o tamanho das cavidades, sendo os cortes produzidos pelas pontas de diamante CVD precisos e conservadores. 
Predebon, Flório e Basting (2006) avaliaram o uso de pontas CVDentus no preparo de cavidades com ultrassom por profissionais. Os autores realizaram mil e sessenta (1060) entrevistas através de questionários via e-mail sobre o uso do sistema no que diz respeito às indicações, necessidade de anestesia, forma final do preparo de cavitário e uso das pontas. Para esses procedimentos, $17.8 \%$ não requereram uso de anestesia local. Foi considerado que a forma final do preparo, comparada com pontas diamantadas de alta velocidade, era mais conservadora para $48.3 \%$ dos profissionais. Com respeito ao uso, $44.4 \%$ dos usuários informaram problemas como fratura do adaptador da ponta e baixa taxa de corte. Para os autores, o sistema CVD parece apresentar limitações com respeito à eficiência cortante, uso além da necessidade do uso de anestesia na maioria de procedimentos restauradores.

Com o crescente desenvolvimento de pontas diamantadas de sistema CVD, Josgrilberg et al. (2007), realizaram um estudo para avaliar o formato dos preparos cavitários onde foram empregados com CVDentus, utilizando-se potências variadas do ultrassom. Foram feitas cavidades na face vestibular em incisivos bovinos utilizando CVDentus cilíndrica. Para a confecção das cavidades, empregou-se uma máquina padronizada para esse tipo de procedimento, e o ultrassom foi aplicado durante 1 minuto em cada preparo. O perfil do preparo foi visualizado com uma lupa estereoscópica e medida a profundidade pelo programa Leica Qwin. A conclusão a que se chegou com esse trabalho foi que a potência indicada pelo fabricante de pontas CVDentus é a mais adequada para o uso da mesma sendo que, para cada tipo de ponta diamantada, existe a potência adequada pelo fabricante.

Para uma análise crítica de comparação de alta velocidade associado à ponta diamantada e ultrassom associado à CVDentus, Lima et al. (2009) fizeram estudo comparativo para observar e analisar a efetividade de corte em esmalte e dentina em dente humano, desses dois equipamentos. Foram preparados vinte molares permanentes, sendo estes seccionados longitudinalmente, resultando 40 espécimes, dividindo 20 espécimes para cada grupo. Em cada espécime foi realizada apenas uma cavidade. A análise foi feita através do software Radiocef 4.0 para determinação da largura e altura das cavidades. A conclusão encontrada pelos autores, nesse trabalho, foi que ambos os instrumentos são eficazes no preparo de 
cavidades em esmalte e dentina, entretanto o alta velocidade acoplado com ponta diamantada convencional mostrou características mais invasivas. 




\section{PROPOSIÇÃO}

Este estudo propõe avaliar a qualidade marginal de preparos cavitários, realizados em função de:

- Diferentes formas de ação dos aparelhos: vibração e alta velocidade;

- Diferentes tipos de uso de pontas diamantadas. 




\section{MATERIAL E MÉTODOS}

\subsection{PREPARO DAS AMOSTRAS}

Foram selecionados 26 dentes bovinos, hígidos, sem trincas, de mesmo tamanho, mantidos em solução fisiológica com $0,1 \%$ Timol até a realização dos procedimentos de metalização para análise no microscópio eletrônico de varredura. Primeiramente eles foram limpos, através da remoção de cálculo e qualquer tipo de pigmento; em seguida, cada dente recebeu planificação de sua face vestibular através de Politriz (Arotec APL-4) e lixa d'agua (Norton®), com granulações decrescentes de 400, 500 e 600. Após a planificação dos dentes, foram feitos acabamento e polimento com lixa d'água com granulações de 1000 e 1200, para que a superfície vestibular ficasse o mais homogênea e lisa possível. (DINIZ et al., 2005, JOSGRILBERG, 2007, VIEIRA, 2007)

Os dentes selecionados foram divididos aleatoriamente em 7 grupos, compondo as seguintes condições experimentais:

GRUPO I - Ultrassom + Ponta CVDentus-Corte

- Subgrupo 1 - Potência $25 \%$

- Subgrupo 2 - Potência 50\%

- Subgrupo 3 - Potência $75 \%$

- Subgrupo 4 - Potência 100\% 
GRUPO II - Ultrassom + CVDentus-Corte + CVDentus-Acabamento

- Subgrupo 1 - Potência 25\%

- Subgrupo 2 - Potência 50\%

- Subgrupo 3 - Potência75\%

- Subgrupo 4 - Potência $100 \%$

Grupo III - Alta Velocidade + Ponta Diamantada Convencional

Grupo IV - Alta Velocidade + Ponta Diamantada Convencional + Baixa

Velocidade + Ponta Diamantada para Acabamento

Grupo V - Velocidade Intermediária + Ponta Diamantada

Convencional

Grupo VI -Baixa-Velocidade + Ponta Diamantada Convencional

Grupo VII - Ultrassom + CVDentus-Corte Potência 50\% + Acabamento Ponta Diamantada/ Velocidade Intermediária 


\subsection{TÉCNICAS PARA A CONFECÇÃO DOS PREPAROS CAVITÁRIOS}

\subsubsection{Grupo I - Ultrassom + CVDentus Corte}

Foram preparadas quatro cavidades com pontas diamantadas para preparo CVDentus $n^{0}$ 82137, cilíndricas de extremo plano, acopladas no aparelho de ultrassom NACplus AE 500 (Adiel Comercial LTDA-Brasil), o qual apresenta uma frequência máxima de $38.000 \mathrm{~Hz}$. As cavidades desse grupo foram confeccionadas com a ponta diamantada cilíndrica de extremo plano n¹060 (KGSorensen - São Paulo - Brasil) trabalhando em movimentos oscilatórios, com a potência de $25 \%$, dentro do modo "scalling"(>>>>). Devido às características vibratórias dos aparelhos ultrassônicos, a realização dos preparos cavitários foi consignada com leve pressão junto ao sobstrato dentário e movimentos oscilatórios verticais e horizontais. De forma oncomitante foi usada irrigação com água destilada, ajustando a bomba peristática em 25\% (Figuras 2A e 2B). A penetração inicial foi realizada com a ponta diamantada em movimento e inclinada em $45^{\circ}$ em relação à superfície externa do dente, com aproximadamente $1,5 \mathrm{~mm}$ de profundidade. Após a penetração inicial, a ponta diamantada é levada para uma posição que proporcione paredes circundantes perpendiculares à superfície externa do dente, ou seja, com a extremidade plana da ponta ativa paralela à parede axial que está sendo esboçada. Com movimentos intermitentes e retilíneos de vaivém, o contorno cavitário é completado seguindo a delimitação anteriormente traçada para as paredes circundantes. A delimitação de todas as cavidades foi determinada por meio da fixação de fita isolante negra, que continha perfurações padronizadas com $2 \mathrm{~mm}$ de diâmetro (Figura 1-B), feitas por meio da ponta ativa do perfurador de borracha de Ainsworth (Figura 1-A). A profundidade da cavidade foi determinada pela altura da ponta ativa da ponta diamantada, que é de $1,5 \mathrm{~mm}$. 

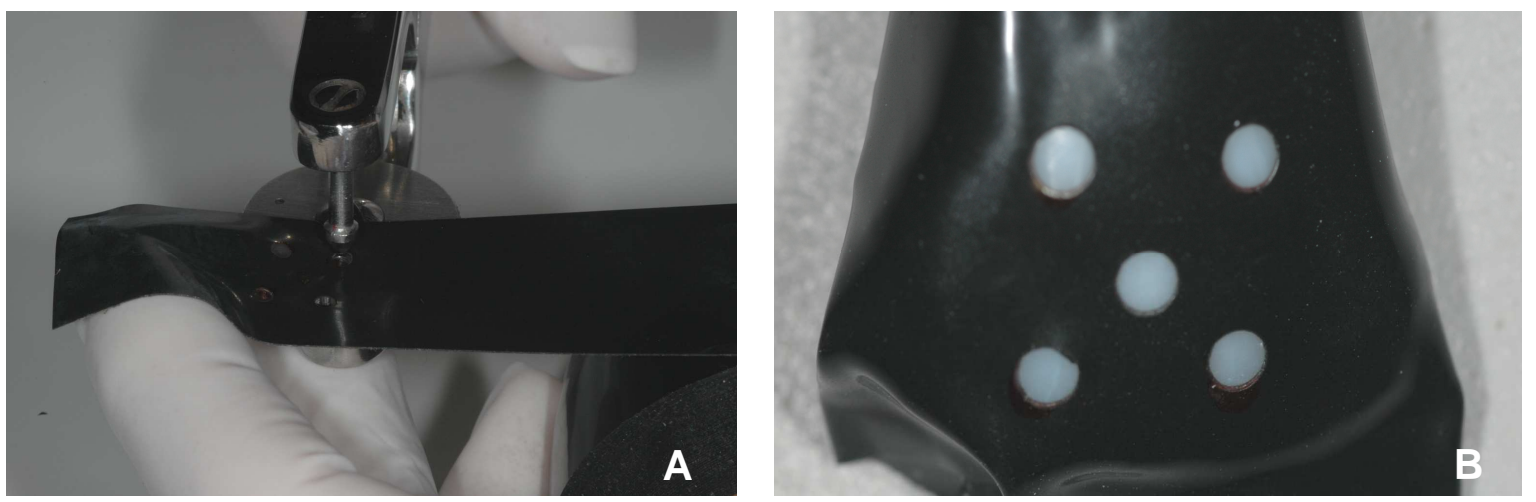

Figura 1 - Perfuração da fita isolante feita com perfurador de borracha para dique, a fim de padronizar o diâmetro das cavidades (A) e fixação da fita isolante sobre a face vestibular do dente $(B)$.
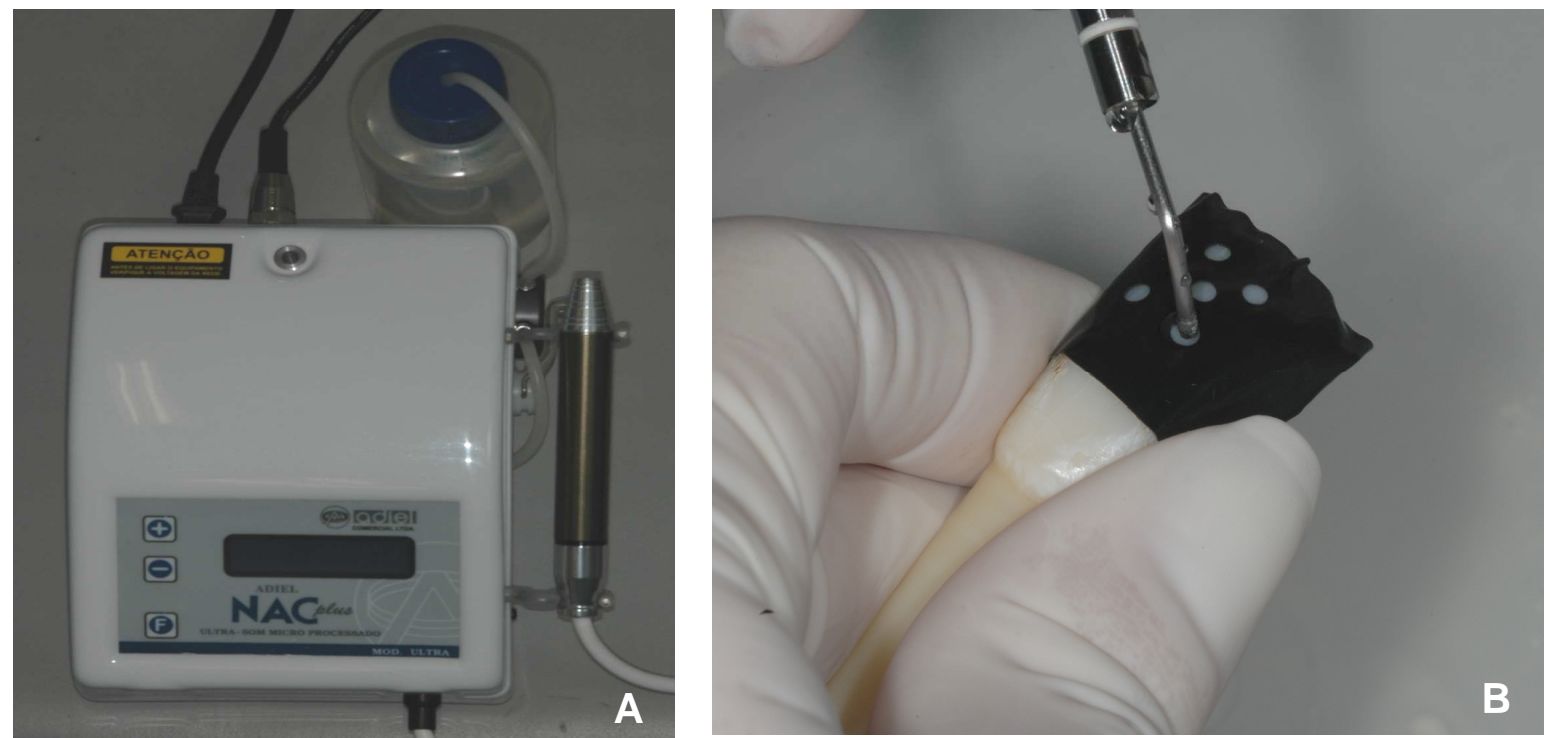

Figura 2 - Aparelho de ultrassom com ponta reta na qual é acoplada a ponta diamantada CVDentus angulada (A), utilizada para preparar cavidades(B).

Os preparos cavitários só foram considerados concluídos após avaliação da regularidade das paredes circundantes e ângulo cavo-superficial, realizado por meio de exame visual minucioso, com iluminação do refletor odontológico, segundo a rotina das inspecções clínicas. 
A limpeza das cavidades foi feita com "spray" ar/água da seringa odontológica, pelo tempo de 30s. Em seguida, os dentes foram armazenados em solução fisiológica com $0,1 \%$ Timol, até o momento de serem processados para metalização e análise em microscópio eletrônico de varredura (Figura 3).

Os preparos das cavidades dos grupos 2,3 e 4 (Figuras 4, 5 e 6 respectivamente) foram realizados seguindo os mesmos passos operatórios estabelecidos para o preparo cavitário do grupo 1 da cavidade 1 , alterando apenas a potência vibratória do aparelho de ultrassom, ou seja 50\%, 75\% e 100\%, respectivamente. Deve-se salientar que, para cada grupo, foram feitos 10 preparos cavitários.

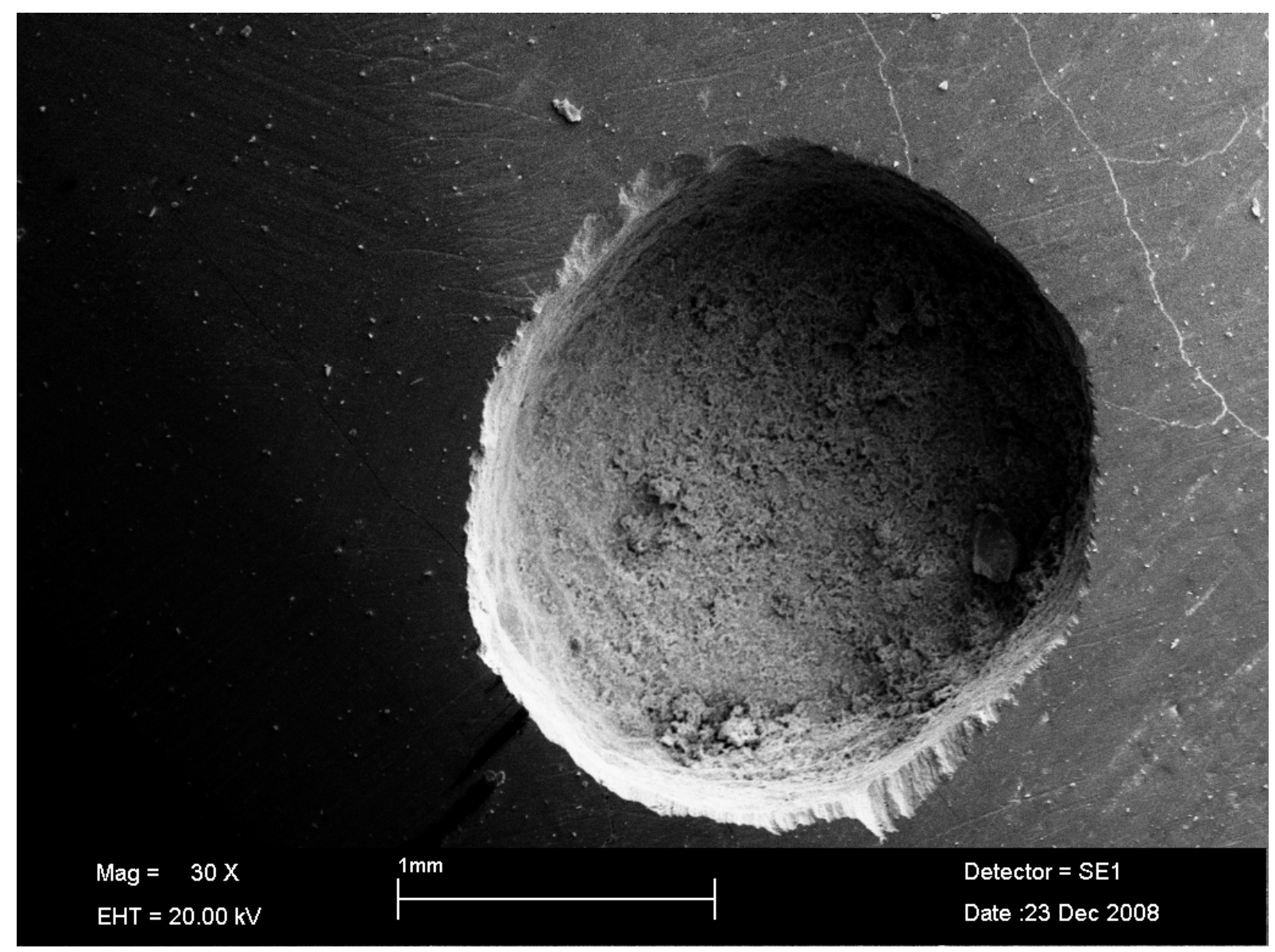

Figura 3 - Fotomicrografia de uma cavidade do grupo G1- SG1-25\%. 


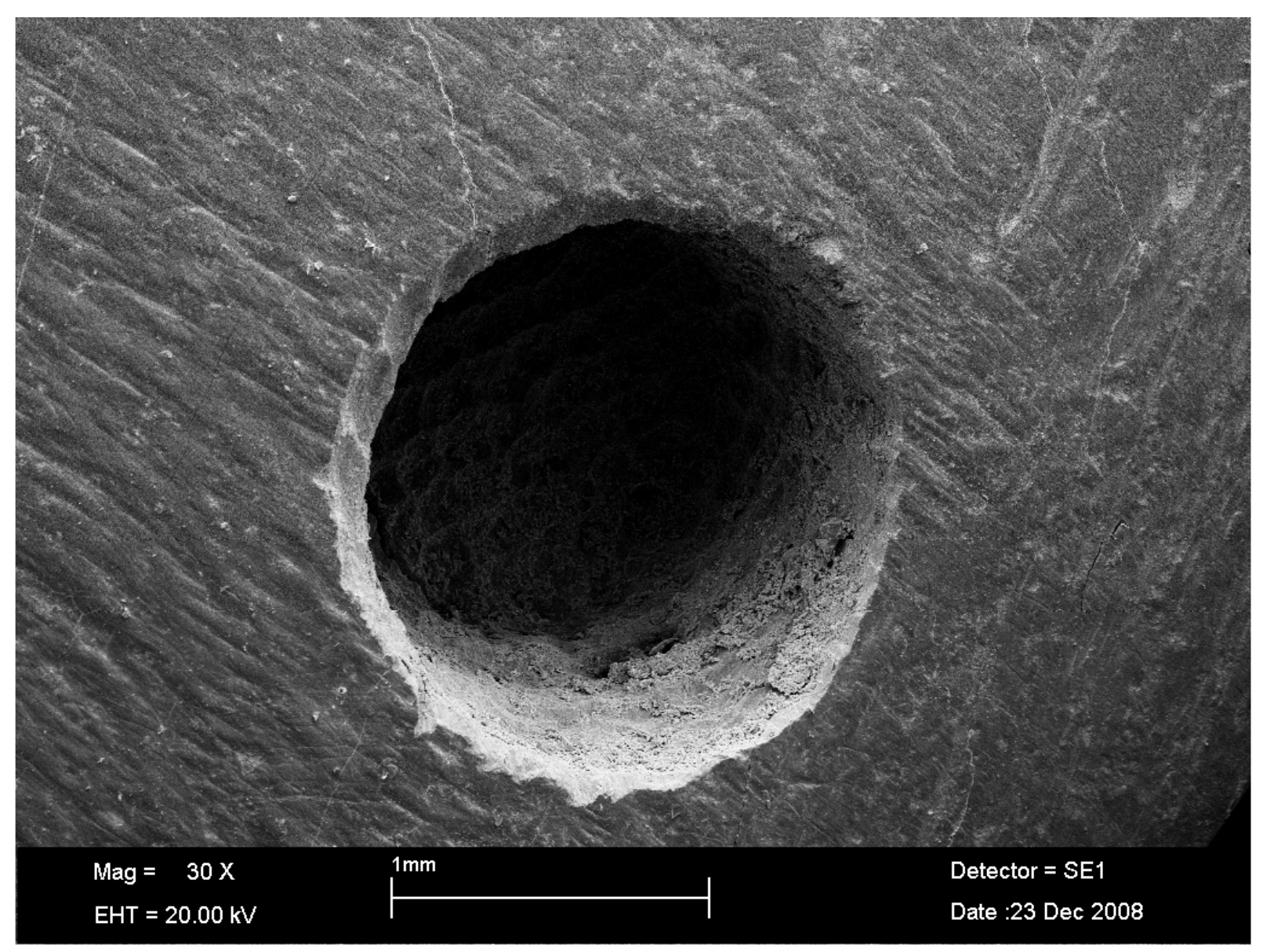

Figura 4 - Fotomicrografia de uma cavidade do grupo G1- SG2 - 50\%. 


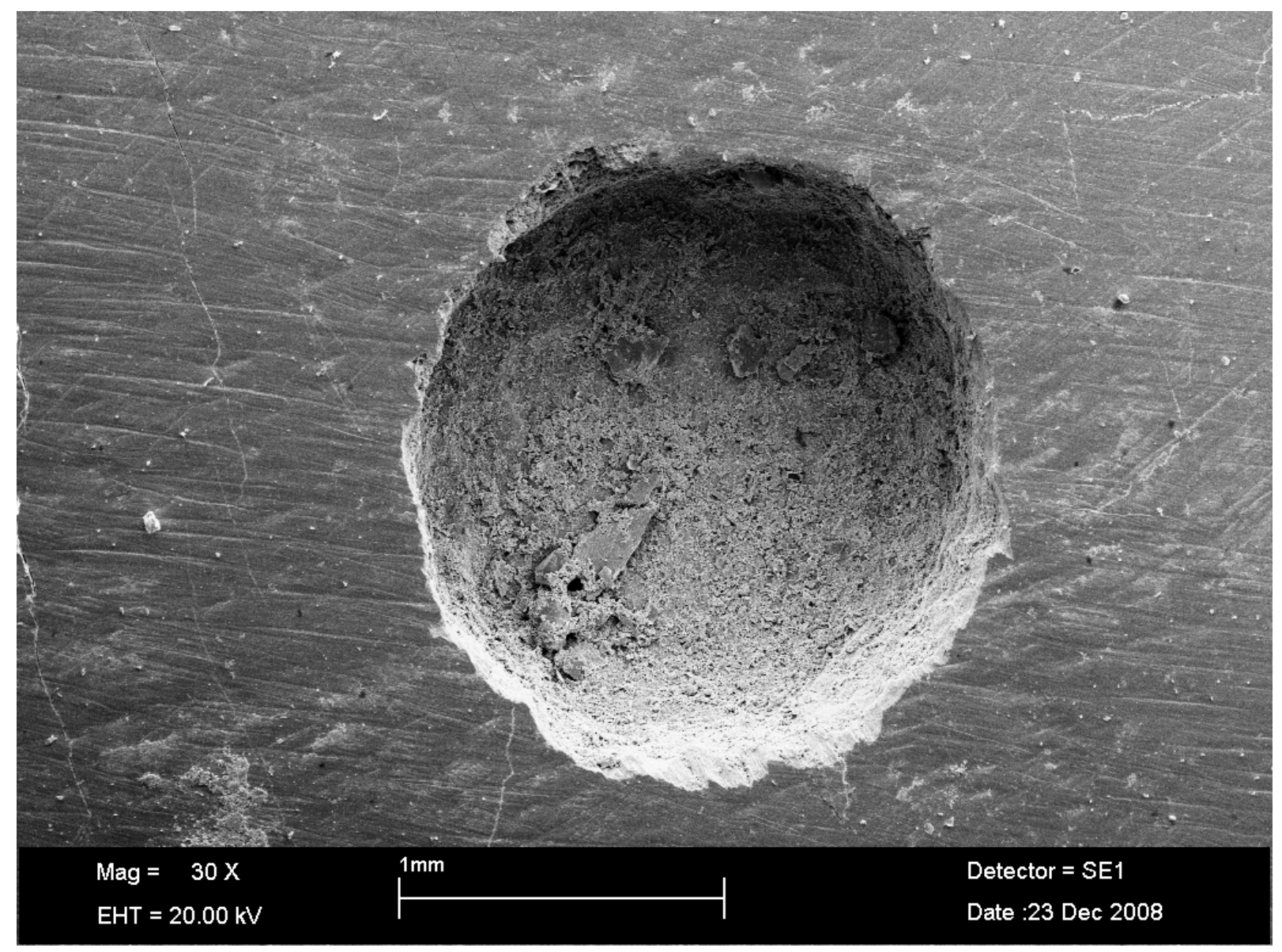

Figura 5 - Fotomicrografia de uma cavidade do grupo G1- SG3 - 75\%. 


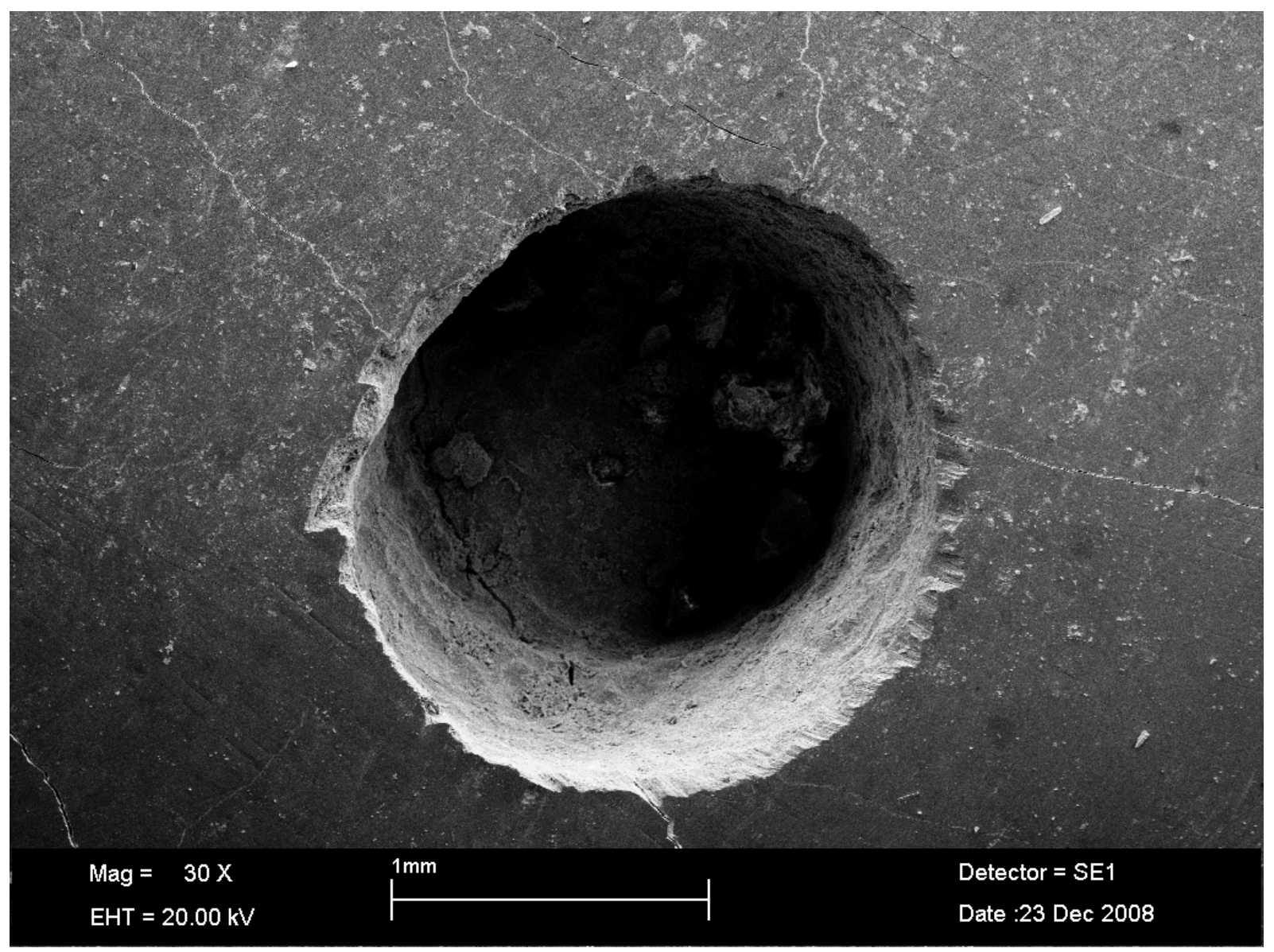

Figura 6 - Fotomicrografia de uma cavidade do grupo G1 - SG4 - 100\%.

\subsubsection{Grupo II- Ultrassom + CVDentus-Corte + CVDentus-Acabamento}

Foram preparadas quarenta cavidades, com as mesmas características das cavidades do Grupo I, subgrupos 1, 2, 3 e 4, também usando-se potência de 25\%, $50 \%, 75 \%$ e 100\%. Após a finalização das cavidades, envolvendo os quatro subgrupos, as mesmas foram submetidas ao procedimento de acabamento. A técnica de acabamento adotada envolveu os mesmo procedimentos para preparar as cavidades, variando apenas o tipo de ponta de diamante artificial CVD. Para tanto, utilizou-se a ponta CVDentus $n^{\circ} 62142$, de textura abrasiva menor do que a utilizada para preparação cavitária. Sua ponta ativa também apresentava 1,5mm de altura. Foram respeitadas as mesmas potências vibratórias preconizadas para 0 grupo I (Figuras 7, 8, 9 e 10). 


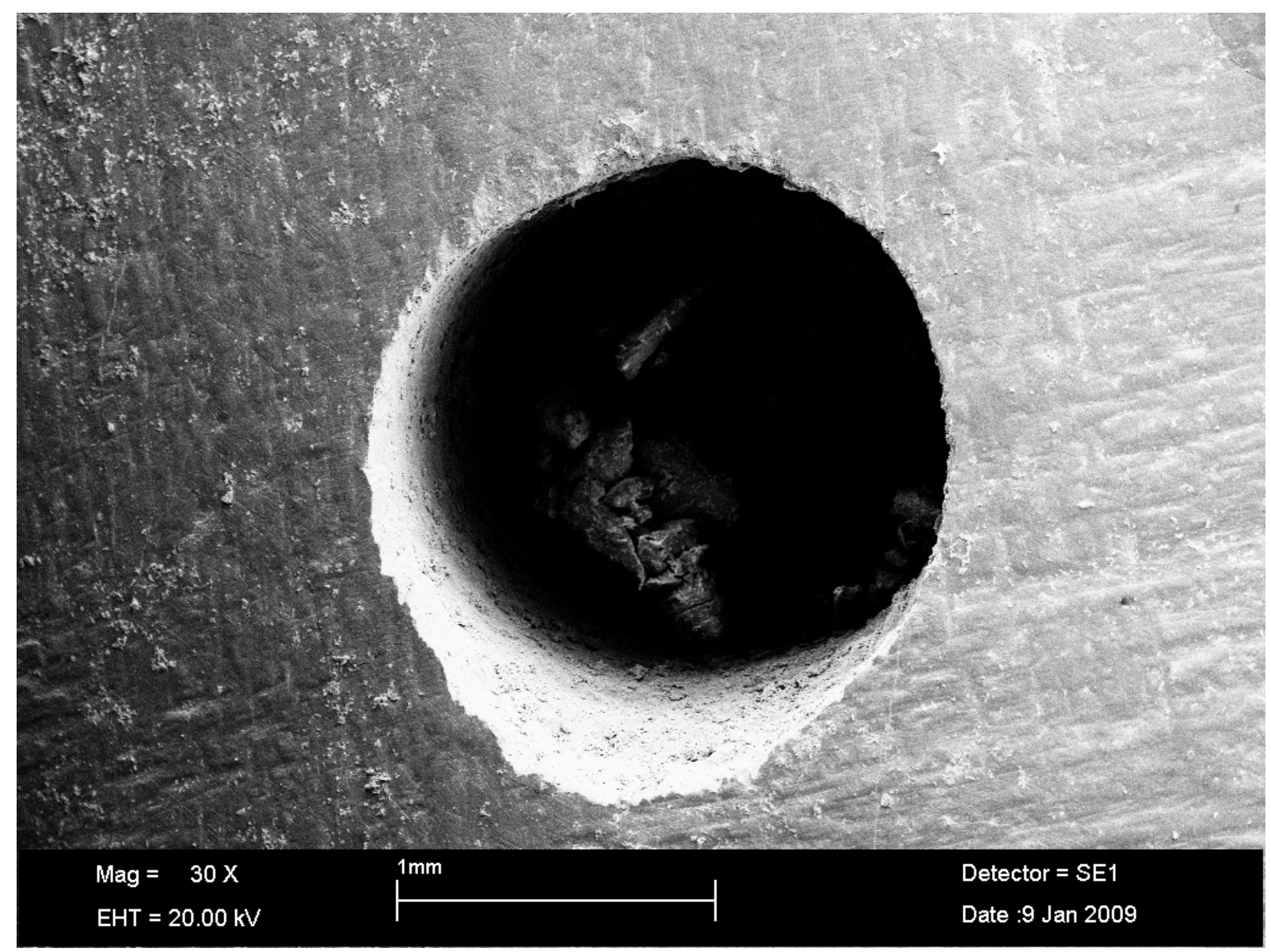

Figura 7 - Fotomicrografia de uma cavidade do grupo G2 - SG1 - 25\%. 


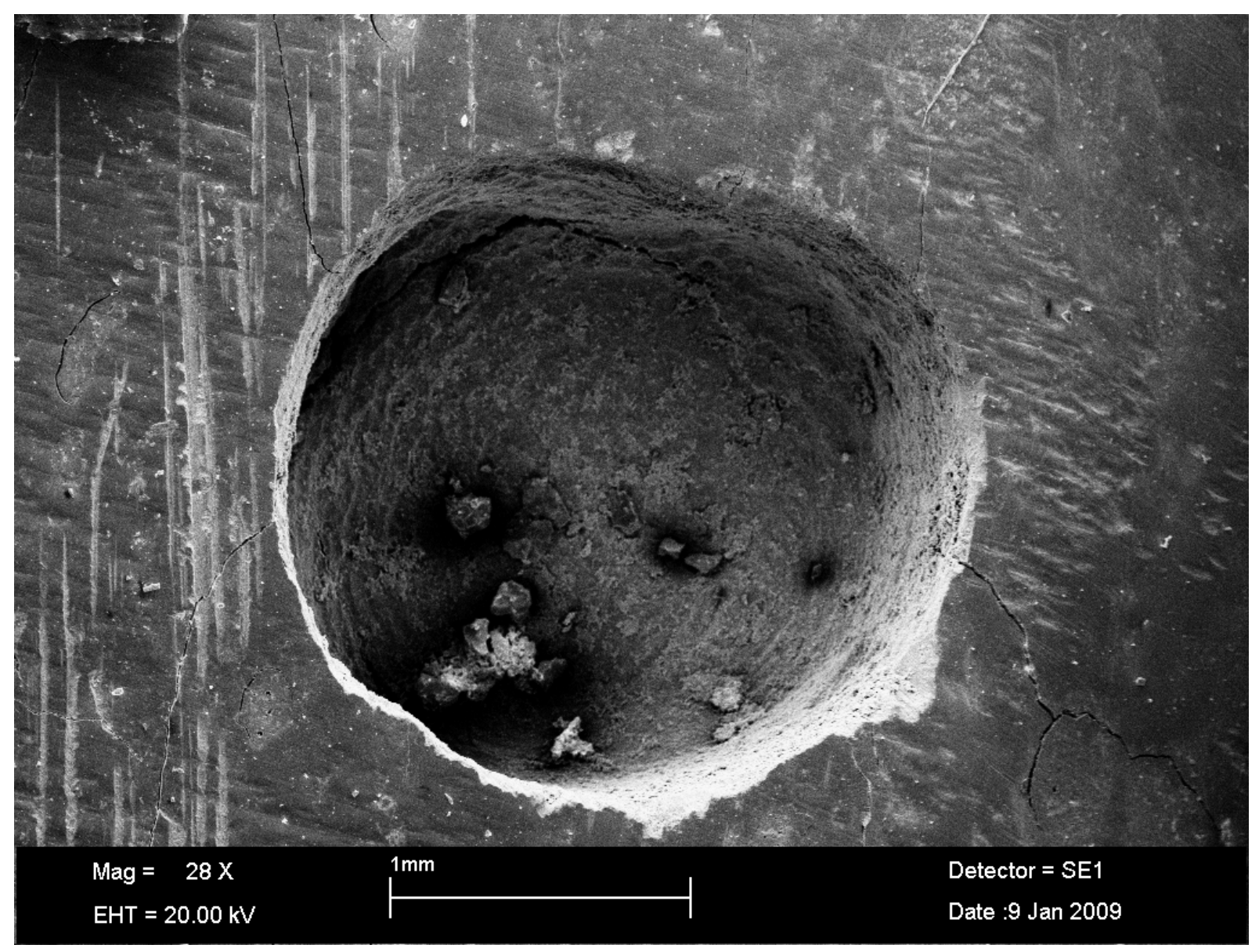

Figura 8 - Fotomicrografia de uma cavidade do grupo G2 - SG2 - 50\%. 


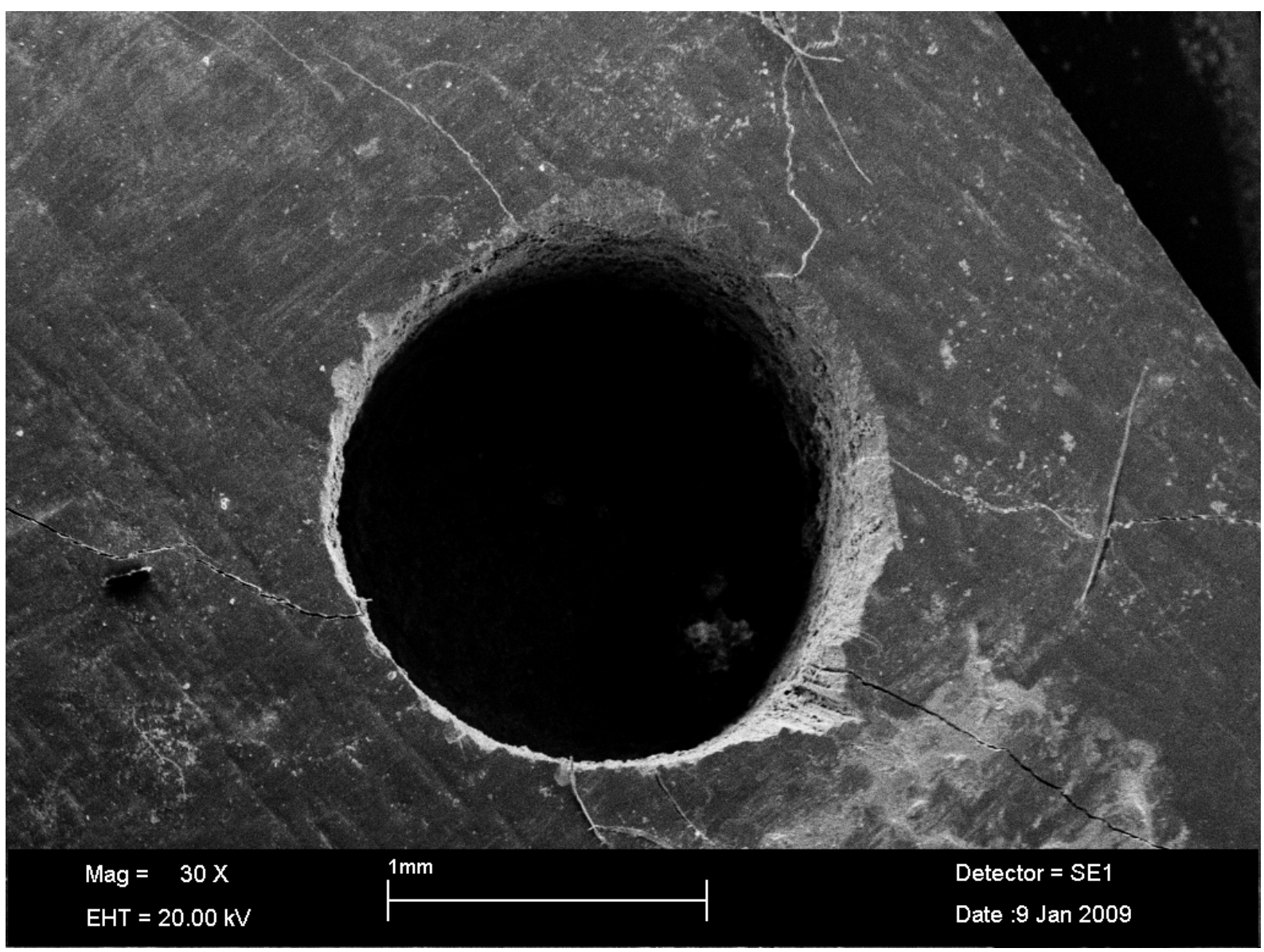

Figura 9 - Fotomicrografia de uma cavidade do grupo G2 - SG3 - 75\%. 


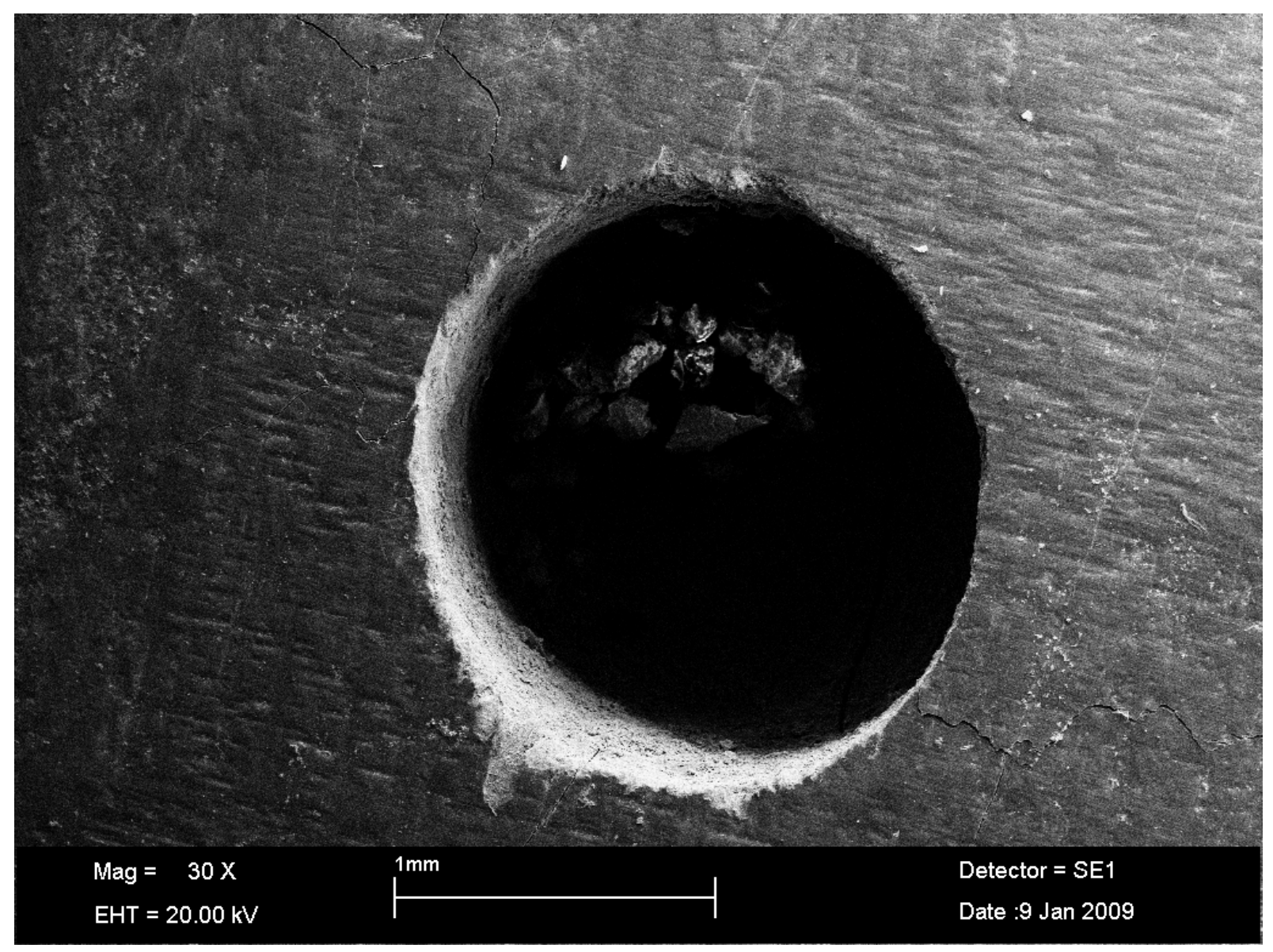

Figura 10 - Fotomicrografia de uma cavidade do grupo G2 - SG4- 100\%.

\subsubsection{Grupo III - Alta Velocidade + Ponta Diamantada Convencional}

Foram preparadas dez cavidades com as mesmas características das cavidades do grupo I, variando-se o aparelho e a ponta diamantada. Foi utilizada uma turbina de alta velocidade (Kavo Extratorq 603 B - Kavo do Brasil, Florianópolis-SC) com velocidade de 360.000 rpm e sistema de refrigeração "spray" ar/água, acopladando-se uma ponta diamantada cilíndrica de extremo plano $\mathrm{n}^{\circ} 1064$ (KG Sorensen - São Paulo - Brasil). A técnica de instrumentação obedeceu os mesmos procedimentos adotados para a preparação das cavidades do grupo I (Figura 11). 


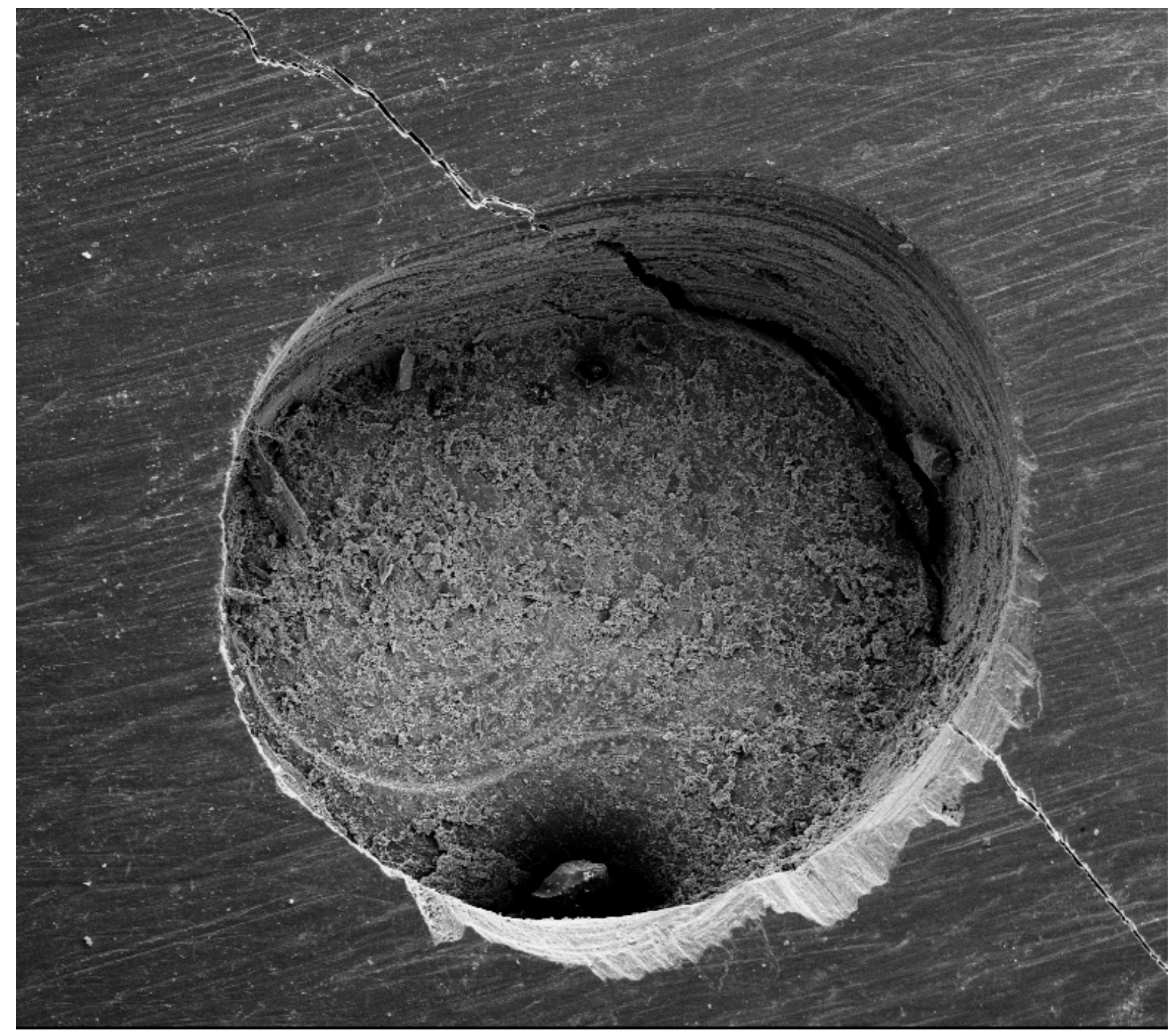

Figura 11 - Fotomicrografia de uma cavidade do grupo G3.

\subsubsection{Grupo IV - Alta velocidade + Ponta Diamantada Convencional + Baixa Velocidade + Ponta Diamantada Acabamento}

Foram preparadas 10 cavidades com as mesmas características e procedimentos do grupo III, acrescentando-se que o acabamento da cavidade foi realizado com contra-ângulo Kavo INTRAmatic 2068 FGBN 1:1 (Kavo do Brasil, Florianópolis-SC), girando a baixa velocidade (5.000 rpm), no qual era acoplada uma ponta diamantada cilíndrica de extremo plano, granulação fina, $n^{0} 1093$ F (KG Sorensen-São Paulo-Brasil). Saliente-se que o procedimento de acabamento da cavidade foi realizado com refrigeração a ar, por meio da seringa triplice para melhor visualização da cavidade (Figura 12). 


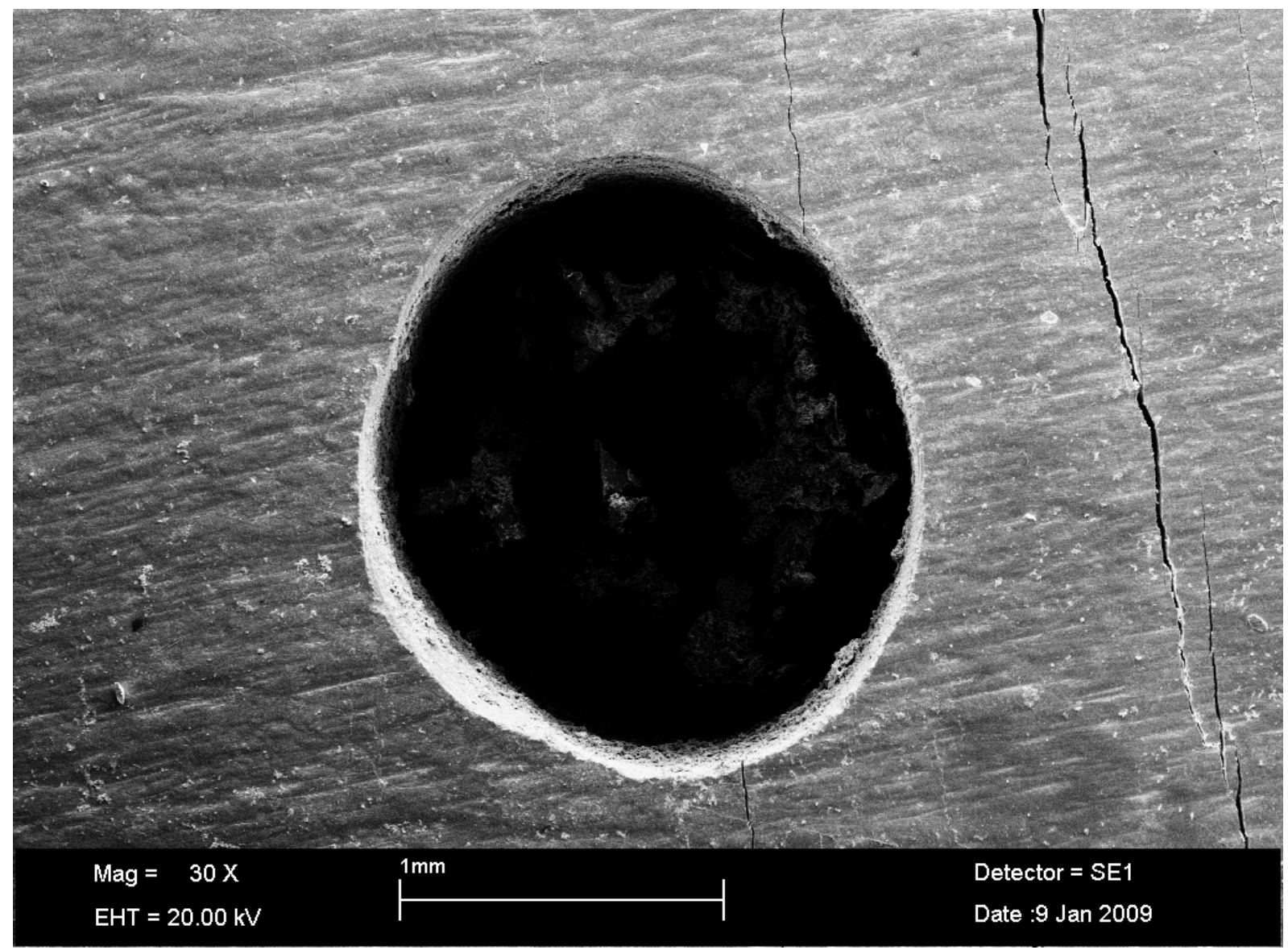

Figura 12 - Fotomicrografia de uma cavidade do grupo G4.

\subsubsection{Grupo V - Velocidade Intermediária + Ponta Diamantada Convencional}

Foram preparadas 10 cavidades com as mesmas características do grupo I, porém realizados com velocidade intermediária 3:1(NSK Low speed-ES-95, Japão), a uma velocidade de 30.000rpm. É considerado intermediário em relação a turbina de alta-rotação e o contra-ângulo de baixa rotação, por triplicar a velocidade do baixa rotação no qual era acoplada uma ponta diamantada cilíndrica de extremo plano $n^{\circ} 1090$ (KG Sorensen-São Paulo-Brasil). Normalmente, esse tipo de instrumento é utilizado para a finalização de preparos protéticos e preparos cavitários removendo os primas de esmalte friáveis e irregularidades constantes nos preparos. Saliente-se que o procedimento de preparo da cavidade foi realizado com refrigeração a ar por meio de seringa triplece (Figura 13). 


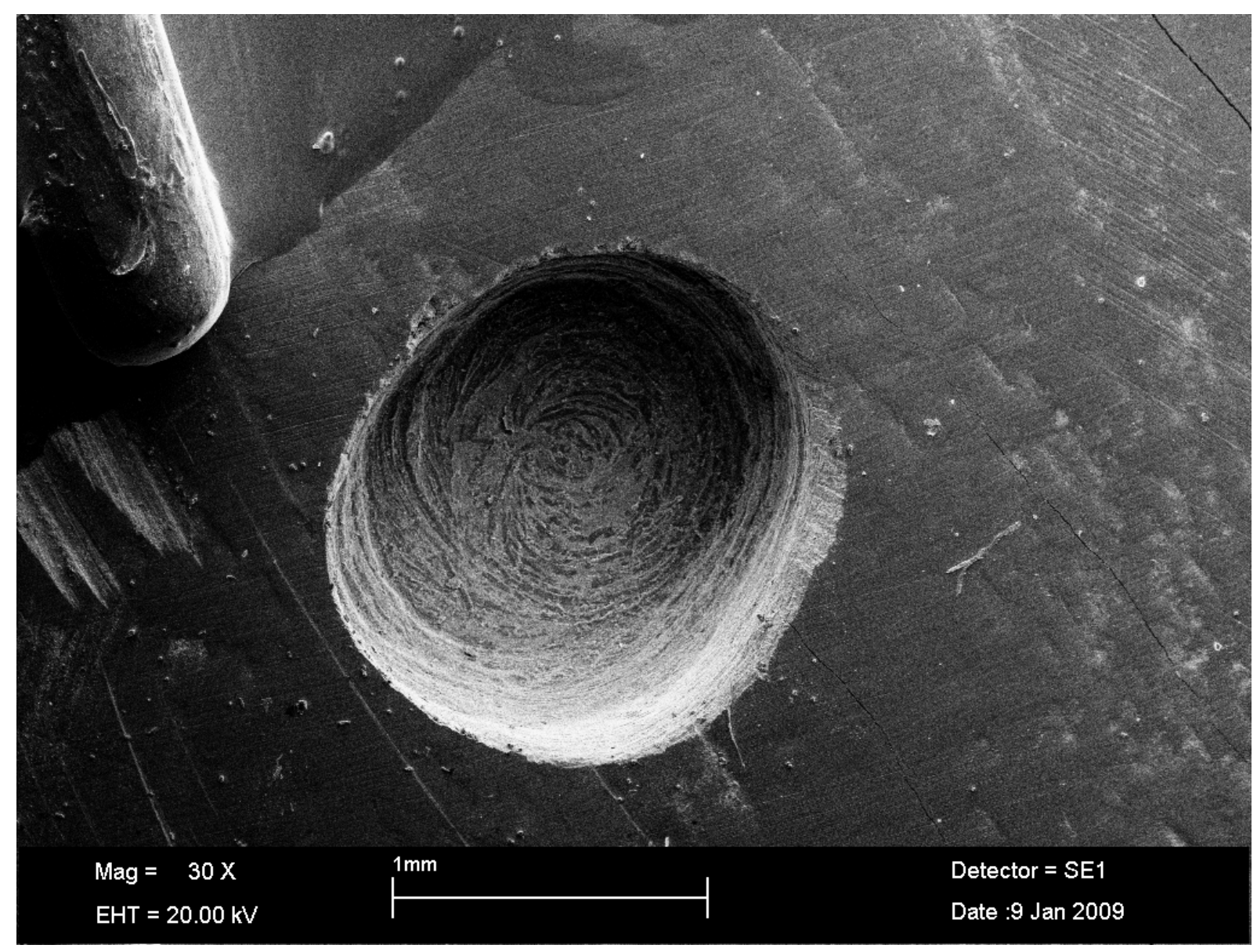

Figura 13 - Fotomicrografia de uma cavidade do grupo G5.

\subsubsection{Grupo VI - Baixa-velocidade + Ponta Diamantada Convencional}

Foram preparadas 10 cavidades com as mesmas características do grupo I, porém efetuados com contra-ângulo Kavo INTRAmatic 2068 FGBN 1:1 (Kavo do Brasil, Florianópolis-SC) a uma velocidade de aproximadamente de 5.000rpm, no qual era acoplada uma ponta diamantada cilíndrica de extremo plano n01090 (KG Sorensen-São Paulo-Brasil). Saliente-se que o procedimento de preparo da cavidade foi realizado com refrigeração a ar com seringa (Figura 14). 


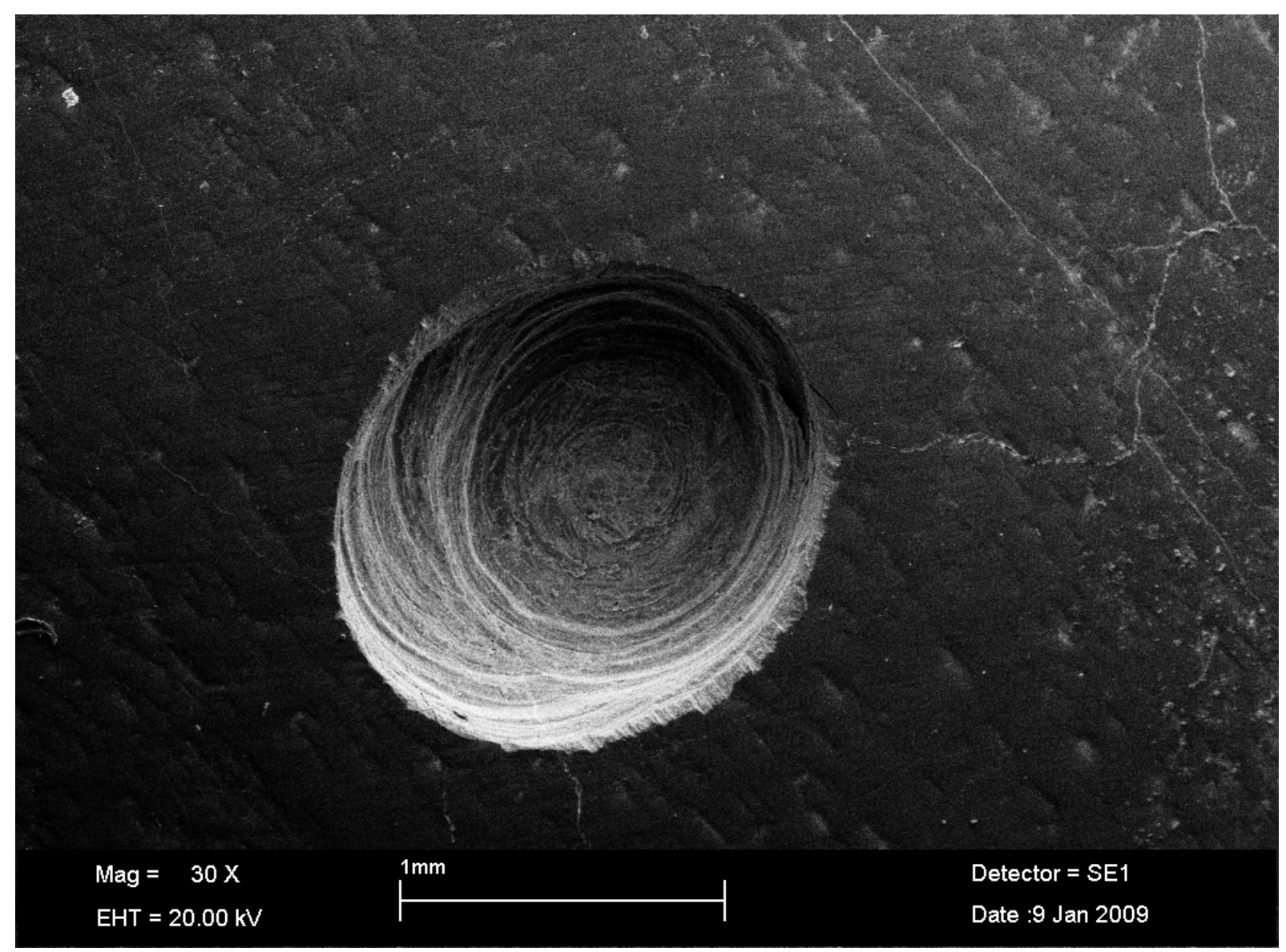

Figura 14 - Fotomicrografia de uma cavidade do grupo G6.

\subsubsection{Grupo VII - Ultrassom + CVDentus-Corte 50\% + Acabamento Ponta Diamantada/Velocidade Intermediária}

Foram preparadas dez cavidades, com as mesmas características das cavidades do Grupo I, utilizando-se a potência de 50\%. O acabamento das cavidades foi realizado com contra-ângulo multiplicador 3:1((NSK Low speed-ES-95, Japão), a uma velocidade de $30.000 \mathrm{rpm}$, no qual era acoplada uma ponta diamantada cilíndrica de extremo plano para acabamento n¹093F (KG SorensenSão Paulo-Brasil) (Figura 15). 


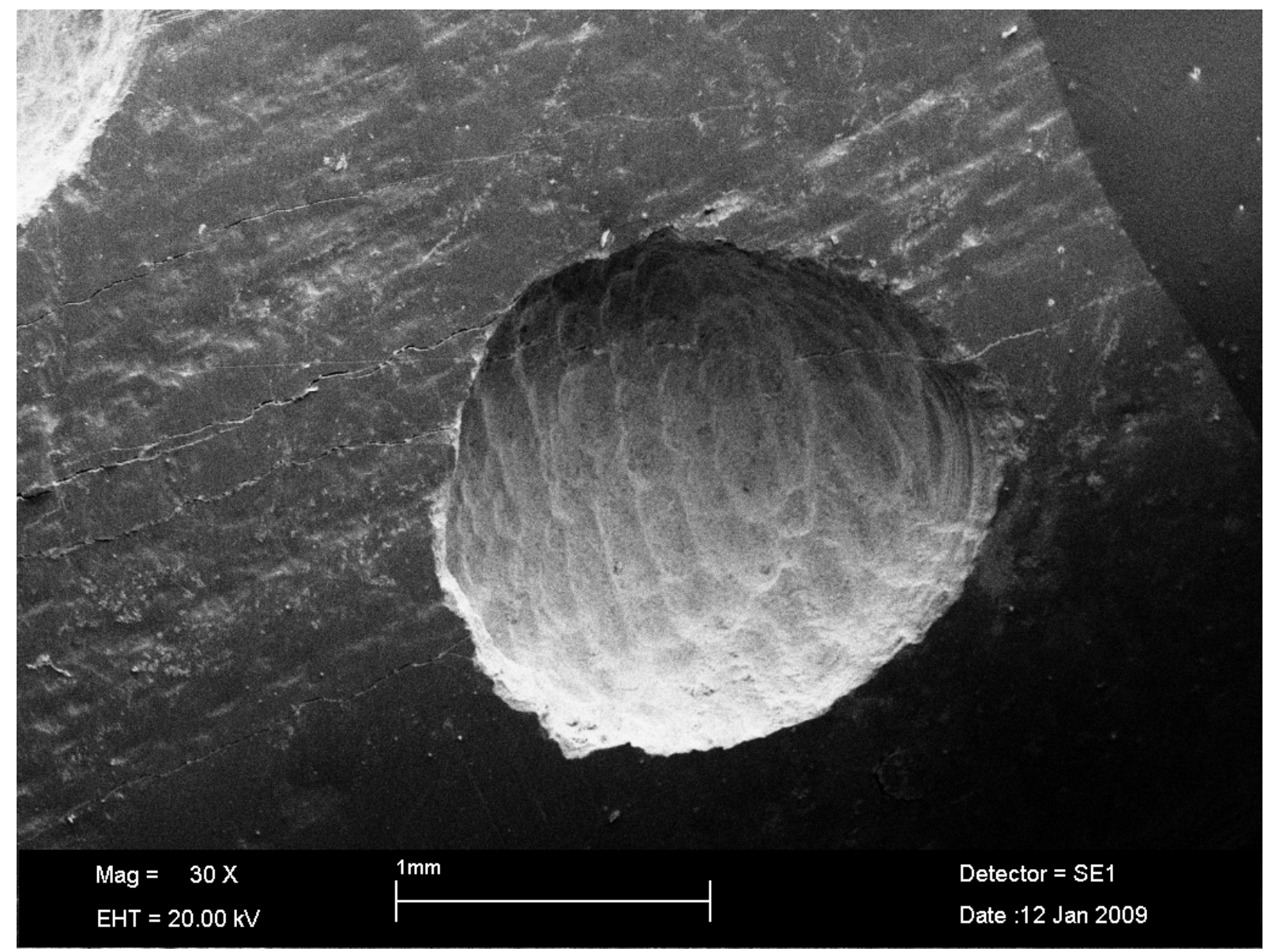

Figura 15 - Fotomicrografia de uma cavidade do grupo G7. 


\subsection{PREPARO DAS AMOSTRAS PARA OBTER IMAGENS DOS PREPAROS CAVITÁRIOS POR MEIO DE MICROSCÓPIO ELETRÔNICO DE VARREDURA, PARA AVALIAÇÃO DA QUALIDADE DA MARGEM DAS CAVIDADES}

Após a preparação das cavidades, as raízes dos dentes foram seccionadas com disco diamantado e refrigeração a água. A face palatina da coroa, foi planificada com lixa d'água para tornar sua superfície paralela à face vestibular e proporcionar estabilidade na base do "stub". Em seguida, os corpos-de-prova foram fixados nos "stubs" através de uma mistura de esmalte de unha e liga de amálgama, sendo mantidos em estufa a $37^{\circ} \mathrm{C}$, com a finalidade de remover toda a umidade do esmalte e dentina, para tornar possível a metalização em ouro (Figura 16A e B). Esse procedimento foi realizado na Escola Superior de Agronomia Luís de Queiroz, da Universidade de São Paulo (ESALQ), na máquina de metalização BALZERS UNIOM MED 010 (Bal-Tec AG, Balzers-Liechtenstein), para então os corpos-deprova serem submetidos à varredura eletrônica e visualizados. As imagens para análise dos corpos-de-prova foram obtidas através do microscópio eletrônico de varredura da ESALQ (LEO 435 VP-605 Cambridge, Inglaterra), com aumento padronizado de 30X. Para cada condição experimental foi obtida uma imagem fotomicrográfica, em posição perpendicular à face vestibular do dente.
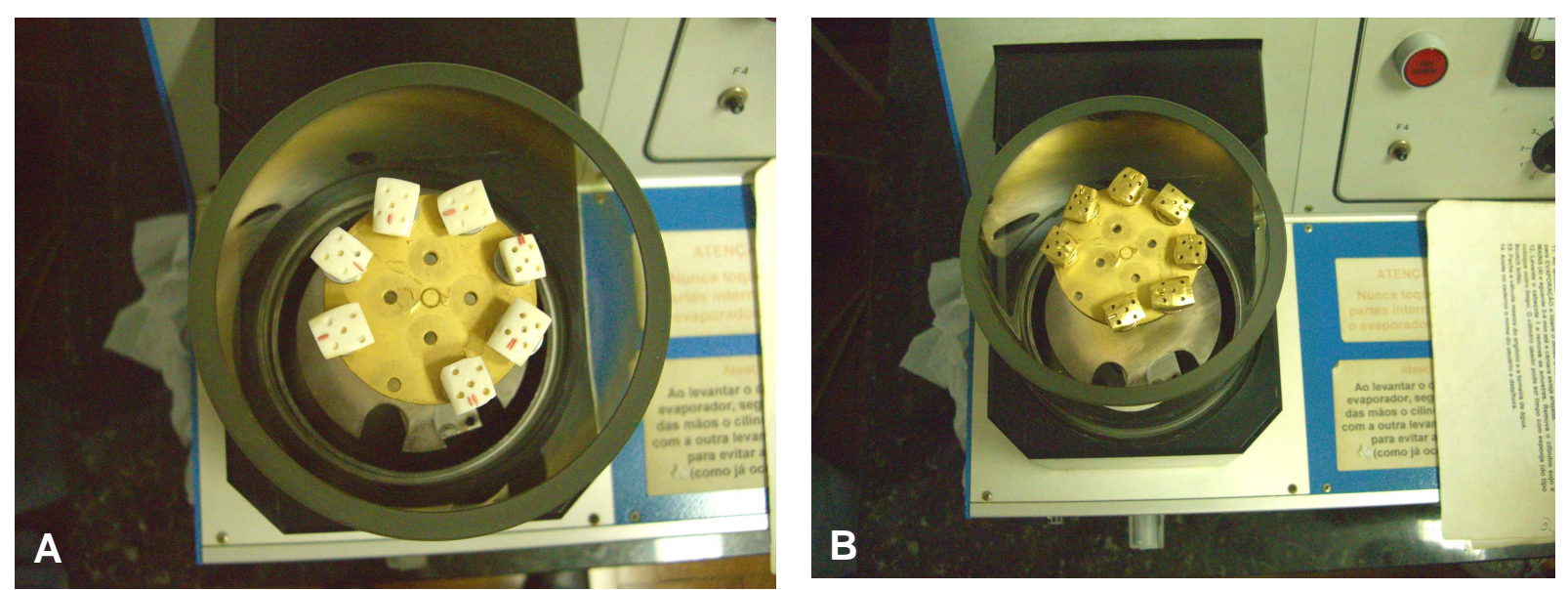

Figura 16 - (A) Amostras fixadas nos "stubs" já na máquina de metalização. (B) Amostras metalizadas em ouro. 
Após a obtenção das imagens, foi feita a análise das margens dos preparos cavitários por meio de um programa de computador denominado Image Tool 3 (Universidade UTSLHA, Texas, USA). Essa análise foi realizada por duas pessoas, que até então não haviam participado da pesquisa. Isso possibilitou uma análise duplo cego, para que não houvesse nenhum tipo de interferência ou influência subjetiva nos resultados da avaliação. Esses dois examinadores foram previamente treinados e calibrados para esse tipo de análise. Para a realização da avaliação, as imagens obtidas foram submetidas ao programa de computador Adobe Photoshop, com a finalidade de determinar o perímetro das cavidades, ao longo do seu ângulo cavo-superficial ou ângulo marginal (Figura 17).

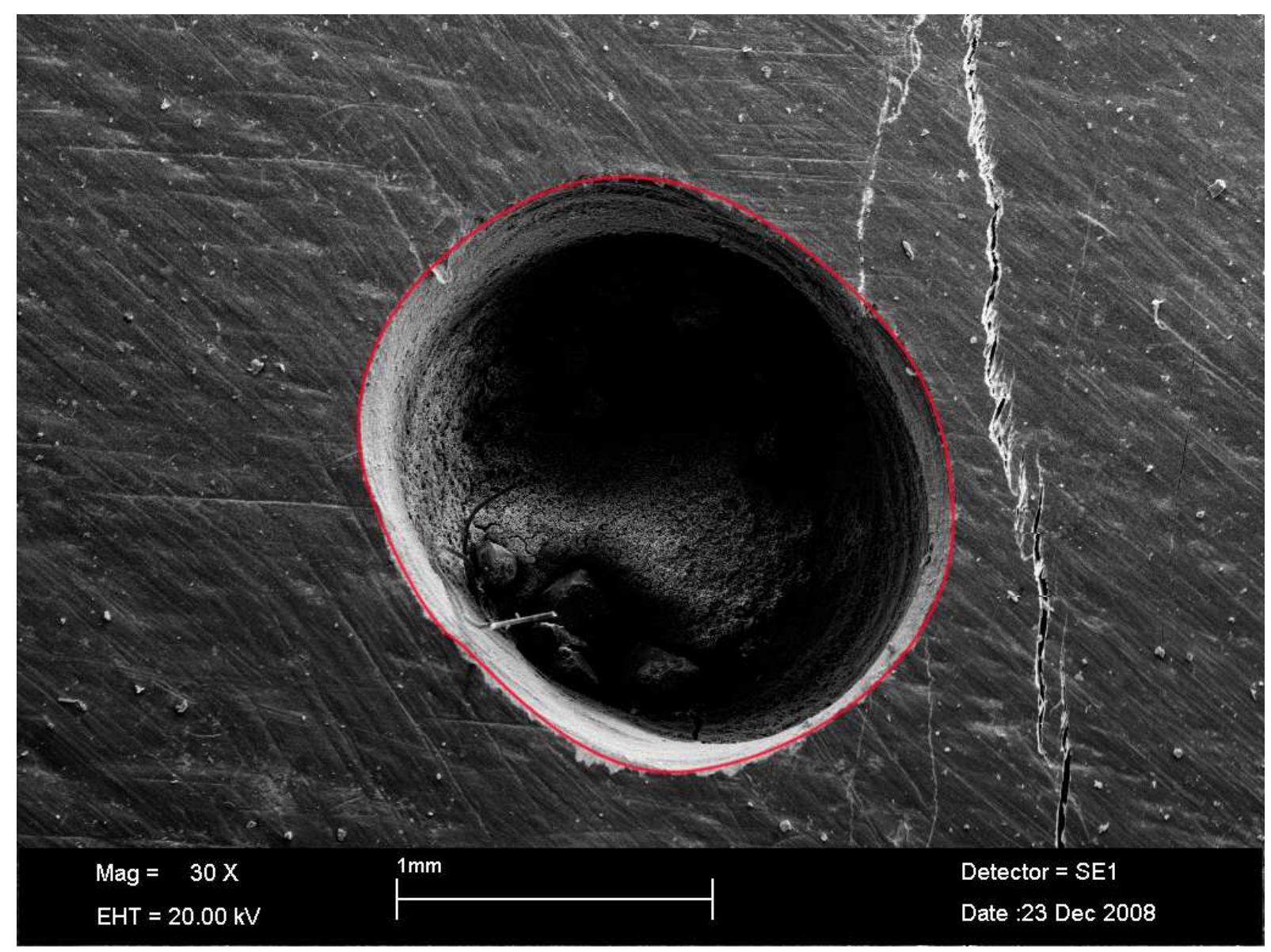

Figura 17 - Imagem da fotomicrografia, mostrando o traçado realizado no programa Adobe Photoshop delimitando o perímetro total da cavidade. 
O programa de computador desenvolvido pela Universidade do Texas, Image Tool 3, foi utilizado para medições do perímetro e áreas de defeito dos preparos cavitários (FRANCISCHONE, 2005, DE PAULA et al, 2008). As análises foram feitas com amplificações das imagens (2X), utilizando-se a ferramenta contida no programa, representada por uma lupa, que determinava-se o perímetro da cavidade em milímetro (Figura 18). Uma outra ferramenta do programa estabelecia a área $\left(\mathrm{mm}^{2}\right)$ quantificando os defeitos marginais dos preparos cavitários (Figura 19). Para cada imagem, foi feita a calibração para depois serem feitas as medições. Os valores, obtidos em $\mathrm{mm}^{2}$ foram convertidos em percentual de defeitos do ângulo cavo-superficial de cada cavidade. O percentual de defeitos representa a quantidade de irregularidades presentes no ângulo cavo-superficial de cada cavidade. Os valores obtidos pelos dois examinadores foram anotados em uma ficha individual para posterior análise estatística. Esses dados encontram-se disponíveis nos Anexos 1 e 2.

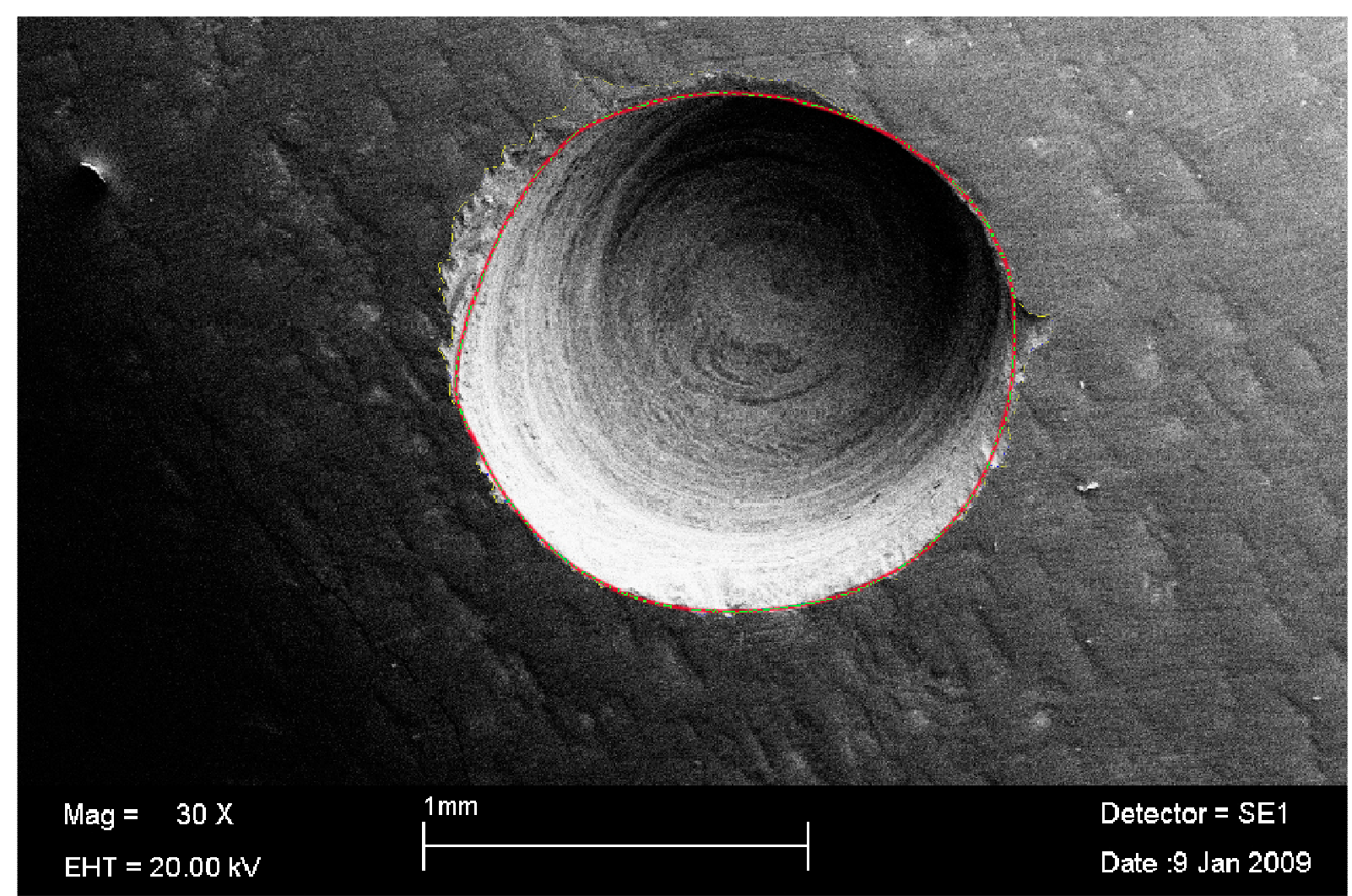

Figura 18 - Imagem da fotomicrografia mostrando o traçado feito do perímetro da margem cavitária. 


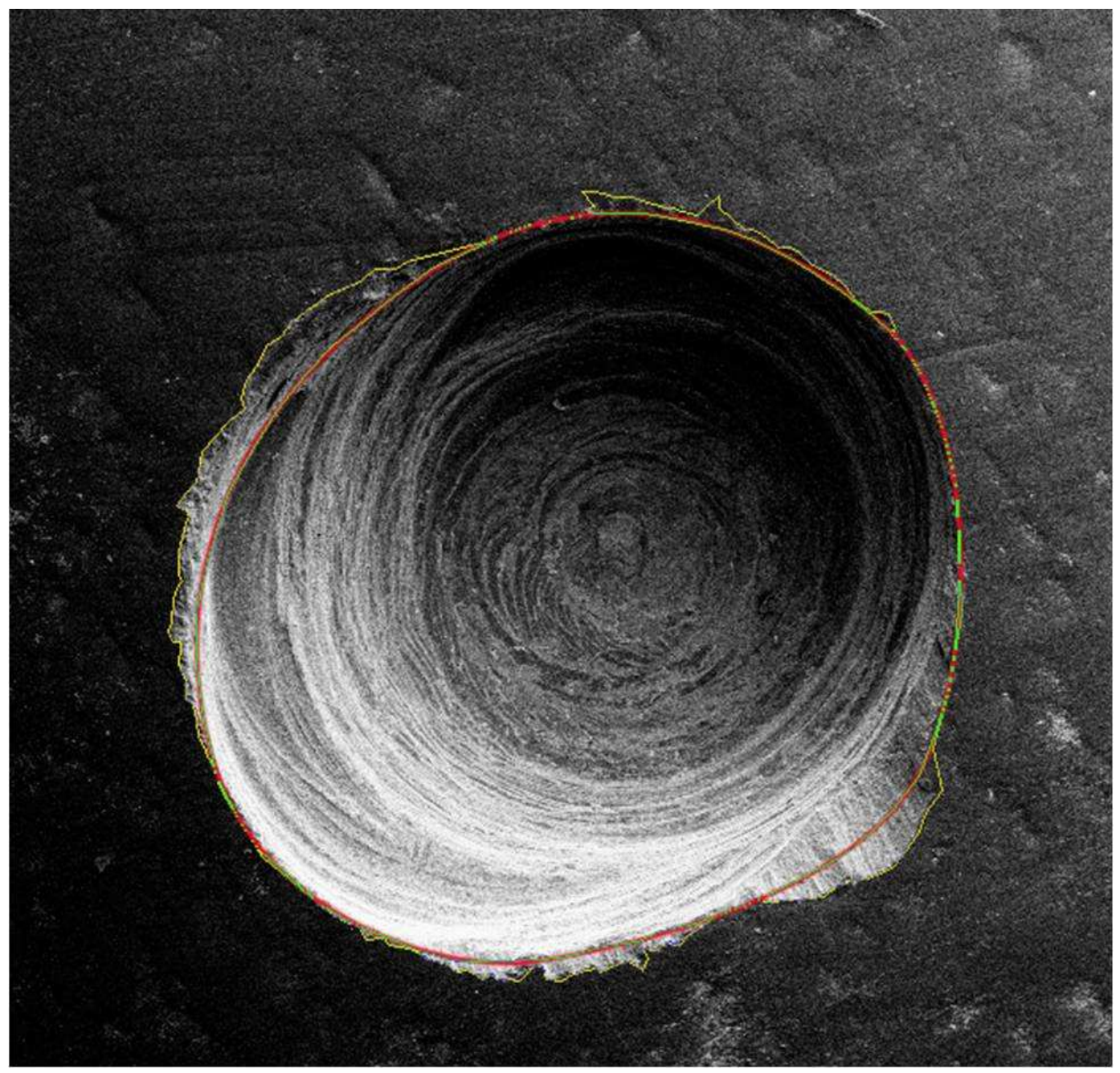

Figura 19 - Imagem da fotomicrografia mostrando o contraste feito para a análise da área de defeito marginal. 


\subsection{PLANEJAMENTO ESTATÍSTICO}

Foi utilizado o coeficiente de concordância de Kendall para a avaliação da qualidade de calibração entre os dois examinadores, tanto para medição do perímetro como da extensão da irregularidade.

Para a comparação entre os grupos, foi aplicada a Análise de Variância (teste de Bartlett).

Para a comparação individual, foi utilizado o teste de Tukey, com nível de significância igual a 0,05. 

O teste estatístico do coeficiente de concordância de Kendall foi aplicado sobre os resultados estabelecidos pelos dois examinadores, conforme mostram as tabelas 5.1 e 5.2

Tabela 5.1 - Coeficiente de Concordância de Kendall aplicado às leituras dos perímetros das cavidades, obtidas pelos dois examinadores

\begin{tabular}{cccccc}
\hline $\begin{array}{l}\text { Número de } \\
\text { espécimes }\end{array}$ & Qui quadrado & $\begin{array}{c}\text { Graus de } \\
\text { liberdade }\end{array}$ & Probabilidade & $\begin{array}{c}\text { Coeficiente } \\
\text { de Kendall }\end{array}$ & Concordância \\
\hline 122 & 236.07 & 121 & 0.000000 & 0.975 & Alta \\
\hline
\end{tabular}

Tabela 5.2 - Coeficiente de Concordância de Kendall aplicado às medições dos defeitos das margens dos preparos cavitários

\begin{tabular}{cccccc}
\hline $\begin{array}{c}\text { Número de } \\
\text { espécimes }\end{array}$ & $\begin{array}{c}\text { Qui } \\
\text { quadrado }\end{array}$ & $\begin{array}{c}\text { Graus de } \\
\text { liberdade }\end{array}$ & Probabilidade & $\begin{array}{c}\text { Coeficidente } \\
\text { de Kendall }\end{array}$ & Concordância \\
\hline 122 & 228.04 & 121 & 0.000000 & 0.942 & Alta \\
\hline
\end{tabular}

A análise das tabelas 5.1 e 5.2 mostra resultado altamente concordante tanto para as leituras dos perímetros das cavidades (0.975) como para as medições das irregularidades das margens das cavidades (0.942).

A tabela 5.3 e o gráfico 5.1 apresentam as médias percentuais, e respectivos desvios- padrão dos defeitos de margem das cavidades e número de espécimes para cada condição experimental estudada. Podem-ser observadas variações no número de espécimes, que ocorreram em função da exclusão de alguns deles devido ao fato de apresentarem artefatos técnicos ou trincas durante a preparação para a microscopia. Os dados obtidos e submetidos a análise estatística prévia, não demonstrou a necessidade do aumento do número de espécimes. 
Tabela 5.3 - Médias e desvios - padrão da porcentagem de defeitos das condições experimentais estudadas

\begin{tabular}{lccc}
\hline COND.EXPERIMENTAIS & MÉDIA \% & DESVIO PADRÃO & N. ESPÉCIMES \\
\hline 1-G1 - SG1 25\% & 4.19 & 1.39 & 10 \\
2-G1 - SG2 50\% & 4.27 & 1.96 & 9 \\
3-G1 - SG3 75\% & 3.44 & 0.82 & 10 \\
4-G1 - SG4 100\% & 4.07 & 0.79 & 9 \\
5-G2 - SG1 25\% & 4.31 & 1.24 & 10 \\
6-G2 - SG2 50\% & 4.26 & 1.90 & 10 \\
7-G2 - SG3 75\% & 3.91 & 2.21 & 9 \\
8-G2 - SG4 100\% & 3.89 & 0.94 & 10 \\
9-G3 & 3.61 & 1.82 & 9 \\
10-G4 & 2.21 & 1.27 & 9 \\
11-G5 & 3.78 & 1.59 & 9 \\
12-G6 & 4.34 & 1.87 & 9 \\
13-G7 & 6.20 & 3.19 & 7 \\
\hline
\end{tabular}

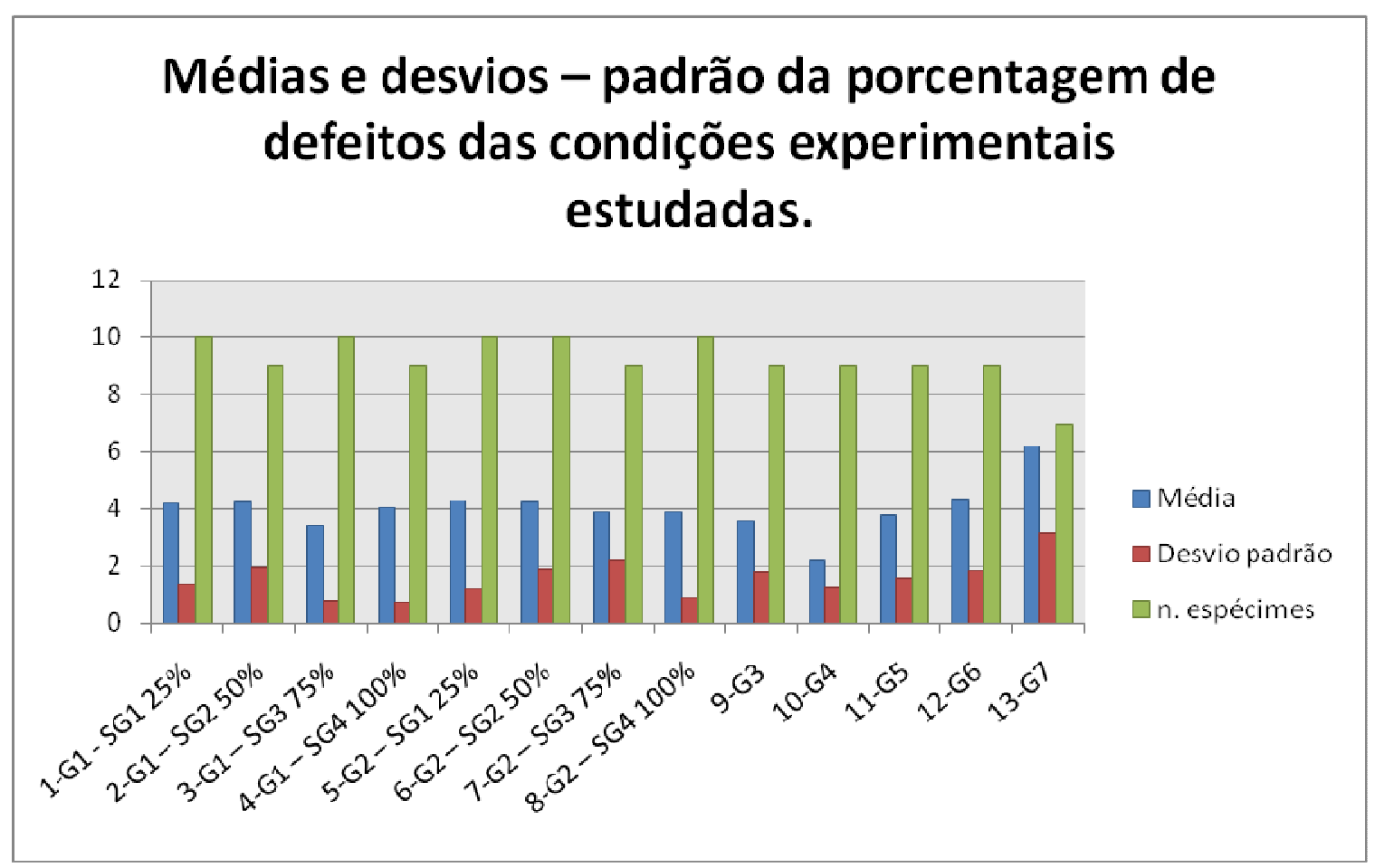

Gráfico 5.1 - Médias e desvios-padrão da porcentagem de defeitos das condições experimentais estudadas 
Tabela 5.4 - Análise de variância - Um critério de classificação aplicada para a comparação entre grupos

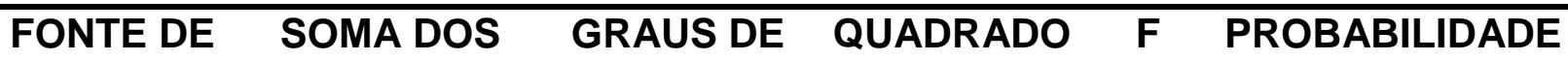 VARIAÇÃO QUADRADOS LIBERDADE MÉDIO}

\begin{tabular}{cccccc}
\hline $\begin{array}{c}\text { Entre } \\
\text { grupos }\end{array}$ & 71,58 & 12 & 5.96 & 2.10 & 0,021 \\
\hline Resíduo & 302.52 & 107 & 2.82 & \\
\hline Total & 374.10 & 119 & & \\
\hline Barlett $=28,24$ & & Prob. $=0,005$ (Significante)
\end{tabular}

Tabela 5.5 - Teste de Tukey - Nível de significância =0,05, para comparações individuais

\begin{tabular}{llcl}
\hline \multicolumn{1}{c}{ COMPARAÇÃo } & DIFERENÇA & VALOR CRÍTICO & INTERPRETAÇÃo \\
\hline G1100 X G125 & $-0,1122222$ & 2,61867805 & Não signific. \\
\hline G1100 X G150 & $-0,2000000$ & 2,68670699 & Não signific. \\
\hline G1100 X G175 & 0,63777778 & 2,61867805 & Não signific. \\
\hline G1100 X G3 & 0,46666667 & 2,68670699 & Não signific. \\
\hline G1100 X G2100 & 0,18777778 & 2,61867805 & Não signific. \\
\hline G1100 X G225 & $-0,2322222$ & 2,61867805 & Não signific. \\
\hline G1100 X G250 & $-0,1822222$ & 2,61867805 & Não signific. \\
\hline G1100 X G275 & 0,16666667 & 2,68670699 & Não signific. \\
\hline G1100 X G4 & 1,86666667 & 2,68670699 & Não signific. \\
\hline G1100 X G5 & 0,28888889 & 2,68670699 & Não signific. \\
\hline G1100 X G6 & $-0,2666666$ & 2,68670699 & Não signific. \\
\hline G1100 X G7 & $-2,1222222$ & 2,87221059 & Não signific. \\
\hline G125 X G150 & $-0,0877777$ & 2,61867805 & Não signific. \\
\hline G125 X G175 & 0,75000000 & 2,54883405 & Não signific. \\
\hline G125 X G3 & 0,57888889 & 2,61867805 & Não signific. \\
\hline G125 X G2100 & 0,30000000 & 2,54883405 & Não signific. \\
\hline G125 X G225 & $-0,1200000$ & 2,54883405 & Não signific. \\
\hline G125 X G250 & $-0,0700000$ & 2,54883405 & Não signific. \\
\hline G125 X G275 & 0,27888889 & 2,61867805 & Não signific. \\
\hline G125 X G4 & 1,97888889 & 2,61867805 & Não signific. \\
\hline
\end{tabular}




\begin{tabular}{llll}
\hline G125 X G5 & 0,40111111 & 2,61867805 & Não signific. \\
\hline G125 X G6 & $-0,1544444$ & 2,61867805 & Não signific. \\
\hline G125 X G7 & $-2,0100000$ & 2,80867833 & Não signific. \\
\hline G150 X G175 & 0,83777778 & 2,61867805 & Não signific. \\
\hline G150 X G3 & 0,66666667 & 2,68670699 & Não signific. \\
\hline G150 X G2100 & 0,38777778 & 2,61867805 & Não signific. \\
\hline G150 X G225 & $-0,0322222$ & 2,61867805 & Não signific. \\
\hline G150 X G250 & 0,01777778 & 2,61867805 & Não signific. \\
\hline G150 X G275 & 0,36666667 & 2,68670699 & Não signific. \\
\hline G150 X G4 & 2,06666667 & 2,68670699 & Não signific. \\
\hline G150 X G5 & 0,48888889 & 2,68670699 & Não signific. \\
\hline G150 X G6 & $-0,0666666$ & 2,68670699 & Não signific. \\
\hline G150 X G7 & $-1,9222222$ & 2,87221059 & Não signific. \\
\hline G175 X G3 & $-0,1711111$ & 2,61867805 & Não signific. \\
\hline G175 X G2100 & $-0,4500000$ & 2,54883405 & Não signific. \\
\hline G175 X G225 & $-0,8700000$ & 2,54883405 & Não signific. \\
\hline G175 X G250 & $-0,8200000$ & 2,54883405 & Não signific. \\
\hline G175 X G275 & $-0,4711111$ & 2,61867805 & Não signific. \\
\hline G175 X G4 & 1,22888889 & 2,61867805 & Não signific. \\
\hline G175 X G5 & $-0,3488888$ & 2,61867805 & Não signific. \\
\hline G175 X G6 & $-0,9044444$ & 2,61867805 & Não signific. \\
\hline G175 X G7 & $-2,7600000$ & 2,80867833 & Não signific. \\
\hline G3 X G2100 & $-0,2788888$ & 2,61867805 & Não signific. \\
\hline G3 X G225 & $-0,6988888$ & 2,61867805 & Não signific. \\
\hline G3 X G250 & $-0,6488888$ & 2,61867805 & Não signific. \\
\hline G3 X G275 & $-0,3000000$ & 2,68670699 & Não signific. \\
\hline G3 X G4 & 1,40000000 & 2,68670699 & Não signific. \\
\hline G3 X G5 & $-0,1777777$ & 2,68670699 & Não signific. \\
\hline G3 X G6 & $-0,7333333$ & 2,68670699 & Não signific. \\
\hline G3 X G7 & $-2,5888888$ & 2,87221059 & Não signific. \\
\hline G2100 X G225 & $-0,4200000$ & 2,54883405 & Não signific. \\
\hline G2100 X G250 & $-0,3700000$ & 2,54883405 & Não signific. \\
\hline
\end{tabular}




\begin{tabular}{lllr}
\hline G2100 X G4 & 1,67888889 & 2,61867805 & Não signific. \\
\hline G2100 X G5 & 0,10111111 & 2,61867805 & Não signific. \\
\hline G2100 X G6 & $-0,4544444$ & 2,61867805 & Não signific. \\
\hline G2100 X G7 & $-2,3100000$ & 2,80867833 & Não signific. \\
\hline G225 X G250 & 0,05000000 & 2,54883405 & Não signific. \\
\hline G225 X G275 & 0,39888889 & 2,61867805 & Não signific. \\
\hline G225 X G4 & 2,09888889 & 2,61867805 & Não signific. \\
\hline G225 X G5 & 0,52111111 & 2,61867805 & Não signific. \\
\hline G225 X G6 & $-0,0344444$ & 2,61867805 & Não signific. \\
\hline G225 X G7 & $-1,8900000$ & 2,80867833 & Não signific. \\
\hline G250 X G275 & 0,34888889 & 2,61867805 & Não signific. \\
\hline G250 X G4 & 2,04888889 & 2,61867805 & Não signific. \\
\hline G250 X G5 & 0,47111111 & 2,61867805 & Não signific. \\
\hline G250 X G6 & $-0,0844444$ & 2,61867805 & Não signific. \\
\hline G250 X G7 & $-1,9400000$ & 2,80867833 & Não signific. \\
\hline G275 X G4 & 1,70000000 & 2,68670699 & Não signific. \\
\hline G275 X G5 & 0,12222222 & 2,68670699 & Não signific. \\
\hline G275 X G6 & $-0,4333333$ & 2,68670699 & Não signific. \\
\hline G275 X G7 & $-2,2888888$ & 2,87221059 & Não signific. \\
\hline G4 X G5 & $-1,5777777$ & 2,68670699 & Não signific. \\
\hline G4 X G6 & $-2,1333333$ & 2,68670699 & Não signific. \\
\hline G4 X G7 & $-3,9888888$ & 2,87221059 & SIGNIFICANTE \\
\hline G5 X G6 & $-0,5555555$ & 2,68670699 & Não signific. \\
\hline G5 X G7 & $-2,4111111$ & 2,87221059 & Não signific. \\
\hline G6 X G7 & $-1,8555555$ & 2,87221059 & Não signific. \\
\hline & & & \\
\hline
\end{tabular}

$\mathrm{Na}$ comparação entre os grupos, quanto à porcentagem de defeito, constatou-se diferença estatisticamente significante $(P<0,05)$ entre o grupo $G 4$ e o grupo G7. Nas demais comparações, não houve diferença estatisticamente significante $(P>0,05)$. 




\section{DISCUSSÃO}

\subsection{DA METODOLOGIA}

Neste trabalho foram utilizados dentes bovinos (incisivos centrais inferiores), cujas faces vestibulares foram planificadas, com a finalidadenão só de apará-las como também remover a camada aprismática. Esse procedimento foi realizado com lixas d'água granulações sequênciais e, em seguida foram realizados o acabamento e o polimento, também com lixa d'água, de granulação extra-fina, para que não houvesse interferência de irregularidades de esmalte para a análise microscópica da área marginal das cavidades que seriam preparadas. (OHMOTO, 1994, JOSGRILBERG, 2007, DINIZ et al., 2005).

Dentes bovinos são comumente usados em pesquisas odontológicas, devido à dificuldade de obtenção de dentes humanos extraídos e com superfícies dentárias padronizadas e também por apresentarem semelhanças com os dentes humanos (OHMOTO, 1994). Há na literatura trabalhos confirmando que não há diferenças estruturais e/ou de resultados obtidos com dentes bovinos e humanos, em relação à adesão. (NAKABAYASHI; KOJIMA; MASUHARA, 1982, OHMOTO, 1994).

Muitas variáveis podem influenciar o desgaste da estrutura dentária durante o preparo cavitário, alterando diretamente a qualidade das margens (Lester, 1978). Black (1945), já afirmava que, os instrumentos rotatórios convencionais, para preparos cavitários, geram calor e vibração, mesmo sob refrigeração, produzindo sulcos e estrias nas paredes e margens das cavidades. Com o intuito de suprir algumas deficiências no preparo cavitário realizado com pontas diamantadas convencionais, foi desenvolvida, recentemente a ponta CVDentus, sendo denominada pelos fabricantes como uma pedra única de diamante artificial obtido pelo processo CVD (Chemical Vapor Deposition) (DINIZ et al., 2005). Antes do desenvolvimento das pontas com tecnologia CVD, alguns estudos foram feitos com outros tipos de ultrassom, porém seus resultados não encorajaram as empresas a difundirem ou conscializarem esse tipo de alternativa para a realização de preparos cavitários. (POSTLE, 1958, LIMA et al., 2009). Com o desenvolvimento dessas 
novas tecnologias utilizando as pontas CVDentus, o ultrassom passou a ser utilizado com mais potência não só para preparos cavitários (LIMA et al., 2009, JOSGRILBERG, 2007) como também em periodontia e endodontia (BERNARDES, 2009; WUCHENICH; MEADOWS; TORABINEJAD, 1994). Tem havido, nos últimos anos, um esforço muito grande das indústrias e empresas não só para que essa tecnologia seja melhorada e mais aceita pelos profissionais da Odontologia, como também para otimização e facilidade de acesso aos aparelhos e pontas diamantadas, desenvolvimento de investigações laboratoriais e clínicas. Os objetivos estão voltados para que os resultados, desde que favoráveis, venham dar suporte e confiança para o uso dessa tecnologia. Por essas considerações, houve motivação para a realização do presente trabalho, com foco na avaliação microscópica, das margens dos preparos cavitários, em função da variação da potência da vibração ultrassônica, comparativamente à instrumentação com diferentes tipos de equipamentos rotatórios e da abrasividdade das pontas diamantadas convencional e sintética (CVDentus).

A opção por realizar preparos cavitários em forma circular, com $2 \mathrm{~mm}$ de diâmetro, foi para que houvesse a possibilidade da realização de 5 cavidades em um único dente, e assim utilizar as diferentes intensidades de potência do ultrassom e instrumentos para a análise comparativa entre eles. Assim, a escolha da configuração das cavidades, em forma circular, permitiu a padronização dos preparos cavitários para todos os tipos de pontas e aparelhos utilizados.

Para a visualização em microscopia eletrônica de varredura (MEV), os espécimes foram desidratados, seguindo a metalização em ouro e, posteriormente, transferidos para a câmara a vácuo do MEV propriamente dito. Este processo, entretanto, cria eventualmente solução de continuidade nas amostras, em forma de trincas ou rachaduras que, quando pequenas, não interferiram na análise do ângulo cavo superficial (BOYDE, 1976). Essa intercorrência é inerente à própria tecnologia de metalização de dentes naturais para análise em MEV.

Até a década de 50 , os estudos de visualização do cavo-superficial ou paredes de preparos cavitários eram feitos com visualização direta ou por fotografias ampliadas obtidas pelo microscópio óptico (MJÖR, 1985, GRIEVE 1968). Nos anos seguintes, alguns outros aparelhos passaram a ser utilizados no auxílio de avaliações das paredes cavitárias, como o perfilômetro (CHARBENEAU; PEYTON, 
1958, DE FIORI, 1994, LAMMIE, 1957) ou rugosímetro (DE FIORI, 1994) e, no final dos anos 60, a microscopia eletrônica de varredura (BOYD, 1985, LEIDAL; TRONSTAD, 1975, LESTER, 1978).

Há poucos anos, os métodos de avaliação utilizados para determinar o grau de irregularidade de cada preparo consistia na análise de fotografias; sobre a fotografia era colocada uma folha transparente de projeção para que, então, a área do preparo cavitário fosse delimitada pelo traçado e preenchidas com tinta as que eram consideradas irregularidades $\left(\mu \mathrm{m}^{2}\right)$, por sua vez divididas pelo perímetro estimado $(\mu \mathrm{m})$. (COUTINHO, 1995, GRIEVE, 1968)

Nos dias atuais, muitos são os equipamentos disponíveis para a análise de margens de preparos cavitários, e alguns deles já são digitalizados. Na ESALQ, onde foram realizadas as fotomicrografias do presente trabalho, a imagem estabelecida pelo MEV é arquivada no próprio computador. Para análise das fotos foi usado o programa de computador Image Tool, desenvolvido pela Universidade do Texas, o qual, por meio de ferramentas especiais, permite fazer medidas do perímetro e área do preparo cavitário, conforme estudo de Coutinho (1995), porém computadorizada.

O método de avaliação utilizado para a determinação do grau de irregularidade de cada preparo cavitário foi traçado no programa Image Tool. $\mathrm{O}$ primeiro traçado foi referente ao perímetro total da cavidade, entendido como contorno ideal, e o segundo traçado teve por base a área de irregularidades junto ao ângulo cavo-superficial de cada cavidade e de todos os grupos com os diferentes instrumentos. Assim, a adoção da presente metodologia de avaliação com base pelos trabalhos anteriores de Francischone (2005) e De Paula et al. (2008). 


\subsection{DOS RESULTADOS}

Um dos requisitos fundamentais para que um preparo cavitário proporcione longevidade à restauração, independente do tipo de material odontológico, seja de uso direto ou indireto, metálico ou não metálico, é apresentar margem contínua e regular. Para isso, é necessária a utilização de procedimentos de acabamento de margem como já recomendava Black, em 1908, o que até hoje continua sendo um dos passos mais importante. (MONDELLI, 2006, CHAN; EDIE; SVARE, 1977, COUTINHO, 1995, DE FIORI, 1994, DINIZ et al., 2005, VIEIRA et al., 2007). Várias são as técnicas de acabamento de margem das cavidades, incluindo diferentes tipos de aparelhos (motores e micromotores) com seus torques, velocidades e vibrações, até as brocas e pontas diamantadas de diferentes texturas e composições. Pela grande diversidade e opções disponíveis de técnicas de acabamento das margens das cavidades, para esta pesquisa recorreu-se a algumas que são clássicas na literatura especializada e outras que ainda carecem de mais estudos para comprovar a sua real eficiência.

Analisando a Tabela 5.5, observa-se que não houve diferenças estatisticamente significantes entre todas as comparações individuais, com exceção dos grupos GIV(Alta velocidade + Ponta Diamantada Convencional + Baixa Velocidade + Ponta Diamantada Acabamento) x GVII (Ultrassom + CVDentus-Corte Potência $50 \%+$ Velocidade intermediária + Acabamento Ponta Diamantada/Velocidade Intermediária)(significante $\mathrm{p}<0.05)$. Independente dessa análise, o Grupo GIV foi o que proporcionou menores irregularidades em termos de qualidade de margem, quando comparado aos demais grupos. Pode-se evidenciar, portanto, que o uso de ponta diamantada convencional em alta velocidade e em seguida, ponta diamantada para acabamento girando em baixa velocidade estabelece uma melhor regularidade marginal. Este resultado vem ao encontro dos resultados obtidos por Josgrilberg et al. (2007) e que endossam essa técnica como confiável e clássica para esse tipo de procedimento operatório.

Khambay e Walmsley (2000a, 2000b) compararam a qualidade de corte de instrumentos rotatórios convencionais com os de ultrassom, verificando que as pontas diamantadas acionadas por rotação apresentam maior precisão do que as 
pontas usadas com vibração ultrassônicas, confirmando assim os dados obtidos na presente pesquisa.

Por outro lado, quando se analisa criteriosamente as fotomicrografias de todas as técnicas de preparo e acabamento de margem das cavidades, nota-se uma proximidade muito grande na quantidade de irregularidades do cavo-superficial quando comparadas com as do grupo IV. Este fato demonstra que todas as formas de acabamento de margem adotadas para esta pesquisa não contemplam uma definição precisa do ângulo cavo-superficial. Isso é comprovado, com exceção do grupo VII, pela variação de porcentagem dos defeitos de margem de 2,21\% até $4,34 \%$, o que representa uma diferença pequena para se quantificar a superioridade da margem cavitária em função dos diferentes procedimentos de instrumentação.

Apesar dos percentuais de irregularidades de margem serem menores do que $10 \%$ e não apresentarem diferenças estatísticas significantes, entre as condições testadas, com exceção à comparação entre os grupos IV e VII, deve-se interpretar esses dados com alguns cuidados, especialmente se transportados para a aplicação clínica.

A análise dos defeitos de margem observados nas fotomicrografias mostram variabilidade quanto à profundidade e extensão, sendo que a quantificação estabelecida pelos examinadores permitiu a avaliação em termos de extensão superficial e não em profundidade. Nesse sentido, deve-se considerar que uma irregularidade pode apresentar diferentes graus de profundidade, mas o mesmo valor numérico de área de superfície, pois a delimitação da linha estabelece medição do defeito marginal e terá a mesma extensão nas duas condições, determinando resultados finais iguais. Do ponto de vista clínico, um defeito mais profundo da margem do preparo será mais difícil para permitir o acabamento da cavidade e para a melhor adaptação do material restaurador. Isso pode trazer consequências ao longo do tempo, em relação à infiltração marginal e ao desenvolvimento de lesões cariosas. Esses aspectos são igualmente destacados em trabalhos de Coutinho (1995), Giampaolo et al. (2003), Diniz et al. (2005) e Corona et al. (2001), indicando a necessidade de procedimentos complementares que realizem a melhor definição do término da cavidade.

Essa situação ficou mais clara quando se examinaram os defeitos provocados pelos aparelhos de ultrassom com suas respectivas pontas diamantadas 
para preparos. Pôde-se evidenciar que essa tecnologia induz a presença de irregularidades do esmalte marginal, mais evidente quando comparada às pontas diamantadas associadas ao uso de instrumentos rotatórios (Figuras 6.1 e 6.2). 

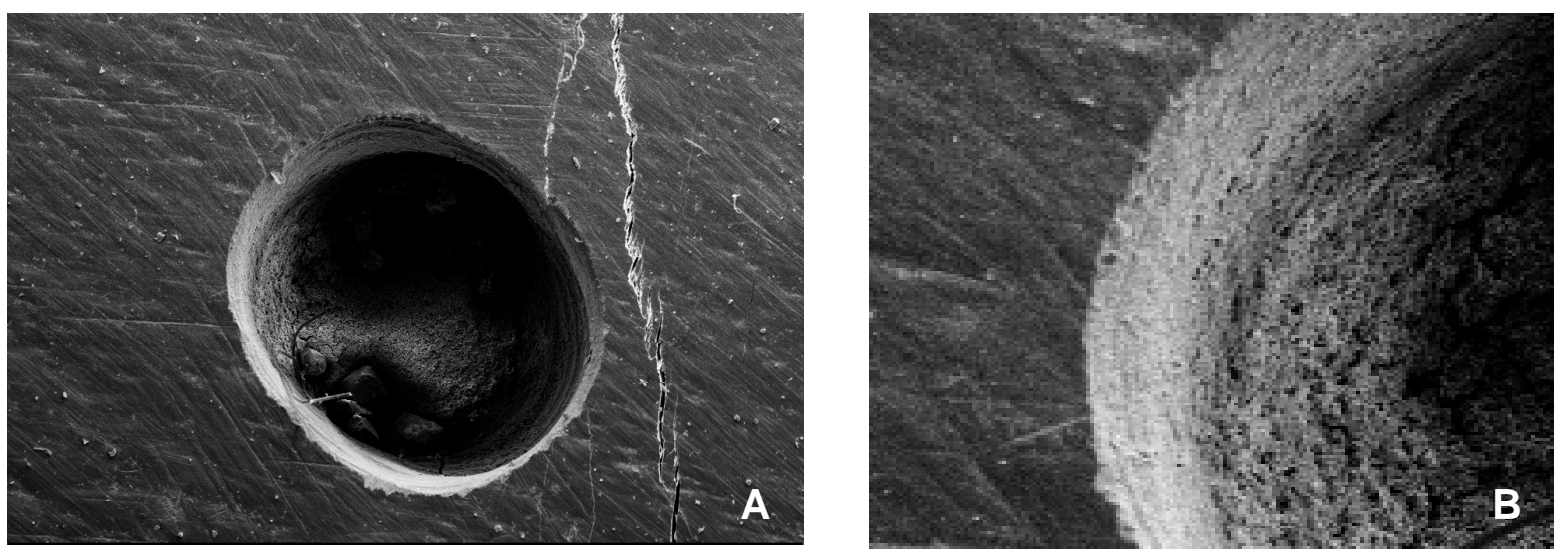

Figura 6.1 - Fotomicrografias mostrando as características dos defeitos na margem causados com o uso de alta velocidade e ponta diamantada (A). Em maior aumento (B), observa-se a boa regularidade da margem da cavidade.
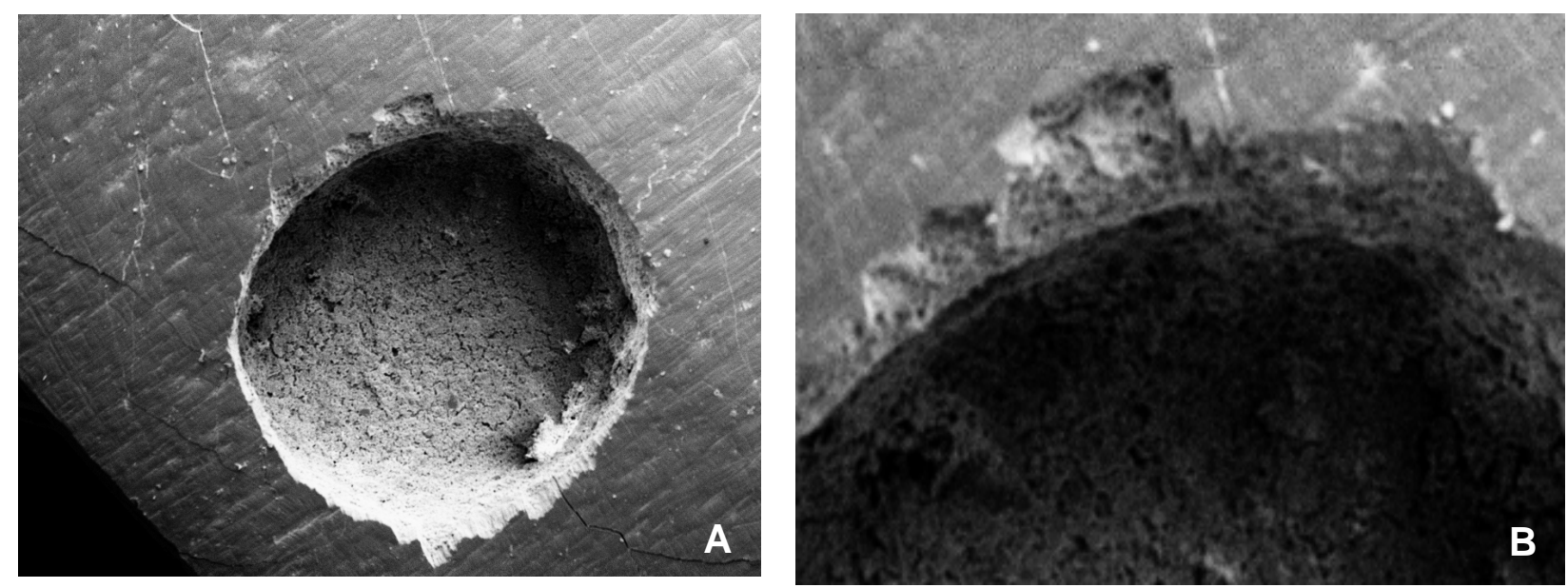

Figura 6.2 - Fotomicrografias mostrando as características dos defeitos na margem causadas com o uso de ultrassom associado à ponta CVDentus $(A)$. Em maior aumento $(B)$, é evidente a presença de defeitos de esmalte, características do uso do ultrassom.

A observação adicional em MEV permitiu verificar que as irregularidades do esmalte marginal parecem estar diretamente relacionados com o aumento da intensidade de vibração do aparelho de ultrassom, em decorrência do impacto ou amplitude vibracional a medida que se atinge a potência de $100 \%$ onde pode-se evidenciar defeitos de esmalte mais profundos e maiores do que em intensidades menores. 
No Brasil, somente uma empresa disponibiliza as pontas diamantadas CVDentus e, para cada tipo de ponta, há indicação da máxima potência de uso, em porcentagem, no sentido de permitir maior durabilidade das mesmas. Porém a literatura odontológica não traz evidências científicas que referendem, em relação às intensidades extremas e intermediárias, as definições marginais decorrentes destas diferentes potências. Portanto a utilização de diferentes potência de vibração: 25\%, $50 \%, 75 \%$ e $100 \%$, que correspondem às intensidades estabelecidas pelo aparelho de ultrassom NACPlus, na função "scalling" permite visualizar que as diferentes potências não influenciam significantemente na terminação marginal, tendo em provavelmente influência na conservação e durabilidade do diamante incorporado à haste metálica.

De forma comparativa, Josgrilberg et al. (2007) estudaram a influência de diferentes intensidades de vibração ultrassônica no tamanho e profundidade de preparos cavitários. Observaram que a potência de vibração IV (100\%), feita com o aparelho Prof I (AS Ceramic - Dabi Atlante®, Ribeirão Preto, Sp, Brasil), determinava cavidades mais profundas e maiores comparadas com intensidades menores. Também verificaram que as cavidades realizadas com a potência de vibração III (75\%) apresentaram dimensões semelhantes às da ponta cilindrica CVDentus utilizada. Concluíram que a intensidade III (75\%), indicada pelo fabricante, é a mais adequada para o uso do sistema CVDentus. Se compararmos esses resultados com os da presente pesquisa pode-se verificar que nos 2 grupos onde se utilizou intensidade de vibração de 75\% (G1-SG3-75\% = 3.44 e G2-SG3-75\% = $3,91)$ os percentuais de defeitos de margem de esmalte foram menor ou igual aos demais grupos de ultrassom corroborando com os dados obtidos por Josgrilberg et al. (2007).

Dentro dessa linha de pesquisa com integração de pontas diamantadas ativadas por vibrações ultrassônica, Waplington et al. (1995) concluíram que o uso de intensidade de vibração maior pode remover lascas do substrato e produzir cavidades maiores e mais profundas que as desejáveis. Esses achados podem endossar as nossas constatações de que intensidades de frequências de vibração mais altas promoveram maiores e mais profundas irregularidades na margem do preparo cavitário, quando comparadas com as margens feitas com intensidades de 
potência de vibração mais baixas. Provavelmente, isso é decorrente da presença de maior impacto ocasionado pela intensidade de potência de vibração mais alta.

Tendo em vista os resultados encontrados de equivalência da qualidade de acabamento das margens das cavidades entre as técnicas convencionais já consagradas e a técnica de preparo e acabamento com ponta diamantada e ultrassom, torna-se oportuno salientar algumas vantagens e situações clínicas para a recomendação do uso da técnologia ultrassônica. Por sua particularidade de mecanismo de ação, possibilita indicações excelentes para sua aplicação clínica (MESQUITA, KUNERT, 2006). Lussi (1995) constatou que 89\% dos dentes adjacentes têm suas faces proximais danificadas quando somente instrumentos rotatórios são utilizados nesse tipo de preparação. Moopnar e Faulkner (1991) relataram que $73 \%$ dos dentes vizinhos são danificados e a região cervico-radicular é mais frequentemente envolvida que a coronária. Danos iatrogênicos aos dentes vizinhos aumentam substancialmente o desenvolvimente e a progressão da lesão cariosa e há necessidade de novas intervenções terapêutica (MESQUITA, KUNERT, 2006). O desenvolvimento tecnológico e específico de pontas diamantadas para serem utilizadas em aparelhos de ultrassom podem substituir o uso dos instrumentos rotatórios com vontagens. Com isso, o acesso e a preparação de cavidades proximais feita com essas pontas diamantadas, permite a ação vibratória do instrumento, sem danos ou necessidades adicionais de proteção da face proximal adjacente do dente vizinho. É uma forma de conveniência e preservadora importante e que sobrepuja a técnica tradicional. Este fato se torna ainda mais prático em áreas de difícil acesso, coadjuvado com a fabricação de pontas CVDentus com diversas angulações.

A técnica de preparação de cavidades conservativas de classe II realizadas com ultrassom não difere daquela feita com instrumentos rotatórios. Entretanto, deve-se salientar que os preparos feitos com ultrassom deixem de ser meros coadjuvantes e passem a ser alternativos ou substituitos dos instrumentos rotatórios. Ao mesmo tempo em que o preparo cavitário vai sendo realizado a técnica de ultrassom permite paredes e margens com menos riscos e estrias, além de, pelo fenômeno de cavitação da água, promover uma maior remoção da "smear layer" (MESQUITA, KUNERT, 2006). 
A extensão subgengival de preparações de coroas totais também podem ser realizados com vantagens por meio do uso das pontas ultrassônicas. Ao mesmo tempo que é realizado a extensão subgengival do preparo, pelo seu mecanismo de ação, protege o tecido gengival de traumatismo (FERRARI; NATHANSON, 1995). Da mesma forma que para os preparos cavitários e acabamento de classe II em áreas de difícil acesso são facilitados pela técnica de instrumentação ultrassônica, os preparos de coroas totais também são beneficiados pela mesma técnica, tendo em vista as pontas serem confeccionadas com formas e inclinações específicas para esse fim. Além disso, as pontas ultrassônicas permitem preparos mais conservadores quando comparadas às pontas diamantadas para alta velocidade (MAGNE; DOUGLAS, 1999, MAGNE et al., 1999, MAGNE et al., 2000).

Outro aspecto que deve-se levar em consideração e que pode implementar o uso da instrumentação ultrassonica está relacionado à diminuição significativa de ruídos durante sua ação quando comparada com turbinas de alta velocidade. Isto traz benefícios e maior conforto não só para os pacientes, mas principalmente para os profissionais em função do uso sistemático (LOPES et al., 2009). Em estudo comparativo das intensidades de ruídos provocados pelas turbinas de alta velocidade e vibrações ultrassônicas, Lopes et al. (2009), verificaram um valor médio de ruídos de $82 \mathrm{~dB}$ para as turbinas e de $76 \mathrm{~dB}$ para as vibrações ultrassônicas. Concluíram que o uso repetitivo e prolongado desses instrumentos pode promover maiores possibilidades de surdez especialmente nos profissionais, quanto maior for à intensidade de ruídos provocados por tais instrumentos.

Dessa forma, os resultados observados respaldam que o uso do ultrassom com diferentes potências do aprelho NACPlus, na função "scalling" não influenciam diretamente na qualidade marginal dos preparos, devendo atender a recomendação do fabricante das ponstas CVDentus para que não se ultrapasse o limite de potência, para cada tipo de ponta haja vista a possibilidade de se afetar a durabilidade específica das mesma. 



\section{CONCLUSÕES}

Com base na metodologia e resultados obtidos nesta pesquisa, concluiu-se que:

- A qualidade marginal dos preparos cavitários foi estatísticamente semelhante para todas as variáveis testadas, independente dos tipos de pontas diamantadas utilizados nas instrumentações rotatórias e ultrassônicas. 




\section{REFÊRENCIAS}

ALLAN, D. N. Cavity finishing. Brit Dent J, London, v. 125, n. 17, p. 540-545, Dec. 1968.

ANGUS, J. C.; WILL, H. A.; STANKO, W. S. Growth of diamond seed crystals by vapor deposition. J Appl Phys, New York, v. 39, p. 5818, 1968.

BERNARDES, R. A. et al. Evaluation of apical cavity preparation with a new type of ultrasonic diamond tip. J Endod, Chicago, v. 33, n. 4, p. 484-487, 2007.

BERNARDES, R. A. et al. Ultrasonic chemical vapor deposition-coated tip versus high- and low-speed carbide burs for apicoectomy: time required for resection and scanning electron microscopy analysis of the root-end surfaces. J Endod, Chicago, v. 35, n. 2, p. 265-268, Feb. 2009.

BIANCHI, A. R. R. et al. Possibilidades do emprego das pontas diamantadas na odontologia moderna. Rev Bras Eng Biomed, Campinas, v. 15, n. 1/2, p. 39-48, jan./ago. 1999.

BLACK, G.V. Cavity preparation. In:

Chicago: Medico-Dental, 1908. v. 2, p. $\overline{105-116 .}$

A work on operative dentistry.

BLACK, R. Technique for non-mechanical preparation of cavities and prophylaxis. $\mathbf{J}$ Am Dent Assoc, Chicago, v. 32, p.955-965, 1945.

BORGES, C.F. et al. Dental diamond burs made with a new technology. J Prosthet Dent, St. Louis, v. 82, n.1, p. 73-79, July 1999.

BOYD, M. A.; RICHARDSON, A. S. Frequency of amalgam replacement in general dental practice. J Canad Dent Ass, Toronto, v. 51, n. 10, p. 763-766. Oct. 1985.

BOYDE, A. Enamel structure and cavity margins. Oper Dent, Seattle, v. 1, n. 1, p. 13-28, 1976.

BOYDE, A.; KNIGHT, P. J. The use of scanning electron microscopy in clinical dental research. Brit Dent J, London, v. 127, n. 6, p. 313-322, Oct. 1969.

BOYER, D. B.; SVARE, C. W. The effect of rotary instrumentation on the permeability of dentin. J Dent Res, Chicago, v. 60, n. 6, p. 966-971, June 1981.

BUNDY, F. P. Diamonds. Science, Washington, v. 207, n. 4434, p. 974, Feb. 1980.

CARDOSO, M. V. et al. Influence of dentin cavity surface finishing on micro-tensile bond strength of adhesives. Dent Mater, Copenhagen, v. 24, n. 4, p. 492-501, Apr. 2007. 
CARVALHO, C. A. et al. The use of CVD diamond burs for ultraconservative cavity preparations: a report of two cases. J Esthet Restor Dent, London, v. 19, n. 1, p. 1928, 2007.

CHAN, K. C.; EDIE, J. W.; SVARE, C. W. Scanning electron microscope study of marginal adaptation of amalgam in restoration finishing techniques. J Prosthet Dent, St. Louis, v. 38, n. 2, p.165-168, Aug. 1977.

CHARBENEAU, G. T.; PEYTON, F. A. Some effects of cavity instrumentation on the adaptation of gold castings and amalgam. J Prosthet Dent, St. Louis, v. 8, n. 3, p. 514-525, 1958.

CHRISTENSEN, G. J. The high-speed handpiece dilemma. J Am Dent Ass, Chicago, v. 130, n. 10, p. 1494-1496, Oct. 1999.

CHRISTENSEN, G. J. Are electric handpieces an improvement? J Am Dent Ass, Chicago, v. 133, n. 10, p.1433-1434, Oct. 2002.

COPPA, A. et al. Palaeontology: early Neolithic tradition of dentistry. Nature, London, v. 440, n. 7085, p.755-756, Apr. 2006.

CORONA, S. A. et al. Microleakage of class $\mathrm{V}$ resin composite restorations after bur, air-abrasion or Er:YAG laser preparation. Oper Dent, Seattle, v. 26, n. 5, p.491-497, Sept.-Oct. 2001.

COUTINHO, M. Avaliação do acabamento marginal de preparos cavitários em função de diferentes formas de instrumentação. Bauru, 1995. 131 p. Dissertação (Mestrado em Odontologia) - Faculdade de Odontologia de Bauru, Universidade de São Paulo, Bauru, 1995.

DE FIORI, S. R. Influência da textura da linha de terminação biselada em esmalte com instrumentos de corte rotatórios e não rotatórios no assentamento das coroas totais. São Paulo, 1994. 114 p. Tese (Doutorado em Odontologia) - Faculdade de Odontologia, Universidade de São Paulo, São Paulo, 1994.

DE PAULA, A. B. et al. Effect of restorative technique and thermal/mechanical treatment on marginal adptation and compressive stregth of esthetic restorations. Oper Dent, Seattle, v. 33, n. 4, p. 434-440, July-Aug. 2008.

DERYAGIN, B. V.; FEDOSEEV, D. V. Epitaxial synthesis of diamond in the metastable region. Russ Chem Rev, Moscow, v. 39, n. 9, p. 783-788, 1970.

DERYAGIN, B. V. et al. Diamond crystal synthesis on nondiamond substrates. Soviet Physics Doklady, Washington, v. 21, p. 676, 1976.

DINIZ, M. B. et al. Microinfiltração marginal em cavidades preparadas com pontas cvdentus e diamantadas convencionais. Cienc Odontol Bras, São José dos Campos, v. 8, n. 1, p. 75-81, jan./mar. 2005.

DYSON, J. E.; DARVELL, B. W. Flow and free running speed characterization of dental air turbine handpieces. J Dent, Bristol, v. 27, n. 7, p. 465-477, Sept. 1999. 
EICK, J. D. et al. Sanning Electron Microscopy of Cut Tooth Surfaces and Identification of Debris by Use of Electron Microprobe. J Dent Res, Chicago, v. 49, n. 6, p. 1359-1368, Nov.-Dec. 1970. Supplement.

FERRARI, M.; NATHANSON, D. Tissue management and retraction technique combined with all-ceramic crows: a case report. Pract Periodontics Aesthet Dent, Mahwah, v. 7, n. 3, p. 87-94, Apr. 1995.

FRANCISCHONE, A. C. Prevalência das proporções áurea e estética dos dentes ântero-superiores e respectivos segmentos dentários relacionadas com a largura do sorriso em indivíduos com oclusão normal. 2005. 81 p. Dissertação (Mestrado em Odontologia - Faculdade de Odontologia de Bauru, Universidade de São Paulo, Bauru, 2005.

GÄBLER, J. et al. Micro abrasive pencils with CVD diamond coating. Diam Relat Mater, Switzerland, v. 12, n. 3-7, p. 707-710, Mar./July 2003.

GEGAUFF, A. G. et al. Handpiece degradation associated with performance testing of diamond rotary cutting instruments. Aust Dent J, Sydney, v. 43, n. 5, p. 342-348, Oct. 1998.

GIAMPAOLO, E. T. et al. Different methods of finishing and polishing enamel. $\mathbf{J}$ Prosthet Dent, St. Louis, v. 89, n. 2, p. 135-140, Feb. 2003.

GILBOE, D. B. et al. Dentinal smearing: an investigation of the phenomenon. $\mathbf{J}$ Prosthet Dent, St. Louis, v. 44, n. 3, p. 310-316, Sept. 1980.

GOROKHOVSKY, V. I. Characterization of cascade arc assisted CVD diamondcoating technology : Part II. Coating properties and applications. Surface \& coatings technology, Lausanne, v. 194, n. 2/3, p. 300-318, 2005.

GRIEVE, A. R. Finishing cavity margins. Br Dent J, London, v. 125, n. 1, p. 12-17, July 1968.

HARKNESS, N., DAVIES, E. H. The cleaning of dental diamond burs. Br Dent J, London, v. 154, n. 2, p. 42-45, Jan. 1983.

HARTLEY, J. L et al. Methods for evaluation of rotating diamond-abrasive dental instrumentens. J Am Dent Ass, Chicago, v. 54, n. 5, p.637-644, May 1957.

JOSGRILBERG, E. B. et al. Influence of the power level of an ultra-sonic system on dental cavity preparation. Braz Oral Res, São Paulo, v. 21, n. 4, p. 362-367, Oct.Dec. 2007.

KHAMBAY, B. S; WALMSLEY, A. D. Investigations into the use of an ultrasonic chisel to cut bone. Part 1: forces applied by clinicians. J Dent, Bristol, v. 28, n. 1, p.31-37, Jan. 2000a.

KHAMBAY, B. S; WALMSLEY, A. D. Investigations into the use of an ultrasonic chisel to cut bone. Part 2: cutting ability. J Dent, Bristol, v. 28, n. 1, p.39-44, Jan. 2000b. 
KAMO, M. et al. Diamond synthesis from gas phase in microwave plasma. $\mathbf{J}$ Cryst Growth, Amsterdam, v. 62, n. 3, p. 642-644, 1983.

LAMMIE, G. A. The measurement of surface roughness of teeth cut by rotary dental instruments. Br Dent J, London, v. 103, p. 242-245, 1957.

LEIDAL, T. I.; TRONSTAD, L. Scanning electron microscopy of cavity margins finished with ultra-speed instruments. J Dent Res, Chicago, v. 54, n. 1, p. 152-159, Jan.-Fev. 1975.

LESTER, K. S. Burs, teeth and hand instruments. Aust Dent J, Sydney, v. 23, n. 3, p. 231-236, June 1978.

LIMA, L. M. et al. Cutting characteristics of dental diamond burs made with CVD technology. Braz Oral Res, São Paulo, v. 20, n. 2, p.155-161, apr./june 2006.

LIMA, L. M. et al. Comparative cutting effectiveness of an ultrasonic diamond tip and a high-speed diamond bur. Minerva Stomatol, Torino, v. 58, n. 3, p.93-98, Mar. 2009.

Lopes, AC. Ruído em odontologia: interferência na saúde auditiva. Bauru (SP):

Universidade de São Paulo, Faculdade de Odontologia de Bauru; 2007. Relatório

Final:Processo FAPESP no 2007/01074-7, 2009.

LUSSI, A.; HUGO, B.; HOTZ, P. Einfluss zweier finierungs methoden auf die mikromorphologie des approximalen kastenrandes. Schweiz Monatsschr Zahnmed, Bern, v. 102, n. 10, p. 1175-1180, 1992.

MAGNE, P.; DOUGLAS. W. H. Additive contour of porcelain veneers: key element in enamel preservation adhesion and esthetic for the againg dentition. $\mathbf{J}$ Adhesive Dent, New Malden, v. 1, n. 1, p. 81-91, 1999.

MAGNE, P. et al. Crack propensity of porcelain laminate venners: a simulated operatory evaluation. J Prosthet Dent, St. Louis v. 81, n. 3, p. 327-334, Mar. 1999.

MAGNE, $P$ et al. Clinical performance of novel-design porcelain veneers for the recovery of coronal volume and length. Int $\mathbf{J}$ Periodontics Restorative Dent, Chicago, v. 20, n. 5, p. 440-457, Oct. 2000.

MARTINS, M. E. L.; FARIA, M. R.; MATSON, M. R. Análise micromorfológica da dentina humana condicionado por primer autocondicionante variando-se a técnica de preparo: ponta diamantada, broca carbide e ponta CVDentus. Pesq Bras Odontoped Clin Integr, João Pessoa, v. 6, n. 2, p. 161-166, mai./ago.2006.

MATSUMOTO, S. et al. Vapor deposition of diamond particles from methane, Jpn J Appl Phys, Tokyo, v. 21, n. 4, p. L183-L185, Apr. 1982a.

MATSUMOTO, S. et al. Growth of diamond particles from methane-hydrogen gas. J. Mater Sci, London, v. 17, p. 3106-3112, $1982 b$. 
MATSUMOTO, S.; MATSUI, Y. Electron microscopic observation of diamond particles grown from the vapour phase $\mathbf{J}$ Mat Sci, London, v. 18, n. 6, p. 1785-1793, June 1983.

MAY, P. W. CVD Diamond: a new technology for the future? Endeavour Magazine, Grimsby, v. 19, n. 3, p.101-06, 1995.

MAY, P. W. Diamond thin films: a 21st-century material. Phil Trans R Soc Lond A, London, 358, p. 473-495, 2000.

MENEGALE, C.; SWARTZ, L. M.; PHILLIPS, R. W. Adaptation of restorative materials as influenced by roughness of cavity walls. J Dent Res, Chicago, v. 39, n. 4, p. 825-835, July-Ago. 1960.

MESQUITA, E.; KUNERT, I.R. Ultra-som na prática odontológica. Porto Alegre: Artmed, 2006, $264 \mathrm{p}$.

MJÖR, I. A. Frequency of secondary caries at various anatomical locations. Oper Dent, Seatle, v. 10, n. 2, p. 88-92, Mar.-Apr. 1985.

MONDELLI, J. Fundamentos de Dentística Operatória. São Paulo: Ed. Santos, 2006.

MOOPNAR, M.; FAULKNER, K. D. Accidental damage to teeth adjacent to crownprepared abutment teeth. Aust Dent J, Sydney, v. 36, n. 2, p. 136-40, Apr. 1991.

NAKABAYASHI, N.; KOJIMA, K.; MASUHARA, E. The promotion of adhesion by the infiltration of monomers into tooth substrates. J Biomed Mater Res, Hoboken, v. 16, n. 3, p. 265-273, May 1982.

OHMOTO, K. et al. Studies on dental high-speed cutting with carbide burs used on bovine dentin. J Prosthet Dent, St. Louis, v. 71, n. 3, p. 319-323, Mar. 1994.

PARULA, N. Técnica de operatória dental. 5. ed. Buenos Aires: Mundi, 1972. p. 176-178, 182-185, 202-203.

PILCHER, E. S.; TIETGE, J. D.; DRAUGHN, R. A. Comparison of cutting rates among single-patient-use and multiple-patient-use diamond burs. J Prosthodont, Philadelphia, v. 9, n. 2, p. 66-70, June 2000.

POFERL, D. J.; GARDNER, N. C.; ANGUS, J.C. Growth of boron-doped diamond seed crystals by vapor deposition. J Appl Phys, New York, v. 44, p. 1428, 1973.

POSTLE, H. H. Ultrasonic cavity preparation. J Prosthet Dent, St. Louis, v. 8, n. 1, p.153-160, 1958.

PREDEBON, J. C.; FLÓRIO, F. M.; BASTING, R. T. Use of CVDentus diamond tips for ultrasound in cavity preparation. J Contemp Dent Pract, Cincinnati, v. 7, n. 3, p. 1-7, July 2006.

RING, M. E. Dentistry: an illustrated history. New York: Harry N. Abrams, 1985. 
ROCHE, H. A. Demonstration at the Annual Meeting - The Ultrasonic Drill. Br Dental J, v.17, p. 96-98, 1954.

SAITO, Y., MATSUDA, S.; NOGITA, S. Synthesis of diamond by decomposition of methane in microwave plasma. J Mater Sci Let, London, v. 5, p. 565-568, 1986.

SALMON, V. Current research in sound. IRETransactions in Sound, v. 9, n. 30, p. 37-40, 1963.

SCOTT, D.B.; O 'NEIL, J. R. The microstructure of enamel and dentin as related to cavity preparation. In: PHILLIPS, R. W. Workshop on adhesive restorative materials. Spencer: Owen Litto Service, 1961, p. 27-37.

SHILLINBURG JUNIOR, H. T. et al. Instrumento rotatório. In:

Fundamentos dos prepares dentários para restaurações metálicas e de porcelana. São Paulo: Quintessence, cap.3, p. 61-81, 1988.

SIEGEL, S. C; VON FRAUNHOFER, V. Dental cutting: the historical development of diamond burs. J Am Dent Assoc, Chicago, v. 129, n. 6, p. 740-745, June 1998.

SIEGEL, S. C.; VON FRAUNHOFER, J. A. Cutting efficiency of three diamond bur grit sizes. J Am Dent Assoc, Chicago, v. 131, n. 12, p. 1706-1710, Dec. 2000.

SIEGEL, S. C.; VON FRAUNHOFER, J. A. The effect of handpiece spray patterns on cutting efficiency, J Am Dent Assoc, Chicago, v. 133, n. 2, p. 184-188, Feb. 2002.

SPITSYN, B. V.; BOUILOV, L. L.; DERYAGIN, B. V. Growth of diamond on diamond and other surfaces. J Cryst Growth, Amsterdam, v. 52, p. 219-226, 1981.

STREET, E.V. Effects of various instruments on enamel walls.J Am Dent Assoc, Chicago, v. 46, n. 3 p. 274-280, Mar. 1953.

SCHUCHARD, A.; WATKINS, E. C. Cutting effectiveness of tungsten carbide burs and diamond points at ultra-high rotational speeds. J Prosthet Dent, St. Louis, v. 18, n. 1, p. 58-65, July 1967.

TRAVA-AIROLDI, V. J. et al. Hot filament scaling-up for CVD diamond burr manufacturing. Surf Coat Technol, Lausanne, v. 76/77, p. 797-802, Dec. 1995.

TRAVA-AIROLDI, V. J. et al. CVD diamond burrs: development and applications. Diam Relat Mater, Amsterdam, v. 5, n. 6/8, p. 857-860, May 1996.

TRAVA-AIROLDI, V. J.; CORAT, E. J.; MORO, J. R. Studies of CVD diamond applications as ultrasound abrading devices in odontology and related uses. Rev Bras Aplic Vácuo, Bauru, v. 25, n. 2, p. 71-74, 2006.

TRONSTAD, L.; LEIDAL, T. I. Scanning electron microscopy of cavity margins finished with chisels or rotating instruments at low speed. J Dent Res, Chicago, v. 53, n. 5, p. 1167-1174, Sept.-Oct. 1974.

UNION CARBIDE CORPORATION. William G. Eversole; N. Y. Kenmore. Synthesis diamond. USPTO 3.030.188, 17 Apr. 1962. 
VALERA, M. C. et al. Pontas de diamantes-CVD. Rev Gaúcha Odontol, Porto Alegre, v. 44, n. 2, p.104-108, mar.-abr. 1996.

VIEIRA, A. S. B. et al. Preparation time and sealing effect of cavities prepared by na ultrasonic device and high-speed diamond Rotary cutting system. J Oral Sci, Tokyo, v. 49, n. 3, p. 207-211, Sept. 2007.

VINSKY, I. Two hundred and fitty years of rotary instruments in dentristry. Br Dent J, London, v. 146, n. 7, p. 217-223, Apr. 1979.

WALSH, J.P. Critical review of cutting instruments in cavity preparation: I. diamond stone. Int Dent J, London, v. 4, n. 1, p. 36-43, 1953.

WAPLINGTON, M., et al. Dental hard tissue cutting characteristics of an ultrasonic drill. Int Dent J, London, v.35, n.2, p.339-43, 1995.

WATSON, T. F.; FLANAGAN, D.; STONE, D. G. High and low torque handpieces: cutting dynamics, enamel cracking and tooth temperature. $\mathbf{B r}$ Dent $\mathbf{J}$, London, v. 188, n. 12, p. 680-686, June 2000.

WESTLAND, I. A. The energy requirement of the dental cutting process. $\mathbf{J}$ Oral Rehabil, Oxford, v. 7, n. 1, p. 51-63 Jan. 1980.

WUCHENICH, G.; MEADOWS, D.; TORABINEJAD, M. A comparison between two root end preparation techniques in human cadavers. J Endod, Chicago, v. 20, n. 6, p. 279-282, 1994.

$\mathrm{XU}, \mathrm{H}$. H., et al. Enamel subsurface damage due to tooth preparation with diamonds. J Dent Res, Chicago, v. 76, n. 10, p. 1698-1706, Oct. 1997. 


ANEXO 1 - Anotações das medidas do perímetro e área de defeito do primeiro examinador

\begin{tabular}{|c|c|c|}
\hline ESPÉCIME & PERÍMETRO (mm) & ÁREA DE DEFEITOS $\left(\mathrm{mm}^{2}\right)$ \\
\hline G1-1-25\% 06 & 6,49 & 0,17 \\
\hline G1-1-25\%06 copia & 5,70 & 0,14 \\
\hline G1-1-50\%07 copia & 6,32 & 0,29 \\
\hline G1-1-75\%08 copia & 5,81 & 0,23 \\
\hline G1-1-100\%09 & 6,03 & 0,17 \\
\hline G1-1-controle10 copia & 6,28 & 0,22 \\
\hline G1-2-25\%11 cópia & 6,06 & 0,16 \\
\hline G1-2-75\%13 cópia & 6,49 & 0,24 \\
\hline G1-2-100\%14 cópia & 6,90 & 0,27 \\
\hline G1-2-controle\%15 cópia & 6,22 & 0,32 \\
\hline G1-3-25\%16 cópia & 5,89 & 0,22 \\
\hline G1-3-50\%17 cópia & 6,01 & 0,44 \\
\hline G1-3-75\%18 cópia & 6,46 & 0,23 \\
\hline G1-3-100\%19 cópia & 6,53 & 0,31 \\
\hline G1-3-controle20 cópia & 6,68 & 0,21 \\
\hline G1-4-25\%21 cópia & 6,27 & 0,25 \\
\hline G1-4-50\%22 & 6,73 & 0,22 \\
\hline G1-4-75\%23 cópia & 6,06 & 0,22 \\
\hline G1-4-100\%24 cópia & 5,95 & 0,26 \\
\hline G1-4-controle25 cópia & 5,81 & 0,06 \\
\hline G1-5-25\%26 cópia & 6,41 & 0,20 \\
\hline G1-5-50\%27 cópia & 6,73 & 0,18 \\
\hline G1-5-75\%28 cópia & 5,86 & 0,12 \\
\hline G1-5-100\%29 cópia & 5,95 & 0,26 \\
\hline G1-5-controle30 cópia & 6,01 & 0,13 \\
\hline G1-6-25\%31 cópia & 5,52 & 0,16 \\
\hline G1-6-50\%32 cópia & 5,94 & 0,17 \\
\hline G1-6-75\%33 cópia & 6,26 & 0,30 \\
\hline G1-6-100\%34 cópia & 5,97 & 0,19 \\
\hline G1-6-controle35 cópia & 5,77 & 0,18 \\
\hline G1-7-25\%36 cópia & 5,66 & 0,33 \\
\hline G1-7-50\%37 cópia & 5,41 & 0,14 \\
\hline G1-7-75\%38 cópia & 5,11 & 0,16 \\
\hline
\end{tabular}




\begin{tabular}{|c|c|c|}
\hline G1-7-100\%39 cópia & 5,97 & 0,27 \\
\hline G1-7-controle40 cópia & 5,37 & 0,25 \\
\hline G1-8-25\%41 cópia & 6,48 & 0,23 \\
\hline G1-8-50\%42 cópia & 5,71 & 0,07 \\
\hline G1-8-75\%43 cópia & 5,72 & 0,13 \\
\hline G1-8-100\%44 cópia & 6,01 & 0,16 \\
\hline G1-8-controle45 cópia & 6,13 & 0,09 \\
\hline G1-9-25\%010 cópia & 6,19 & 0,37 \\
\hline G1-9-50\%011 cópia & 6,12 & 0,22 \\
\hline G1-9-75\%012 cópia & 5,91 & 0,18 \\
\hline G1-9-100\%013 cópia & 6,14 & 0,14 \\
\hline G1-9-CONTROLE014 cópia & 6,33 & 0,40 \\
\hline G1-10-25\%015 cópia & 7,06 & 0,45 \\
\hline G1-10-50\%016 cópia & 7,09 & 0,43 \\
\hline G1-10-75\%017 cópia & 6,36 & 0,17 \\
\hline G1-10-100\%018 cópia & 6,70 & 0,28 \\
\hline G1-10-CONTROLE019 cópia & 6,31 & 0,30 \\
\hline G2-1-25\%034 cópia & 7,06 & 0,28 \\
\hline G2-1-50\%035 cópia & ${ }^{\star} 7,11$ & 0,24 \\
\hline G2-1-75\%036 cópia & ${ }^{\star} 7,41$ & 0,47 \\
\hline G2-1-100\%037 cópia & 6,23 & 0,29 \\
\hline G2-1-CONTROLE038 cópia & 6,54 & 0,12 \\
\hline G2-2-25\%039 cópia & 7,08 & 0,18 \\
\hline G2-2-50\%040 cópia & 6,10 & 0,22 \\
\hline G2-2-75\%041 cópia & 6,90 & 0,17 \\
\hline G2-2-100\%042 cópia & 6,92 & 0,28 \\
\hline G2-2-CONTROLE043 cópia & 7,60 & ${ }^{*} 0,15$ \\
\hline G2-3-25\%044 cópia & 5,95 & 0,20 \\
\hline G2-3-50\%045 cópia & 5,98 & 0,12 \\
\hline G2-3-75\%046 cópia & 6,02 & 0,09 \\
\hline G2-3-100\%047 cópia & 5,83 & 0,19 \\
\hline G2-3-CONTROLE048 cópia & 5,80 & 0,05 \\
\hline G2-4-25\%049 cópia & 5,30 & 0,19 \\
\hline G2-4-50\%050 cópia & 5,47 & ${ }^{*} 0,34$ \\
\hline G2-4-75\%051 cópia & 5,45 & ${ }^{\star} 0,31$ \\
\hline
\end{tabular}




\begin{tabular}{|c|c|c|}
\hline G2-4-100\%052 cópia & 6,08 & 0,13 \\
\hline G2-4-CONTROLE053 cópia & 5,32 & 0,07 \\
\hline G2-5-25\%054 cópia & 5,89 & 0,18 \\
\hline G2-5-50\%055 cópia & 6,15 & 0,19 \\
\hline G2-5-75\%056 cópia & 5,56 & 0,15 \\
\hline G2-5-100\%057 cópia & 5,84 & 0,17 \\
\hline G2-5-CONTROLE058 cópia & 5,69 & 0,03 \\
\hline G2-6-25\%059 cópia & 6,29 & 0,25 \\
\hline G2-6-50\%060 cópia & 7,07 & 0,23 \\
\hline G2-6-75\%061 cópia & 6,29 & 0,22 \\
\hline G2-6-100\%062 cópia & 6,03 & 0,25 \\
\hline G2-6-CONTROLE063 cópia & 6,56 & 0,15 \\
\hline G2-7-25\%064 cópia & 5,91 & 0,14 \\
\hline G2-7-50\%065 cópia & 5,43 & 0,14 \\
\hline G2-7-75\%066 cópia & 5,88 & ${ }^{\star} 0,15$ \\
\hline G2-7-100\%067 cópia & 6,39 & 0,23 \\
\hline G2-7-CONTROLE068 cópia & 5,48 & 0,05 \\
\hline G2-8-25\%069 cópia & 5,71 & 0,32 \\
\hline G2-8-50\%070 cópia & 5,38 & 0,36 \\
\hline G2-8-75\%071 cópia & 5,89 & 0,19 \\
\hline G2-8-100\%072 cópia & 5,72 & 0,27 \\
\hline G2-8-CONTROLE073 cópia & 5,59 & ${ }^{*} 0,09$ \\
\hline G2-9-25\%074 cópia & 6,60 & 0,43 \\
\hline G2-9-50\%075 cópia & 6,07 & 0,18 \\
\hline G2-9-75\%076 cópia & 6,10 & 0,21 \\
\hline G2-9-100\%077 cópia & 6,01 & 0,20 \\
\hline G2-9-CONTROLE078 cópia & 5,87 & 0,14 \\
\hline G2-10-25\%079 cópia & 6,42 & 0,18 \\
\hline G2-10-50\%080 cópia & 5,68 & 0,39 \\
\hline G2-10-75\%081 cópia & 5,87 & 0,50 \\
\hline G2-10-100\%082 cópia & 6,34 & 0,16 \\
\hline G2-10-CONTROLE083 cópia & 6,01 & 0,29 \\
\hline G3-1084 cópia & 5,01 & 0,25 \\
\hline G3-2085 cópia & 5,02 & 0,12 \\
\hline G3-3086 cópia & 5,08 & 0,18 \\
\hline
\end{tabular}




\begin{tabular}{lll}
\hline G3-4087 cópia & 4,90 & ${ }^{*} 0,16$ \\
\hline G3-5088 cópia & 4,86 & ${ }^{*} 0,35$ \\
\hline G3-6089 cópia & & ${ }^{*} 0,10$ \\
\hline G3-7090 cópia & 5,34 & ${ }^{*} 0,20$ \\
\hline G3-8091 cópia & 5,10 & 0,11 \\
\hline G3-9092 cópia & 5,10 & ${ }^{*} 0,18$ \\
\hline G3-10093 cópia & 5,18 & ${ }^{*} 0,15$ \\
\hline G4-1094 cópia & 5,11 & 0,27 \\
\hline G4-2095 cópia & 4,91 & 0,09 \\
\hline G4-3096 cópia & 4,77 & 0,12 \\
\hline G4-4097 cópia & 4,45 & 0,13 \\
\hline G4-5098 cópia & 4,81 & 0,25 \\
\hline G4-6099 cópia & 4,86 & \\
\hline G4-7100 cópia & & 0,53 \\
\hline G4-8101 cópia & ${ }^{*} 6,32$ & 0,42 \\
\hline G4-9102 cópia & 4,99 & 0,31 \\
\hline G4-10103 cópia & 4,69 & 0,10 \\
\hline G5-1104 cópia & 5,13 & 0,37 \\
\hline G5-2105 cópia & 6,29 & 0,18 \\
\hline G5-3106 cópia & 5,02 & 0,27 \\
\hline G5-4107 cópia & 5,33 & 0,16 \\
\hline G5-5108 cópia & 5,32 & \\
\hline G5-6109 cópia & 5,016 \\
\hline G5-7110 cópia & & 0,33 \\
\hline G5-8111 cópia & 5,16 \\
\hline
\end{tabular}


ANEXO 2 - Anotações das medidas do perímetro e área de defeito do segundo examinador

\begin{tabular}{|c|c|c|c|}
\hline AMOSTRA & $\begin{array}{c}\text { MEDIDA DA } \\
\text { RÉGUA } \\
\text { (CALIBRATE-1MM) }\end{array}$ & $\begin{array}{c}\text { ÁREA DE } \\
\text { DEFEITO } \\
\text { (MM2) }\end{array}$ & $\begin{array}{l}\text { PERÍMETRO } \\
\text { (MM) }\end{array}$ \\
\hline G1-1-25\%06-cópia & 277 & 0,14 & 5,81 \\
\hline G1-1-25\%06 & 253 & 0,2 & 6,57 \\
\hline G1-1-50\%07 cópia & 238 & 0,32 & 6,46 \\
\hline G1-1-75\%08 cópia & 261 & 0,25 & 5,82 \\
\hline G1-1-100\%09 & 256 & 0,19 & 6,15 \\
\hline G1-1-controle10 cópia & 254 & 0,24 & 6,27 \\
\hline G1-2-25\%11 cópia & 256 & 0,17 & 6,13 \\
\hline G1-2-75\%13 cópia. & 260 & 0,31 & 6,54 \\
\hline G1-2-100\%14 cópia & 241 & 0,32 & 6,96 \\
\hline G1-2-controle\%15 cópia & 261 & 0,36 & 6,23 \\
\hline G1-3-25\%16 cópia & 256 & 0,26 & 5,9 \\
\hline G1-3-50\%17 cópia & 258 & 0,51 & 6,15 \\
\hline G1-3-75\%18 cópia & 259 & 0,25 & 6,64 \\
\hline G1-3-100\%19 cópia & 254 & 0,39 & 6,59 \\
\hline G1-3-controle20 cópia & 256 & 0,29 & 6,77 \\
\hline G1-4-25\%21 cópia. & 243,01 & 0,27 & 6,43 \\
\hline G1-4-50\%22 & 241 & 0,56 & 6,78 \\
\hline G1-4-75\%23 cópia. & 250,01 & 0,22 & 6,1 \\
\hline G1-4-100\%24 cópia. & 265 & 0,28 & 6 \\
\hline G1-4-controle25 cópia & 255,1 & 0,07 & 5,94 \\
\hline G1-5-25\%26 cópia. & 257 & 0,22 & 6,48 \\
\hline G1-5-50\%27 cópia & 250 & 0,21 & 6,79 \\
\hline G1-5-75\%28 cópia & 259,01 & 0,13 & 5,9 \\
\hline G1-5-100\%29 cópia & 257 & 0,29 & 6,04 \\
\hline G1-5-controle30 cópia & 257,01 & 0,15 & 6,05 \\
\hline G1-6-25\%31 cópia & 256 & 0,24 & 5,62 \\
\hline G1-6-50\%32 cópia. & 258,01 & 0,2 & 6,07 \\
\hline G1-6-75\%33 cópia & 259 & 0,34 & 6,29 \\
\hline G1-6-100\%34 cópia. & 260 & 0,22 & 6,08 \\
\hline G1-6-controle35 cópia & 262 & 0,2 & 5,88 \\
\hline G1-7-25\%36 cópia & 260 & 0,34 & 5,76 \\
\hline G1-7-50\%37 cópia & 264 & 0,14 & 5,43 \\
\hline
\end{tabular}




\begin{tabular}{|c|c|c|c|}
\hline G1-7-75\%38 cópia & 254,02 & 0,18 & 5,22 \\
\hline G1-7-100\%39 cópia & 255,01 & 0,31 & 6,06 \\
\hline G1-7-controle40 cópia & 261 & 0,28 & 5,44 \\
\hline G1-8-25\%41 cópia. & 258 & 0,26 & 6,55 \\
\hline G1-8-50\%42 cópia & 258 & 0,16 & 5,86 \\
\hline G1-8-75\%43 cópia. & 260 & 0,18 & 5,8 \\
\hline G1-8-100\%44 cópia & 259 & 0,24 & 6,13 \\
\hline G1-8-controle45 cópia & 256 & 0,12 & 6,22 \\
\hline G1-9-25\%010 cópia. & 238 & 0,36 & 6,25 \\
\hline G1-9-50\%011 cópia & 257 & 0,27 & 6,21 \\
\hline G1-9-75\%012 cópia. & 257 & 0,22 & 5,96 \\
\hline \multicolumn{4}{|l|}{ G1-9-100\%013 cópia } \\
\hline G1-9-CONTROLE014 cópia. & 256 & 0,43 & 6,36 \\
\hline G1-10-25\%015 cópia. & 227 & 0,5 & 7,07 \\
\hline G1-10-50\%016 cópia & 228 & 0,48 & 7,07 \\
\hline G1-10-75\%017 cópia & 246 & 0,21 & 6,36 \\
\hline G1-10-100\%018 cópia. & 231 & 0,28 & 6,65 \\
\hline G1-10-CONTROLE019 cópia & 231 & 0,34 & 6,35 \\
\hline G2-1-25\%034 cópia. & 214 & 0,33 & 7,18 \\
\hline G2-1-50\%035 cópia & 214 & 0,22 & 7,23 \\
\hline G2-1-75\%036 cópia. & 220 & & \\
\hline G2-1-100\%037 cópia. & 259 & 0,35 & 6,32 \\
\hline G2-1-CONTROLE038 cópia & 261 & 0,15 & 6,54 \\
\hline G2-2-25\%039 cópia & 231 & 0,37 & 7,27 \\
\hline G2-2-50\%040 cópia & & 0,27 & 6,22 \\
\hline G2-2-75\%041 cópia & 231 & 0,14 & 7,02 \\
\hline G2-2-100\%042 cópia & 235 & 0,33 & 6,95 \\
\hline \multicolumn{4}{|l|}{ G2-2-CONTROLE043 cópia } \\
\hline G2-3-25\%044 cópia. & 258 & 0,23 & 6,05 \\
\hline G2-3-50\%045 cópia & 260 & 18 & 6 \\
\hline G2-3-75\%046 cópia & 257 & 0,19 & 6,09 \\
\hline G2-3-100\%047 cópia & 262 & 0,25 & 5,83 \\
\hline G2-3-CONTROLE048 cópia. & 264 & 0,08 & 5,74 \\
\hline G2-4-25\%049 cópia & 261 & 0,23 & 5,32 \\
\hline
\end{tabular}




\begin{tabular}{|c|c|c|c|}
\hline G2-4-50\%050 cópia. & 260 & 0,36 & 5,54 \\
\hline G2-4-75\%051 cópia & 262 & 0,36 & 5,44 \\
\hline G2-4-100\%052 cópia & 261 & 0,15 & 6,11 \\
\hline G2-4-CONTROLE053 cópia & 261 & 0,09 & 5,35 \\
\hline G2-5-25\%054 cópia. & 259 & 0,21 & 5,93 \\
\hline G2-5-50\%055 cópia & 255 & 0,22 & 6,27 \\
\hline G2-5-75\%056 cópia & 259 & 0,17 & 5,62 \\
\hline G2-5-100\%057 cópia & 263 & 0,19 & 5,87 \\
\hline G2-5-CONTROLE058 cópia. & 260 & 0,07 & 5,7 \\
\hline G2-6-25\%059 cópia.j & 258 & 0,28 & 6,36 \\
\hline G2-6-50\%060 cópia & 249 & 0,32 & 7,08 \\
\hline G2-6-75\%061 cópia & 259 & 0,24 & 6,23 \\
\hline G2-6-100\%062 cópia & 242 & 0,35 & 6,07 \\
\hline G2-6-CONTROLE063 cópia & 243 & 0,19 & 6,68 \\
\hline G2-7-25\%064 cópia & 259 & 0,17 & 5,95 \\
\hline G2-7-50\%065 cópia & 256 & 0,15 & 5,51 \\
\hline G2-7-75\%066 cópia & 260 & 0,19 & 5,92 \\
\hline G2-7-100\%067 cópia & 247 & 0,26 & 6,5 \\
\hline G2-7-CONTROLE068 cópia & 262 & 0,12 & 5,56 \\
\hline G2-8-25\%069 cópia. & 257 & 0,37 & 5,82 \\
\hline G2-8-50\%070 cópia & 260 & 0,42 & 5,42 \\
\hline G2-8-75\%071 cópia. & 259 & 0,2 & 5,94 \\
\hline G2-8-100\%072 cópia & 262 & 0,32 & 5,73 \\
\hline G2-8-CONTROLE073 cópia. & 263 & 0,3 & 5,61 \\
\hline G2-9-25\%074 cópia & 247 & 0,49 & 6,55 \\
\hline G2-9-50\%075 cópia & 250 & 0,21 & 5,98 \\
\hline G2-9-75\%076 cópia & 239 & 0,25 & 6,25 \\
\hline G2-9-CONTROLE078 cópia & 258 & 0,17 & 6 \\
\hline G2-10-25\%079 cópia. & 262 & 0,52 & 5,69 \\
\hline G2-10-50\%080 cópia. & 259 & 0,47 & 5,77 \\
\hline G2-10-75\%081 cópia & 245 & 0,57 & 6,04 \\
\hline G2-10-100\%082 cópia. & 261 & 0,31 & 6,19 \\
\hline G3-1084 cópia & 255,1 & 0,28 & 5 \\
\hline G3-2085 cópia. & 260 & 0,12 & 5,07 \\
\hline G3-3086 cópia & 257 & 0,21 & 5,11 \\
\hline
\end{tabular}




\begin{tabular}{|c|c|c|c|}
\hline G3-4087 cópia. & 258 & 0,17 & 4,92 \\
\hline G3-5088 cópia & 261 & 0,37 & 4,89 \\
\hline \multicolumn{4}{|l|}{ G3-6089 cópia. } \\
\hline G3-7090 cópia & 257 & 0,14 & 5,36 \\
\hline G3-8091 cópia & 260 & 0,22 & 5,13 \\
\hline G3-9092 cópia & 261 & 0,14 & 5,14 \\
\hline G3-10093 cópia & 259 & 0,24 & 5,14 \\
\hline G4-1094 cópia. & 260 & 0,17 & 5,1 \\
\hline G4-2095 cópia & 259,1 & 0,32 & 5,02 \\
\hline G4-3096 cópia. & 260 & 0,12 & 4,81 \\
\hline G4-4097 cópia & 261 & 0,15 & 4,46 \\
\hline G4-5098 cópia & 262 & 0,21 & 4,82 \\
\hline G4-6099 cópia & 256,01 & 0,32 & 4,85 \\
\hline G4-7100 cópia & 259 & 0,31 & 5,01 \\
\hline G4-8101 cópia & 258 & 0,31 & 5,05 \\
\hline G4-9102 cópia & 254,02 & 0,4 & 4,7 \\
\hline G4-10103 cópia & 253 & 0,22 & 5,17 \\
\hline G5-1104 cópia & 232 & 0,32 & 6,29 \\
\hline G5-2105 cópia & & & 5,1 \\
\hline G5-3106 cópia. & 257 & 0,16 & 5,38 \\
\hline G5-4107 cópia & 256 & 0,22 & 5,39 \\
\hline G5-5108 cópia. & 256 & 0,54 & 5,21 \\
\hline G5-6109 cópia. & 261 & 0,76 & 5,38 \\
\hline G5-7110 cópia & 238 & 0,48 & 6,11 \\
\hline G5-8111 cópia & 236 & 0,34 & 6,4 \\
\hline
\end{tabular}

